\title{
Technical and environmental efficiency of smallholder palm oil and rubber production
}

\author{
presented by \\ Anna Mareike Holtkamp \\ born in Tübingen
}

\begin{abstract}
Dissertation
to obtain the Ph. D. degree

in the International Ph. D. Program for Agricultural Sciences in Göttingen (IPAG) at the Faculty of Agricultural Sciences, Georg-August-University Göttingen, Germany
\end{abstract}

Göttingen, July 2016 
D7

1. Name of supervisor: Prof. Dr. Bernhard Brümmer

2. Name of co-supervisor: Prof. Dr. Matin Qaim

Date of dissertation: 14th July, 2016 
This dissertation is dedicated to my grandfather 



\section{Acknowledgements}

As the title of our umbrella project suggests, this work has been a collaboration on various levels, which brings me to the point of thanking heaps of people who have contributed to this work in various ways.

First of all, I would like to thank my supervisor Bernhard Brümmer, who convinced me to prolong my university career in Göttingen and write a dissertation, an unthinkable goal at the time. Over the years, he always supported and, most of all, motivated me by giving me valuable advice, which has improved the quality of this work. Furthermore he encouraged me to explore new fields for my research - thanks for that. I would also like to thank Professor Qaim and Professor Tscharntke for their time and effort in examining this dissertation.

I would like to thank not only my direct chair colleagues, but also my wider circle of colleagues from other chairs, departments and especially the Collaborative Research Centre 990 (CRC 990) crowd. Having someone next door in the blue tower or three blocks further away has made the last year most enjoyable and interesting in many ways. All academic and non-academic discussions, and especially those in-between, have nourished my inspiration and curiosity in various ways. Furthermore, I dedicate a special thanks to Vijesh Krishna, Michael Euler and the whole C07 sub-project for sharing their hard-collected data! For financial support in this research at the CRC 990 I would like to acknowledge the DFG.

A special thanks goes to 'the boys' and 'the dream team' for their fantastic work during the fieldwork. Thank you for sharing so many wonderful months in the field, on the plots and villages of Jambi. You helped me to understand the people of Sumatra and transformed every place, in which every village we were, into a home. Subsequently, I would like to thank all the farmers who guided us to their plots and invited us into their homes, despite all the time and effort it took - terima kashi atas bantuan dan dukungan yang 
telah diberikan kepada kami.

Last but definitely not least, I would like to extend a thank to my family and friends, especially my parents and brother and their never-ending faith in my abilities and infinite moral support! 


\section{Summary}

As part of the CRC 990: "Ecological and Socioeconomic Functions of Tropical Lowland Rainforest Transformation Systems (Sumatra, Indonesia)" of the University of Göttingen, this thesis is devoted to the subject of the technical and environmental efficiency of smallholder palm oil and rubber production. With this research, we hope to find opportunities to reconcile economically beneficial small-scale palm oil and rubber cultivation in Indonesia with sustainability and diminished degradation of ecosystem services. The challenge to this problem is twofold. Firstly, the economic superiority of the two main crops rubber and oil palm over the traditional crops fostered the expansion of cultivation areas towards zones with the most biologically diverse systems on this planet, such as primary forest. The loss of biodiversity and ecosystems functions and degradation of soils contribute to overall concerns of both monoculture productions. Secondly, due to increasing cultivation of the two main crops, the cultivation systems themselves exploit the limited resources on which they ultimately depend. These factors further increase climate change, wherefore augmenting the productivity of the two production systems without increasing input allocations, contributes to the challenge. We identify these potentials via efficiency analysis.

In three sections, this dissertation analyzes the main transformation systems of oil palm and rubber to reveal the economic benefits, production determinants and the linked efficiencies of production. The analysis first focuses on the technical efficiency aimed at localizing sources of inefficiencies and possibilities to ameliorate the overall degree of efficient production by applying a stochastic frontier analysis. The latter showed that the historical development of the oil palm and rubber sector separated producers in autochthonous and transmigrated groups, leading to significant differences in their production techniques in the case of oil palm. Transmigrated producers, being the most efficient group, reflect the general tendency that security and support change the efficiency in both production systems.

The second analysis enhances the estimation introducing an environmental dimension to the estimation of efficiency in smallholder rubber production. This interaction between rubber production and the status of the environment or the surrounding ecosystem underlies a trade-off function, the shape of which determines the interdependency. The empirical results show that this trade-off function is determined by an outward bending curve, indicating an increase in the desired output and following an increase in the disturbed ecosystem, represented by the number of invasive plants. Next to the general shape, we quantify the overall efficiency levels and specific determinants of an efficient production by analyzing the trade-off curve.

The third analysis focuses on the discussion of interdependence between oil palm and 
rubber production and environmental factors. For this purpose, we make use of a deterministic approach including a two-stage estimation of soil fertility parameters. The estimation revealed that the expansion of the cultivation area aggrandizes towards peat soil and that water-saturated mineral soils result in a higher inefficiency. Moreover, production efficiency is partly dependent on the soil parameters, indicating a possibility of alteration by fertilization. 
Acknowledgements $\quad$ v

List of Figures $\quad$ xi

List of Tables $\quad$ xiii

1 Introduction 1

1.1 Context of the Research . . . . . . . . . . . . . . . . . . . 1

1.2 The Specific Case of Indonesia . . . . . . . . . . . . . . . . . 3

1.3 Research Objectives . . . . . . . . . . . . . . . . 6

1.4 Study Area and Data . . . . . . . . . . . . . . . . . . . 8

1.5 Dissertation Outline . . . . . . . . . . . . . . . . . . . . 10

2 Determinants of Technical Efficiency $\quad 12$

2.1 Introduction . . . . . . . . . . . . . . . . . . . . . . . . . . 12

2.2 Introduction to Stochastic Frontier Analysis (SFA) . . . . . . . . . . . 14

2.3 Data and Empirical Specification . . . . . . . . . . . . . 16

2.3 .1 Data . . . . . . . . . . . . . . . . . 16

2.3.2 Descriptive statistics . . . . . . . . . . . . . . . . 16

2.3.3 Stochastic frontier specification . . . . . . . . . . . . . 17

2.4 Results . . . . . . . . . . . . . . . . . . . . . . . . . . 19

2.4.1 Parameters of the production functions . . . . . . . . . . . 19

2.4.2 Differences between oil palm and rubber production systems . . . . 19

2.4 .3 Efficiency scores . . . . . . . . . . . . . . . . . . 22

2.5 Conclusion . . . . . . . . . . . . . . . . . . . . . . . 29 
3 Environmental Efficiency in the Case of Rubber $\quad 31$

3.1 Introduction . . . . . . . . . . . . . . . . . . . . . . . 31

3.2 Methods and Material . . . . . . . . . . . . . . . . . . 34

3.2.1 Environmental production function and efficiency . . . . . . . . . 34

3.2.2 Specifications for the Directional Output Distance Function (DODF) 37

3.2 .3 Data . . . . . . . . . . . . . . . . . . . . 38

3.3 Results and Discussion . . . . . . . . . . . . . . . . . . . . 39

3.3.1 Technical efficiency of the production . . . . . . . . . . . . 41

3.3.2 Shadow price calculation . . . . . . . . . . . . . . . . 45

3.3.3 Efficiencies and shadow price over different groups . . . . . . . . . . 45

3.4 Conclusion . . . . . . . . . . . . . . . . . . . . . 46

4 Soil Quality Parameters and their Effect on Efficiency 48

4.1 Introduction . . . . . . . . . . . . . . . . . . . . . . . . . . 48

4.2 Theoretical Foundation . . . . . . . . . . . . . . . . . 50

4.2.1 Productivity and efficiency . . . . . . . . . . . . . 50

4.2.2 Data Envelopment Analysis (DEA) construction . . . . . . . . . . . 52

4.3 Data and Study Area . . . . . . . . . . . . . . . . . . . . . 55

4.3 .1 Descriptive statistics . . . . . . . . . . . . . 56

4.4 Results and Discussion . . . . . . . . . . . . . . . . . 57

4.4.1 Results of the efficiency estimation . . . . . . . . . . . . 57

4.4 .2 Soil and efficiency . . . . . . . . . . . . . . . . . 60

4.4 .3 Discussion . . . . . . . . . . . . . . . . . . . 63

4.5 Conclusion . . . . . . . . . . . . . . . . . . 66

5 Conclusion $\quad 67$

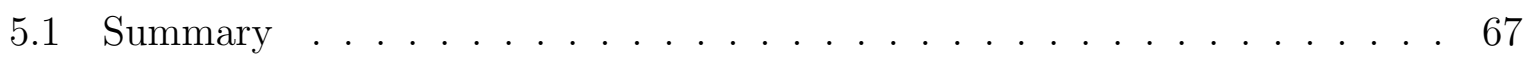

5.2 Policy Implications . . . . . . . . . . . . . . . . . . . . . . . 70

5.3 Limitations and Scope for Further Research . . . . . . . . . . . . 71

$\begin{array}{llr}6 & \text { Bibliography } & 75\end{array}$

$\begin{array}{llr}\text { A Appendix Chapter 2 } & 85\end{array}$

B Appendix Chapter 3 $\quad 90$

$\begin{array}{ll}\text { C Appendix Chapter } 4 & 93\end{array}$ 


\section{List of Figures}

1.1 Study area displaying all villages of the environmental survey . . . . . . . . 9

2.1 Efficiencies over the production systems . . . . . . . . . . . . . . . 22

2.2 Distributions of efficiencies: rubber (top left), oil palm transmigrant (top right), oil palm autochthon (bottom) . . . . . . . . . . . . 24

3.1 Efficiencies over invasive plants . . . . . . . . . . . . . . . . 42

3.2 Interaction of invasive plants and the economic output . . . . . . . . . 43

4.1 DEA input and output-oriented efficiency measure with 1 input and 1 output (on the left); DEA output-oriented efficiency measure with 2 outputs and 1 input (on the right) (after Farrell, 1957) . . . . . . . . . . . 51

4.2 Efficiency under Variable Returns Scale (VRS) and Constant Returns Scale (CRS) (after Farrell, 1957) . . . . . . . . . . . . . . . . 52

4.3 Distribution of fertilizer cost per kg yield over the C-value level - oil palm (A); Distribution of fertilizer cost over the C-value level - oil palm (B); Distribution of fertilizer cost per $\mathrm{kg}$ yield over the C-value level - rubber plantation (C); Distribution of fertilizer cost over the C-value level - rubber plantation $(\mathrm{D}) \ldots \ldots \ldots \ldots \ldots \ldots$

4.4 Differences in efficiency over the bulkdensity, divided in four subgroups a) below 8.2 , b) $8.2-9.4$, c) 9.4 to $1 \ldots \ldots$. . . . . . . . . . . . 61

B.1 Scatterplot of the individual shadowprice against the labor input over both management intensity (red dots $=$ intensive , blue triangle $=$ extensive $). \quad .90$

B.2 Scatterplot of the individual shadowprice against the size input over both management intensity $($ red dots $=$ intensive, blue triangle $=$ extensive $) ~ . ~ . ~ 91$ 
B.3 Distribution of invasive plant and non-invasive plants on average on the sampled plots . . . . . . . . . . . . . . . . . . . . . . 91 91

C.1 Soil sampling frame . . . . . . . . . . . . . . . . . . . . 94

C.2 Oil palm efficiencies over soil quality parameters . . . . . . . . . . . . . 97

C.3 Rubber efficiencies over soil quality parameters . . . . . . . . . . . . . . . . 98 
2.1 LR-test results for testing the presence of inefficiency . . . . . . . . . . . 19

2.2 Returns to Scale for oil palm transmigran, oil palm autochthonous and rubber production . . . . . . . . . . . . . . . . . 21

2.3 Distribution of efficiencies . . . . . . . . . . . . . . . 23

2.4 Estimation results for $z$-variables $\ldots \ldots \ldots \ldots$

3.1 Descriptive statistics . . . . . . . . . . . . . . . . . . . . . . 39

3.2 LR-test results for testing the presence of inefficiency . . . . . . . . . . . 40

3.3 Summary of the elasticities f . . . . . . . . . . . . . . 41

3.4 Distribution of the efficiencies . . . . . . . . . . . . . . . . . 42

3.5 Estimation results of the covariates and the corresponding marginal effects 44

3.6 Shadow price calculated for 2012-2015 by average rubber prices (in .000 IDR $) \ldots \ldots \ldots \ldots \ldots \ldots \ldots$

4.1 Efficiencies of oil palm and rubber, with separation in intensive and exten-

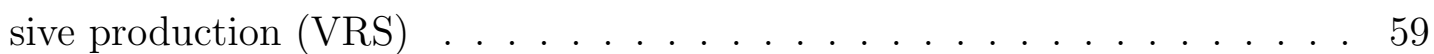

4.2 Estimation of truncated model and bootstrapped model for rubber . . . . . 63

4.3 Estimation of truncated model and bootstrapped model for oil palm . . . . 63

A.1 Descriptive statistics of the samples . . . . . . . . . . . . . 86

A.2 Estimation results: STATA output of the oil palm transmigrant frontier including the $z$-variabels; plot size $(x 1)$, hours of labour (x2), plantation age $(x 3)$, cost of herbicides $(x 5)$, capital $\left(x^{7}\right) \ldots \ldots \ldots$. . . . . . 87 
A.3 Estimation results: STATA output of the oil palm autochtone frontier including the $z$-variables; plot size $(x 1)$, hours of labour per plot (x2), plantation age $(x 3)$, cost of fertilizer $\left(x_{4}\right) \ldots \ldots \ldots . \ldots . \ldots 8$

A.4 Estimation results: STATA output of the rubber frontier including the $z$ variables; plot size $(x 1)$, hours of labour per plot (x2), plantation age (x3), cost of fertilizer $\left(x_{4}\right) \ldots \ldots \ldots \ldots$. . . . . . . . . . . . . . . 89

B.1 STATA output of the directional output distance function including the $z$ variables; size of the plot (Size), hours of labor per plot (Labor), plantation age (Pl. Age), cost of all chemicals (TC. Chemicals), and the bad output times the directional vector and the translation value $\theta,\left(\right.$ bstar $\left.=\left(b_{i}-\theta_{i} g_{b}\right)\right) .92$

C.1 Descriptive statistics of economic and soil inputs for rubber . . . . . . 95

C.2 Descriptive statistics of economic and soil inputs for oil palm . . . . . . . 96

C.3 Efficiencies of oil palm and rubber, with separation in intensive and extensive production $(\mathrm{CRS}) \ldots \ldots \ldots \ldots$. . . . . . . . . . . . . 96

C.4 C-Values distributed over the production types and fertility group (IR = Intensive Rubber, $\mathrm{ER}=$ Extensive Rubber, $\mathrm{OP}=$ Oil Palm $) \ldots . . .96$

C.5 This table displays the correlation matrix of soil quality parameters and all inputs and output . . . . . . . . . . . . . . . . . . . . . . 99

C.6 The separation of cost of fertilizer and labor over the fertility groups . . . . 99 
CCR

Charnes-Cooper-Rhodes

CRS

Constant Returns Scale

CRC 990

Collaborative Research Centre 990

DEA

Data Envelopment Analysis

DDF

Directional Distance Function

DFG

German Research Foundation - Deutsche Forschungs

Gesellschaft

DODF

Directional Output Distance Function

EFForTS

Ecological and Socioeconomic Functions of Tropical Lowland

Rainforest Transformation Systems

EPI

Environmental Performance Index

FFB

Fresh Fruit Bunches

KKPA

Primary Cooperative Credit for Member (Koperasi Kredit

Primer untuk Anggota)

MEA

Millennium Ecosystem Assessment

NES

Nuclear-Estate-Scheme 
ODF

OLS

PIR

RMSE

RSPO

SFA

SOC

SON

TSP

VRS

WWF

WBCSD
Output Distance Function

Ordinary Least Squares

Transmigrant Support Program

Root-Mean-Square Error

Roundtable on Sustainable Oil

Stochastic Frontier Analysis

Soil Organic Carbon

Soil Organic Nitrogen

Transmigrant Support Program

Variable Returns Scale

World Wildlife Fund

World Business Council for Sustainable Development 


\section{CHAPTER 1}

\section{Introduction}

As part of the CRC 990: "Ecological and Socioeconomic Functions of Tropical Lowland Rainforest Transformation Systems (Sumatra, Indonesia)" of the University of Göttingen this thesis is devoted to the subject of the technical and environmental efficiency of smallholder palm oil and rubber production. This dissertation investigates the differences and determinants of technical and environmental efficiency in and between the two main agricultural crops produced in Sumatra, Indonesia: rubber and oil palm. By identifying and analysing the determinants of efficiencies of both crops production levels can be increased, moving producers closer to the best-practice frontier by minimizing inefficiencies. These results will contribute to the urgent demand to reconcile agricultural productions of commodities, such as oil palm and rubber, and environmental and social issues related to sustainable production in order to diminish the pressure on land, which coincides with the topic of the expansion of cultivation areas at the expense of lowland rainforest.

\subsection{Context of the Research}

This chapter introduces the overall context with which this dissertation is concerned. Starting with the global challenges of agricultural production and its predicament of feeding the world and retaining its necessary sustainable production ground, the following chapter will outline this challenge in the Indonesian context, leading to the research questions guiding this research.

Our daily routines highlight the dependency of each and every one of us on agricul- 
ture. Through direct and indirect pathways, agricultural production not only provides nutrition but also sustains livelihoods through income opportunities. It is a vital engine for poverty alleviation and economic growth in developing countries (World Bank, 2008; Alexandratos and Bruinsma, 2012). The task of meeting these various challenges are globally exacerbated at present due to land scarcity and the changing of the surrounding settings (Kastner et al., 2012; World Bank, 2008; Godfray et al., 2010). Even though more than $40 \%$ of the earth's land surface is already dedicated to agricultural production, expected population growth of up to nearly 10 billion in 2050, along with shifts in diet, is likely to create a higher demand for agriculture products and consequently the compulsion for land expansion. The latter mostly pushes land transformation towards primary forest frontiers and necessary compensation areas (Tilman et al., 2001; United Nations, 2013; Foley, 2005).

Following Normand Borlaug, who is seen as the father of the green revolution, one idea for increased production avoiding transformation expansion is the intensification on existing production areas which could also alleviate pressure on natural ecosystems. The effects of intensification have already resulted in the retention of landscapes threatened by transformation. Adaptations of higher yielding varieties, in the same revolution, met the desired augmentation of outputs (Evenson and Gollin, 2003). However, intensification coheres with an exploitation of natural resources, leaving ecosystem services heavily degraded. The Millennium Ecosystem Assessment (MEA) reported degraded and unsustainable ecosystem services in $60 \%$ of the examined ecosystems (MEA, 2005). Agriculture production exploits limited resources and furthermore decreases the functionality of the ecosystems on which it relies. The persistent challenges of production, growing losses of natural resources in virtue of degradation, and declining productivity rates of the hybrids position agriculture again at the edge of land transformations (Foley, 2005; Gibbs et al., 2010).

Over the last four decades land transition has followed a linear increase of 4 million hectares annually. Estimations for future turnover expect to reach an area of arable land in developing countries of up to 1,036 million ha in 2030, with half of that area located in Asia. At the centre of this problem are countries experiencing growing needs for food and employment combined with the need for land suitable for intensive production, such as developing countries abundant with tropical forests (Alexandratos and Bruinsma, 2012; Gibbs et al., 2010; Ramankutty and Foley, 1999). This transformation of tropical forest is not only linked to losses in global biodiversity and ecosystem functions, but also greenhouse gas emissions. The latter negatively affects climate change (Margono et al., 2014; Lal, 2004) aggravating production grounds further, as examples of extreme weather and climate conditions have shown. In this vicious circle smallholder producers and subsistence farmers, which depend highly on the income generated by agriculture production, are especially affected as they differ in their adaptive and coping abilities compared to 
large scale producers due to their limited resources and higher dependency on the natural habitat (Morton, 2007; FAO, 2014). Thus, deforestation and unsustainable agricultural production in the long-run fosters a cycle of degradation and climate change, thereby reversing attempts at poverty alleviation.

\subsection{The Specific Case of Indonesia}

The dilemmas of agricultural production, issues of sustainability and its potential for economic benefits, is perfectly expressed in the situation of Indonesia, where our project is located.

Indonesia is one of the most important hotspots of land transition for the benefit of agricultural production and economic development in the world (Laumonier et al., 2010; Gaveau et al., 2007). In 2012 alone, agricultural expansion in the country exceeded that of Brazil's, up till then the leader, by nearly doubling the converted areas. Latest calculations report that the turnover rate of forested area to oil palm and rubber plantations has reached an average growth of 47,600 ha per year, a deforested area of 0.84 million ha. The extensive clearing - mainly on Sumatra, Kalimantan, and Papua - diminished not only Indonesia's primary forest cover by $50 \%$ in lowland areas but also pushed the frontier into wetland areas, including peatlands and degraded soils, which has resulted in even higher rates of greenhouse gas emissions (Margono et al., 2014; FAO, 2010).

Indonesia is one of the most affected countries where structural change induced by agricultural production for economic benefits at the cost of natural habitats is observed a phenomena described by Foley (2005). Two of the key commodities associated with transition are rubber and oil palm, both heavily promoted by the government as a vehicle to boost the economy and alleviate rural poverty (Carrasco et al., 2014; Zen et al., 2005; McCarthy, 2010). Recognizing the economic potential of both commodities, Indonesia supported a rapid growth through the liberalization of trade, creation of favorable laws, and private and state support, the result of which is that Indonesia is now the largest palm oil producer and second largest rubber producer in the world (FAO, 2015; Zen et al., 2005; McCarthy, 2010).

\section{Oil palm}

The multipurpose oil extracted from the Fresh Fruit Bunches (FFB) of oil palm (Elais guineensis) is used in a wide variety of products including food, cosmetics, household products as well as in biofuels. The oil palm was originally a subsitence crop, originating on the African continent. As it was adjustable to a range of tropical climates, human induced distribution lead to a spread of oil palm production to other territories such as South-East-Asia. With increasing influence from the 1960s on, oil palm was thought to reconcile social and economic development retracting or at least not promoting climate change, and hence was seen as a sustainable crop. As a result of equatorial expansion 
over four continents, oil palm production now covers up to 15 million ha (Gilbert, 2012; Fitzherbert et al., 2008; Koh and Wilcove, 2008) in zones which used to have biologically diverse systems, providing high levels of ecosystem functioning, much of which is linked to nutrition cycles (Fitzherbert et al., 2008; Koh et al., 2011). The two main producers, Indonesia and Malaysia, produce $80 \%$ of total oil palm production and Indonesia has tripled its cultivation area in the last 30 years (FAO, 2015). At present, oil palm out competes all existing crops as a renewable source of vegetable oil, when considering yield per area cultivated. It produces a yield of 5 to 3 times more biodiesel output per hectare and 3 to 10 times more oil harvest compared to other vegetable oil crops. Moreover, after weathering the first unproductive juvenile 4 year post-planting period, oil palm generates FFB throughout the year for up to 25 - 30 years (Murphy, 2007).

\section{Rubber}

The development of natural rubber (caoutchouc) is a volatile process seldom seen by natural raw materials. Strongly correlated with the evolvement of crude oil price, the raw material of the counter product synthetic rubber, natural rubber experienced a hold in production development after World War II. Improved seedlings and favourable conditions for marketing leveraged the equatorial expansion to zones similar to oil palm, namely West-Africa, South-America, and South-East Asia (Rehm and Espig, 1991; Barlow, 1997). In Indonesia rubber production, mostly in form of the variety of Hevea brasiliensis, has tripled in the last 20 years producing 3.1 million tonnes, just behind the first ranked rubber producing nation Thailand (3.8 million tonnes)(FAO, 2015).

Following the plans of the Indonesian government for the expansion of tree crops, including rubber, it is estimated that rubber production may triple again by 2030 (Wilcove et al., 2013). Furthermore, the chemical advantages of natural rubber in contrast to synthetic rubber, necessary for manufacturing vehicle tyres, will likely increase the production, assuming there is an ongoing demand for vehicles in striving new economies (Rehm and Espig, 1991; Wilcove et al., 2013).

\section{Development of monoculture structures in Indonesia}

Before the twentieth century, Indonesia's foremost cultivation consisted of swidden agriculture for subsistence production. Concomitant with the industrialization and increased demand for natural rubber and timber, smallholders induced the first land transition, replacing primary forest with agroforest (hutan karet) and distributing Para Rubber seeds (Hevea brasiliensis) in certain forested areas. The established permanent agroforestry altered the common tenor on land ownership, adding value to land through cultivation. Shifts in population, due to newcomers interested in the economic benefits and competition over forested area, lead to the implementation of a legal land ownership structure and binding forest reserves, by the Dutch colonial government. The political end of the colony simultaneously exacerbated free access to land for locals, due to the conversion of 
primary forest into government property bound to a concession system (Gouyon, 1993; Feintrenie and Levang, 2009; Zen et al., 2005).

The economic need for the stronger development of smallholders, especially in rural areas on distant islands, focused attention on enhancing balanced production development. Therefore, shortfalls in rubber production were addressed by the World Bank-funded "Smallholders' Rubber Development Program" but nevertheless, the economic development was overtaken by the increasing importance of oil palm production (Zen et al., 2005). Policies focusing on enhanced rural development by including smallholders in productive cultivation systems promoted particular models for smallholders to engage with plantations, and vice versa. This was fostered by nuclear estate and outgrower schemes defining different forms of public-private partnerships (Feintrenie and Levang, 2009).

A highly integrated marketing scheme, in the form of the Nuclear-Estate-Scheme (NES) and Primary Cooperative Credit for Member (Koperasi Kredit Primer untuk Anggota) (KKPA) scheme, describe contractual arrangements linking smallholders in satellite areas (plasma) and plantations, mills, and factory (nucleus), facilitating smallholder participation. While the NES precedes the KKPA, implemented in the 1980, the schemes are distinguishable in terms of land ownership and contractual arrangement, provision of investment and the degree of vertical integration (McCarthy and Cramb, 2009; Zen et al., 2005; Feintrenie and Levang, 2009; Potter and Lee, 1998).

In compliance with governmental policies' aims to support smallholders and enhance the economic potential of outer islands, contractual schemes merged with transmigrant support programs (Transmigrant Support Program (PIR)) -additionally implemented to decrease overpopulation on islands such as Java. And so state-private partnerships in collaboration with farmer groups supported the establishment and funding of transmigrant participation in the oil palm sector (McCarthy and Cramb, 2009; Zen et al., 2005).

The introduction of PIR and NES structures can be seen as a starting point for the spread of oil palm cultivation in Jambi province. Non-participants of such transmigrant programs are mostly found in autochthonous villages and show a time lag in the adoption of oil palm production. Previously, autochthonous villages and farmers mostly grew rubber, and subsequently changed to oil palm production (Gatto et al., 2015). The spillover of an integrated system and management practices to autochthonous villagers was observed in oil palm as well as rubber in the earlier days. The time lag in adoption and the lower extent of support opposed to first integrated systems resulted in an unbalanced diffusion of development (McCarthy et al., 2012).

Financial problems in the 2000s and the shift in power to local politicians as in the course of decentralization, reduced the implementation of out-grower schemes. Opportunities lay in the hands of well-established producers who gained from mid-sized free lands and 
opportunities to take over large plantation entities. In the later years NES structures seldom appeared, mostly as a result of private company contributions or farmer cooperation (McCarthy et al., 2012; Zen et al., 2005; Sayer et al., 2012).

\subsection{Research Objectives}

The global situation and Indonesian situation in the global context, as described in the above section, reveals a twofold challenge with respect to further developments in agricultural production. The next section outlines the focus of this dissertation taking into account the development of oil palm and rubber cultivation and their low-environmentalimpact possibilities.

The first of the two challenges presents itself in the economic superiority of the two main crops, rubber and oil palm, as opposed to traditional crops, and their fostered expansion of cultivation area towards the primary forest, pushing the land frontiers further. The eradication of primary rainforest for the purpose of higher-yielding land use caused substantial criticism with regards to the impact on the environment and sustainable production. Moreover, replacing rainforest land with the monoculture production of oil palm and rubber diminishes biodiversity (Anderson, 1996; Corley and Tinker, 2003; Eye on Aceh, 2007; Belcher et al., 2005). The reduction in biologically diverse ecosystems lowers the regional flora and fauna biodiversity leading to deteriorating ecosystem functions in the environment. To a large extent, excessive degradation of ecosystem functions, soil erosion and the use of chemicals seriously threatens soil fertility (Barnes et al., 2014; Allen et al., 2015; Guillaume et al., 2015; Wilcove and Koh, 2010; Eye on Aceh, 2007; Belcher et al., 2005).

Attempts to reduce these threats to ecosystem services with the implementation of certification and systems of good agricultural practice, began as a global initiative on the part of multi-stakeholders. The Roundtable on Sustainable Oil (RSPO), which was initiated by the World Wildlife Fund (WWF), designed several principles and guidelines for oil palm plantations aiming to generate a certain level of sustainability. With 2819 members, 3 million hectares of global cultivation area of oil palm in 12 countries are certified under RSPO, with 1,469,839 hectares of this in Indonesian (RSPO, 2014). Although RSPO is a starting point for sustainable oil palm cultivation, it has garnered criticism concerning control and implementations, in particular smallholder implementations (Greenpeace, 2013).

The second challenge lies in the management of the cultivation systems themselves, which exploit the limited resources through uncontrolled increasing degrees of intensification. Highly adjusted plantation systems developed for oil palm cultivations, exhibiting nearly closed nutrient cycles with low levels of pollution, could only be partly applied in highly 
monitored plantations, such as large company plantations. The fact that the vast majority of plantations, especially smallholder plantations, are distant from highly adjusted cultivation, (Corley and Tinker, 2003; Vermeulen and Goad, 2006) amplifies the lavish exploitation of strongly limited resources.

At the present time large scale producers - primarily found in oil palm production - account for the larger share of production. Nevertheless, the smallholder concept has gained more credibility recently, resulting in an expansion of production. With smallholder productive volume now standing at $33 \%$ of total annual production, the share of smallholder participation will likely exceed contributions from large scale plantations in future development (Vermeulen and Goad, 2006; Sayer et al., 2012). The Indonesian government aims to double the share of smallholder participation by 2030 (Gilbert, 2012). In this case controlled intensification and generally better adapted production management in both production systems contain ways for lower environmental-impact cultivation (Vermeulen and Goad, 2006).

The change in output levels to reach the government's goal could be achieved via three ways. First, the cultivation area could be enhanced, again pushing the transformation frontier further. The second way, after Borlaug, could aim at higher levels of intensification on the existing plot site, which would, however, compete with the second challenge outlined before. The third way, would be the elevation of output levels on existing production sites through the elimination of inefficiencies in production. The latter option would allow producers to reach a higher output without enhancing the utilized inputs, but would involve changing institutional or structural elements in the production. Changes in the output level will be not due to shifts in the production function, which describes the relation of used inputs and possible producible outputs, but shifts in producers closer to the optimal production function.

In order to change the predicted development into a sustainable one, the underlying production function of both systems need to be quantified and with this the deviations of producers to this best-practice production function; in particular, i) effects on the productions efficiency limiting potential yield levels, ii) the regime of dependencies between production and ecosystem disturbances and iii) influences of structural changes on environmental efficiency.

Despite the highly discussed sustainability of oil palm and rubber production - to the best of our knowledge - scarce to no resources have been devoted to empirically quantifying the determining aspects of the efficiency of these crops. Moreover, even less is known about the direct dependencies of production and ecosystem disturbances in Sumatra Indonesia. Even though a few studies have addressed the technical efficiencies of oil palm production in Indonesia and African countries (Hasnah et al., 2004; Alwarritzi et al., 2015), or oil palm cultivation as a threat to ecosystems (Lee et al., 2013; Wilcove and Koh, 2010; Allen 
et al., 2015; Rubiana et al., 2015), and the economic benefits (Feintrenie et al., 2010; Rist et al., 2010; Belcher et al., 2005), no empirical results have been used to analyse their environmental efficiency and the factors affecting it. This is particularly the case for smallholder rubber production and its comparison with oil palm cultivation.

Against this background, the general goal of the work at hand is to analyse oil palm and rubber transformation systems to reveal the economic benefits while also considering the likely negative by-products, such as threats to biodiversity and land sustainability (Belcher and Schreckenberg, 2007), raising a number of research questions:

I) What determines, if present, differences in the technical efficiency between smallholders within the same transformation system?

II) To what extent are these differences presented in the distributional variability of the technical efficiency between two main transformation systems?

III) How is the trade-off between environmental disturbances and economic benefits defined?

IV) What are the main drivers affecting differences in environmental efficiency?

By answering these questions, the presented study will not only address the research gap mentioned above but will further contribute to the sustainable development of oil palm and rubber production by providing suggestions for diminishing ecosystem disturbance while maximizing the economic benefits. These results will be vital to designing effective policies that amplify sustainable development whilst considering the environmental and economic aspects.

\subsection{Study Area and Data}

The research presented here is part of the CRC 990, also known under the name Ecological and Socioeconomic Functions of Tropical Lowland Rainforest Transformation Systems (EFForTS), financed by the German Research Foundation - Deutsche Forschungs Gesellschaft (DFG). The CRC 990 study area is in Jambi Province, lying in the centre of the Indonesian island Sumatra ( $1^{\circ} 36^{\prime} 53.6^{\prime}$ 'S $103^{\circ} 36^{\prime} 06.5^{\prime}$ E). Jambi exhibits a tropical humid climate $\left(27^{\circ} \mathrm{C} ; 2224 \mathrm{~mm} \mathrm{yr}^{-1} ; 112-260 \mathrm{~mm} \mathrm{month}^{-1}\right)$ with a rainy season lasting from October to April. With nine regencies, Jambi has a population of 3.4 million people. Sumatra and especially Jambi, is a typical example of land transformation for the benefit of agricultural production, highlighting the scarcity of resources as land (Laumonier et al., 2010; Gaveau et al., 2007) and constituting the perfect preconditions for the research goal of the CRC 990 and this sub-project. Within Indonesia, Jambi Province ranks $3^{\text {rd }}$ in rubber production and $5^{\text {th }}$ in oil palm production regarding area and volume (Badan Pusat Statistik Republik Indonesia, 2014). Rubber is still the most dominant crop in 
Jambi, even though the area under rubber cultivation is slowly being replaced by oil palm plantations.

This research relies on two combined surveys; one is a socio-economic household survey including 600 smallholders of Jambi Province on Sumatra, Indonesia, conducted by another sub-project of the CRC $990^{1}$, while the second survey covers environmental data and includes a sub-sample from the household survey of 135 smallholder rubber farmers.

\section{Household survey}

The household survey, conducted by the fellow researchers of the sub-project C07 at the end of 2012, covered five of the nine regencies in Jambi province: Sarolangun, Batanghari, Muara Jambi, Tebo, and Bungo. These regencies fit the classification of production criteria: lowland, non peat, etc. A multi-stage random sampling approach, stratifying on the regency, district, and village levels, seemed the best fit to mirroring geographical and regional disparities, which are stretched out through the province. In a two-step random

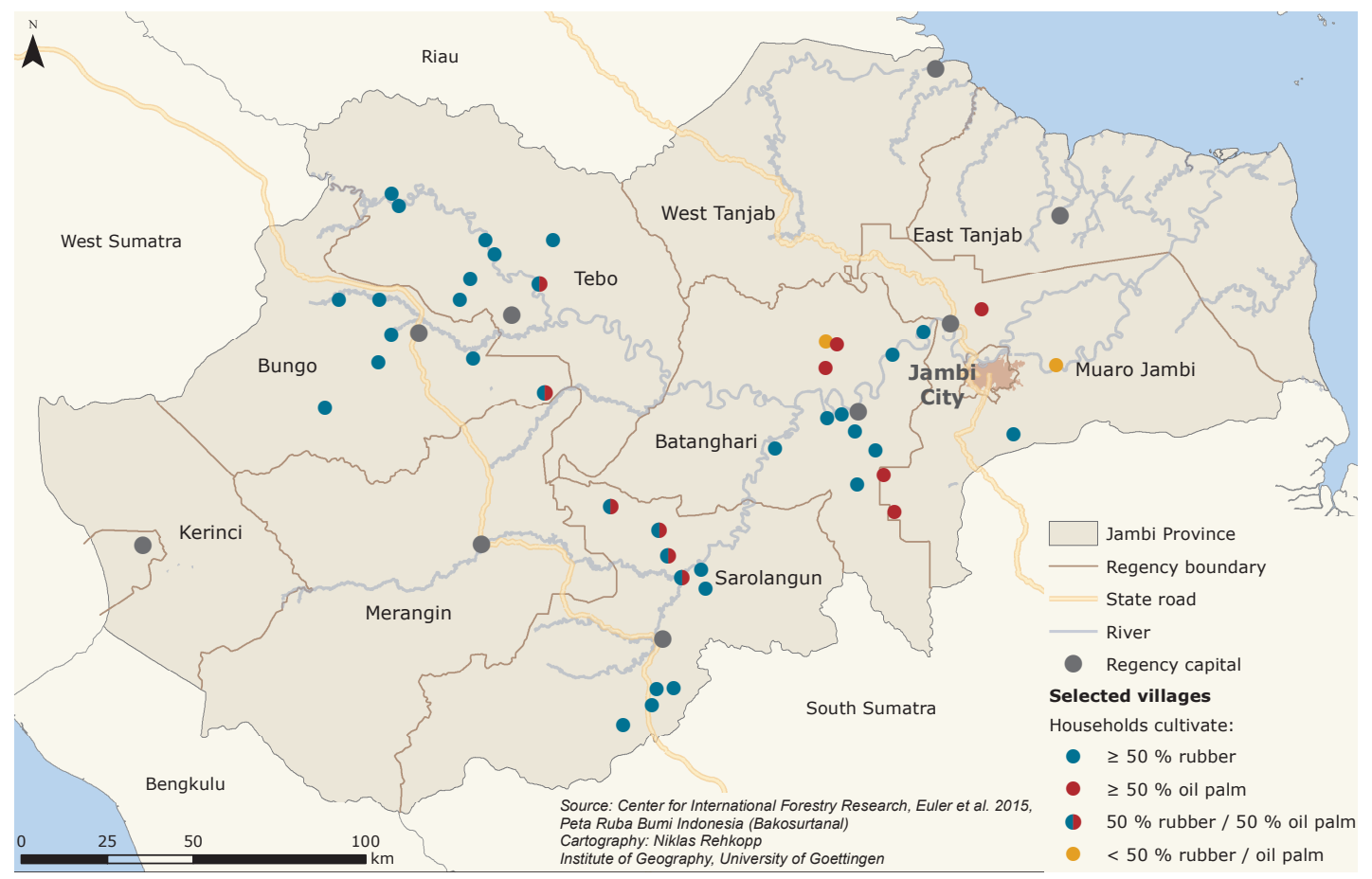

Figure 1.1: Study area displaying all villages of the environmental survey

selection procedure, 40 villages from the five chosen regions were selected. Within each region, four districts and two villages per district were selected randomly. Significant diversity in terms of population size between the villages precluded constant sampling numbers. To reduce the magnitude of this problem, randomly selected villages were reorganized into subsections of four quarters. From these quarters -6 to 12, 18, and 24 - households were selected randomly (Faust et al., 2013). This avoids any under-

\footnotetext{
${ }^{1}$ The household survey covering a variety of socio-economic and consumption data is further described in the publications of Euler et al. (2015); Drescher et al. (2016); Faust et al. (2013)
} 
representation of households from larger villages and over-representation of households from smaller villages.

\section{Environmental data set}

For the environmental data-set, one third of previously sampled households from the household survey were re-sampled to extract information on the state of biological diversity and plant abundance. From each sub-sampled farmer, we collected vegetation data and soil data on the major plantation sites. To that end, a $25 \mathrm{~m}^{2}$ area was identically established inside each plantation at grounds which adequately represented the systematic nature of the plantation. Within the sample square, all plants were counted and identified. Additionally, in each sample site four soil samples were taken according to the plantation's type, oil palm plantation, rubber plantation and extensive rubber (see section 4.3).

\subsection{Dissertation Outline}

This dissertation is divided into four sections. The following three chapters address the above mentioned research questions, while the final Chapter 5 sums up the thesis.

Chapter 2 analyses and evaluates the technical efficiency and its determinants of smallholder rubber and oil palm production, addressing the first two research questions:

"What determines, if present, differences in the technical efficiency between smallholders within the same transformation system?"

"To what extent are these differences presented in the distributional variability of the technical efficiency between two main transformation systems?"

By applying a stochastic frontier analysis, we assess the determinants of efficiency, which constitute the crucial elements in potential augmentations of the producer?s output on the plot, leading, in theory, to the prevention of the expansion of cultivation areas towards forest, by reducing the pressure on land.

Chapter 3 addresses the environmental efficiency of small-scale rubber producers in our study area, tackling the last two research questions:

"How is the trade-off between environmental disturbances and economic benefits defined?"

"What are the main drivers affecting differences in environmental efficiency?"

Building on the previous chapter on distance functions to directional distance functions by introducing an environmental dimension to the estimation, the underlying trade-off function between the economic output and the environmental effects can be quantified. Including a factor measuring the ecosystem disturbance - such as in this case invasive 
plants - this chapter provides a fundamental contribution to the development of sustainable productions and for policy implementation in particular.

Chapter 4 pursues the estimation of interdependence between oil palm and rubber production and environmental factors towards soil fertility. This chapter further contributes to the same research question as Chapter 3. For this purpose, we apply a deterministic approach including a two-stage estimation, which will be explained in the second section with soil fertility parameters.

This dissertation ends by providing a synopsis of the complete research focus in the last chapter, followed by recommendations for policy implementation. The final chapter closes by pointing out the research's limitations and future research objectives. 


\section{CHAPTER 2}

\section{Determinants of Technical Efficiency}

This chapter deals with the analysis and evaluation of technical efficiency and its determinants of smallholder rubber and oil palm production. The assessment of the determinant of efficiency is a crucial factor in the potential augmentations of plot output. In theory, the diminishing of inefficiencies by moving producers closer to the best-practice frontier results in higher output and a reduced pressure on land, coinciding with the prevention of the expansion of cultivation areas towards forest. The next sections contribute to the overall aim of a more sustainable production.

After a general overview of the historical development of monocultures in Jambi, the next section provides a more detailed introduction to the policies and structures of outgrower schemes in the province. The second section presents and explains the methodology of the Stochastic Frontier Analysis (SFA) applied to our data set. The last two sections elaborate on the results, focusing on the effects of inefficiency in production, ending with concluding remarks.

\subsection{Introduction}

Smallholder participation plays a major role in cultivation and appears in various institutional settings and origins of development. Differences in the degrees of vertical integration can be found among farmers. At one end of the spectrum, buyer-independent-farmers produce without oversight and are unregulated in their decisions concerning production and marketing. At the other end of the vertical integration line, closely integrated systems connect smallholders and mills from plantations. 
This highly integrated marketing scheme mostly arises in the form of a NES. Smallholders are pooled in satellite areas (plasma) and bound to a neighboring palm oil plantation or rubber factory (nucleus) which is governed by the state or privately (McCarthy and Cramb, 2009). Smallholders cultivate under their own responsibility but may act with some degree of formal integration within the nucleus. This might solidify in palm-oil plasma villages, where production processes like the application of fertilizer and pesticides are based on recommendations from the core plantation, or where marketing of the harvested products is organized by a cooperative formally tied to the core plantation (McCarthy and Cramb, 2009; Sayer et al., 2012).

The more strongly integrated NESs were forged by governmental policies to foster smallholder participation in the 1960s. Government policies have long supported the participation of smallholders through favorable institutional settings and migration policies. Subsequent programs also supported smallholders in oil palm and rubber production and anticipated a more integrated institutional arrangement. Transmigrant programs, such as the PIR in the 1980s, fostered the participation of transmigrants via joint governmentprivate sector development schemes with farmer groups and cooperatives. This involved the collaboration of the estate plantation and the surrounding satellite area (McCarthy and Cramb, 2009).

Since the establishment of a new plantation requires a high level of investment and technology, the high entry barrier is difficult to overcome for smallholders. Consequently, integrated systems with state or private company-support generate strong incentives for smallholders, leaving them with less financial insecurity.

Next to vertical integration, further institutional settings exist to overcome high entry barriers; sharecropping between two or more farmers (often found in rubber production) incorporates not only establishment costs, but also management costs, into investment requirements which are shared in various ways between participants.

The introduction of the transmigrant program can be seen as a starting point for the spread of oil palm cultivation in Jambi province. Non-participants of such transmigrant programs are mostly found in autochthonous villages and show a time lag in the adoption of oil palm production. Beforehand, autochthonous villages and farmers mostly grew rubber, and subsequently changed to oil palm production (Gatto et al., 2015). The support program fostering the integration of smallholders into the agricultural sector has downsides, which cannot be neglected. In its current form, the NES estate mill or plantation is the only buyer for satellite farmers and therefore experiences a monopsony situation, singularly devolving market price power. Satellite farmers are therefore exposed to local price manipulation without marketing alternatives. Furthermore, the various versions of arrangements in the NES, which have developed through time, have led to a loss of transparency for the farmers when it comes to land ownership and alienation of 
estates. Consequently, the institutional arrangements and support schemes result in gains as well as losses (McCarthy and Cramb, 2009). Thus, a thorough analysis of the effects of heterogeneity in the support schemes and contractual arrangements on the efficiency and key economic outcomes is required.

\subsection{Introduction to Stochastic Frontier Analysis (SFA)}

The structure of the palm oil and rubber production sector shows a strong diversity of smallholders. The different political influences, as well as the various management, and marketing possibilities, has lead to various individual production settings. All these need to be fitted into an elaborate model in order to mirror the underlying production technology and the determinants of efficiency.

The aim of measuring and comparing scales of efficiency over a set of observations with the best attainable level of efficiency has always been alluring. One approach to conceptualizing a production frontier as a feasible upper bound for a given set of input factors was originally introduced by Farrell (1957). His approach led to two main empirical methods for frontier estimation: the deterministic Data Envelopment Analysis (DEA) and the stochastic pendant SFA. The latter technique was developed by Aigner et al. (1977) and Meeusen and Broeck (1977). They independently assimilated a constructed composed error term to circumvent random shocks in the estimation of productivity and especially inefficiency.

The SFA offers us the possibility to appraise the capacity of inputs used against the output produced for each farmer observed, relative to the frontier, giving us the technical efficiency of the farmer. Deviations from the best feasible production level - the production frontier - may result from two variables. One is assigned to technical inefficiency which are systematic shortfalls due to imperfect production adjustments in terms of input use or output levels for a given technology. A second, purely random, cause of deviation might be due to measurement errors and uncontrollable effects described as stochastic effects. Using the SFA, both deviations can be measured for each observation with the composed error term incorporating the traditional random noise term and capturing the stochastic effects. Meanwhile, the one-sided error term, captures the technical inefficiency. We can therefore write the basic frontiers as:

$$
\begin{aligned}
\ln Y_{i}= & \ln f\left(X_{i} ; \beta\right)+\varepsilon_{i} \\
& \varepsilon_{i}=v_{i}-u_{i}
\end{aligned}
$$

where $Y_{i}$ denotes the observed scalar of outputs. $f\left(X_{i} ; \beta\right)$ represents a deterministic kernel subject to the vector of all inputs $x_{i}$ and $\beta$ as the unknown parameter vector to be estimated. $\varepsilon_{i}$ refers to the composed error term consisting of $v_{i}$, the random noise distributed 
as $N\left(0 ; \sigma_{v}^{2}\right)$, and $u_{i}$, the systematic shortfall, both independent from $x_{i}$ and from each other. Furthermore, the error component $u_{i}$ needs to satisfy the assumption $u_{i} \geq 0$. In their original work, Aigner et al. (1977) assumed an underlying distribution of $N^{+}\left(0 ; \sigma_{u}^{2}\right)$ for $u_{i}$. Over time, numerous researchers expanded the distributional assumptions on $u_{i}$ allowing $u_{i}$ to be dependent on some covariates (see Wang and Schmidt, 2002). Pitt and Lee (1981) and Kalirajan (1981) first developed an approach to estimate efficiency effects with a two-step method. In the first step, the production function is specified and the technical inefficiency is predicted. The second step regresses the predicted inefficiency values on the assumed characteristics via Ordinary Least Squares (OLS).

This method has been criticized since the identical distribution assumption on the inefficiencies in the first step contradicts with the regression of the second step by subverting the variation due to inefficiency. Furthermore, correlations between the firm characteristics and the inputs may exist, leading to biased estimates (Wang and Schmidt, 2002).

The issue of biased estimates from the two-step estimation was addressed by Kumbhakar et al. (1991), Battese and Coelli (1995), Reifschneider and Stevenson (1991), Caudill and Ford (1993), Caudill et al. (1995), and Simar et al. (1994). They proposed a simultaneous estimation of the efficiency effect and the production frontier under adequate distributional assumptions. While Kumbhakar et al. (1991) and Battese and Coelli (1995) considered the effect of the characteristics on the mean of the $u$ distribution, Reifschneider and Stevenson (1991), Caudill and Ford (1993), and Caudill et al. (1995) implemented the so - called scaling property, where the parameters of the distribution of $u_{i}$ depend on the efficiency effects.

Adapting the latter dependence with an underlying half-normal distribution of the $u$, we can say that $\sigma_{u}(z, \delta)$ depends on the characteristics $z$, leading to a distribution of $u$ in the form of $N^{+}\left(0 ; \sigma_{u}(z, \delta)^{2}\right)$, where $\sigma_{u, i}^{2}(z, \delta)=\sigma \exp \left(z_{i}^{\prime} \delta\right)$ or correspondingly

$$
\begin{aligned}
\sigma_{u, i}^{2}(z, \delta) & =\sigma \quad h(z, \delta) \\
h(z, \delta) & =\exp \left(z_{i}^{\prime} \delta\right)
\end{aligned}
$$

The magnitude of the effect of the $z$-variables is computed by Equation 2.3, due to the non-linear relationship between $E\left(u_{i}\right)$ and $z$. Based on the half-normal distribution of $u$ and the parametrization of the exogenous effects on inefficiency the computation of the marginal effect is given by

$$
\frac{\partial E\left(u_{i}\right)}{\partial z[k]}=\delta[k] \frac{\sigma_{u, i}}{2}\left[\frac{\phi(0)}{\Phi(0)}\right]=\delta[k] \sigma_{u, i} \phi(0)
$$

The technical efficiency and corresponding noise term for each individual can be extracted through the mode of the conditional distribution of $u$ as proposed by Jondrow et al. (1982) or Battese and Coelli (1988). The point obtained estimates the efficiency values, and can 
be derived via

$$
T E_{i}=E\left[e^{-u_{i}} \mid \varepsilon_{i}\right]
$$

as presented by Kumbhakar and Lovell (2000).

\subsection{Data and Empirical Specification}

\subsubsection{Data}

This research here relies on a socio-economic household survey profiling 600 smallholders from the Province of Jambi on Sumatra, Indonesia. The household survey was conducted at the end of 2012 and covered five regions (Sarolangun, Batanghari, Muara Jambi, Tebo, and Bungo). As a sampling procedure, a stratified sampling approach seemed the best fit in reflecting the geographical and regional dissimilarities of the province. In a twostep random-selection procedure, 40 villages from the five chosen regions were selected. Within each region, four districts and two villages per district were selected randomly. Significant diversity in terms of population size between the villages precluded constant sampling numbers. To reduce the magnitude of this problem, randomly selected villages were reorganized into subsections of four quarters. From these quarters -6 to 12, 18, and 24 - households were selected randomly (Faust et al., 2013). This avoids any underrepresentation of households from larger villages and over-representation of households from smaller villages.

\subsubsection{Descriptive statistics}

The focus of this research lies in the differences and determinants of productivity and efficiency in the two production systems of rubber and oil palm plantations. As some farmers cultivate several plots and fruits simultaneously, we separate and analyse the data on a plot level for each production system. An overview of the main sample characteristics of the variables and efficiency effects is presented in Table A.1. Comparing two different types of output, the mean yield does not give any further insight into either the production or the productivity.

Nevertheless, the descriptions of the inputs and general allocation hints at some differences in the production systems. The most striking disparity appears in the inputs of labour and cost of fertilizer. Oil palm cultivation engages one-sixth of the hours used for rubber production, but results in a six times higher share of fertilizer costs. This may already indicate a labour-intensive rubber production. The mean age of the trees and palms shows a longer average production duration for rubber trees, nearly double that of the oil palm usage. The morphology of oil palm generally allows harvesting to start earlier than in the case of rubber, although the first fruit bunches are comparatively small. According to literature, the suggested production length for oil palm cultivation is between 28 and 
30 years, while for rubber it ranges from 30 to 35 years. In recent times, the latter has lessened to 25 years thanks to new high-yielding varieties of rubber (Rehm and Espig, 1991; Corley and Tinker, 2003). A higher allocation of capital is found in oil palm production, which coincides with the cost of chemicals (herbicides and fertilizer) hinting at a more capital-intensive production in comparison to rubber. Finally, the share of herbicides and fertilizer with respect to the total chemical application is higher in rubber production at $35 \%$, compared to $10 \%$ in oil palm production.

\subsubsection{Stochastic frontier specification}

For our estimations, we choose the general empirical model in the form of the translog (transcendental logarithmic) production function to allow for high flexibility. The fit of the translog functional form was tested against the Cobb-Douglas form, confirming our choice in both productions at a $1 \%$ significance level. Testing the model for goodness of fit, the underlying data set for oil palm production shows the necessity for a split estimation, separating the groups of transmigrants and autochthon farmers. The F-test allows us to reject the zero hypothesis, claiming a pooled estimation in favor of the alternative split estimation at a $1 \%$ level. In the case of rubber, the test whether a pooled estimation is a better fit to the underlying production is rejected. Therefore the differences between transmigrant producers and the autochthon producers do not significantly influence the production frontier. Consequently we specify and estimate three models for this research:

a) Oil palm - Transmigrant model

The underlying production function used to describe transmigrant production includes variables for plot size, hours of labour, plantation age, and the cost of herbicides. This specification was tested for the selection of variables (inputs) to avoid overestimation and omitted variable bias using the LR-test.

b) Oil palm - autochthon model

For the oil palm production of autochthon smallholders, the coefficients differ in terms of the utilization of chemicals. Thus the autochthon oil palm estimation includes the cost of fertilizer instead of the cost of herbicides. Otherwise, the models are identical in terms of inputs and were again tested for the inclusion of the correct variables to avoid over or underestimation.

c) Rubber

The rubber production of smallholders is defined by plot size, hours of labour, plantation age, cost of chemicals, and the allocated capital.

As mentioned in the methodology, we expect variation at the technical efficiency level 
due to farm-specific characteristics (contractual support, production specialization, management settings etc.), so we take advantage of the Wang and Schmidt (2002) scaling property in our stochastic frontier estimation. The latter was chosen due to the estimation of the technical efficiency while acknowledging the effects of random errors in the estimation. Nevertheless, we proceed to test the fit of the SFA against OLS.

Keeping the production specification in mind, the general model can be written as:

$$
\begin{gathered}
\ln y_{i}=\beta_{0}+\sum_{j=1}^{k} \beta_{i} \ln x_{j i}+\frac{1}{2} \sum_{j=1}^{k} \sum_{l=1}^{k} \beta_{i} \ln x_{j i} \ln x_{l i}+v_{i}-u_{i} \\
\text { for } \forall i=1, \ldots, N \\
u_{i} \sim N^{+}\left(0 ; \sigma_{u i}\left(z_{i}, \delta\right)^{2}\right) \\
v_{i} \sim N\left(0 ;\left(\sigma_{v}^{2}\right)\right.
\end{gathered}
$$

Here, $y_{i}$ denotes the yield in $\mathrm{kg} /$ year of the farmer per plot, and $x_{j i}$ denotes the inputs which are specific to the production process. In the estimation, we scale all variables by their sample mean prior to taking the logarithms to facilitate the convergence of the likelihood function. Additionally, we add a regional dummy for oil palm production to explore productivity differences between the five regions (Sarolangun, Batanghari, Muara Jambi, Tebo,and Bungo).

Moreover, for the analysis of the impact of producers' characteristics, $z$ variables, on the efficiency, we specify further $h\left(z_{i} ; \delta\right)$ functions via the scaling property introduced by Wang and Schmidt (2002):

$$
\begin{aligned}
h\left(z_{i} ; \delta\right)^{R P} & =\exp \left(\delta_{1}+\delta_{2} \ln L S_{i}+\delta_{3} D i_{i}+\delta_{4} D i_{i}^{2}+\delta_{5} C y_{i}+\delta_{6} S h_{i}\right) \\
h\left(z_{i} ; \delta\right)^{O P_{-} T M} & =\exp \left(\delta_{1}+\delta_{2} \ln D P_{i}+\delta_{3} C S_{i}+\delta_{4} S p_{i}+\delta_{5} S i_{i}\right) \\
h\left(z_{i} ; \delta\right)^{O O P_{-} A T} & =\exp \left(\delta_{1}+\delta_{2} \ln D P_{i}+\delta_{3} C S_{i}+\delta_{4} L S_{i}+\delta_{5} D i_{i}+\delta_{6} D i_{i}^{2}\right) \\
& R P=\text { Rubber,OP_TM}=\text { Oil palm Transmigrant,OP_AT}=\text { Oil palm autochthon }
\end{aligned}
$$

where $L S_{i}$ reflects the share of land owned by the farmer which is given a value between 0 , meaning no land certificate, and 1 where the certificate is held for the complete plot. $D i_{i}$ and $D i_{i}^{2}$ measure the distance between the buyer and the output, $C y_{i}$ is a categorical variable representing the harvesting interval and $L S_{i}$ is a dummy for entering sharecropping arrangements. Additional variables included in the scaling property of oil palm production are $D P_{i}$, representing a dummy which describes whether the farmer produces oil palm and rubber; $C S_{i}$ is a second dummy variable indicating support through contrac- 
tual arrangements, $S p_{i}$ defines the degree of diversification in the income of a household with values between 1 and 0 ; calculated by the Herfindal index, and $S i_{i}$ captures the size of the plot. All descriptions of the $z$ variables are given in Table A.1.

\subsection{Results}

\subsubsection{Parameters of the production functions}

The overall models which were estimated for the two different production systems seem to be an acceptable fit, considering the amount of significant coefficients. In general, the models feature the desired assumptions and restrictions to ensure estimation accuracy. There were some small violations against monotonicity in the case of two variables in the transmigrant oil palm estimation and these will be discussed later.

In their final specification, all models were tested for the existence of $u_{i}$ against the alternative hypothesis of no presence of inefficiency leading to an OLS estimation. In all three cases, our SFA specified model was the better choice at a $1 \%$ significance level. Results of the test are listed in Table 2.1.

Table 2.1: LR-test results for testing the presence of inefficiency

\begin{tabular}{llllll}
\hline & $L L_{O L S}$ & $L L_{S F A}$ & $L R_{\text {crit }}(\mathrm{df})$ & $L R_{\text {calc }}$ & Decision \\
\hline Rubber & -605.028 & -512.924 & $13.742(6)$ & 184.208 & reject $H_{0}$ \\
Oil palm_Trans & -67.833 & -31.367 & $12.103(5)$ & 72.933 & reject $H_{0}$ \\
Oil palm_Auto & -144.169 & -110.921 & $13.742(6)$ & 66.496 & reject $H_{0}$ \\
\hline
\end{tabular}

The complete estimation results are included in the appendix. The first-order estimates can be interpreted as partial production elasticities of the production inputs since the data was mean-scaled prior to taking the logarithms.

\subsubsection{Differences between oil palm and rubber production systems}

With regard to partial production elasticities, a few distinctions between the importance of input factors in both crop production systems can be emphasized (appendix Table A.2,A.3 and A.4.

In general, three production variables are equally included in both crop production system estimations: plot size, hours of labour, and plantation age. The size of the plot is significant in both crop transformation systems. Nevertheless, the magnitude of the effect of an increase in the plot size, ceteris paribus, is larger in both oil palm estimations transmigrant and autochthonous but not in rubber. These results may indicate a higher scarcity of land in the production system of oil palm in comparison to rubber. The descriptives from Table A.1 highlight a smaller plot size for oil palm, emphasizing these findings. Transmigrant producers are distinct in the category of oil palm producers, managing smaller plot sizes as a result of the political Transmigrant Support Program (TSP) 
which allocates a maximum of three ha per farmer. The structure of further support programs limits the possibility of expansion for transmigrant framers. Therefore, the higher marginal product, all remaining variables being equal, reflects the underlying scarcity of land for transmigrant farmers in contrast to the less restricted autochthonous farmers.

The input of labour is also significant in both production systems but a clear distinction between both production systems is less obvious.

A marginal difference is found between the coefficient in rubber production and in autochthonous palm oil production, which are both substantially higher than the coefficient in transmigrant oil palm production.

Looking closely at differences within the oil palm production system, transmigrant farmers, with a higher degree of specialization, have a higher marginal product of labour than autochthonous farmers. The reduced effect of labour increase towards the output, in comparison to the autochthonous farmers, may indicate a more productive allocation of the scarce factor than their local counterpart. In general the relatively small differences stemming from the effect of a labour increase allows us to conclude that labour is equally relevant in all systems.

In rubber production the effect of plantation age is insignificant but, for both oil palm productions, the effect is significant. Autochthonous oil palm cultivation experiences a positive effect from an increase in plantation age, which is actively not possible. In any event, transmigrants' production of oil palm decreases with increasing plantation age, ceteris paribus. This diverse reaction may result from the different stages of the plantations. At the mean, transmigrant plantations are 15 years old while autochthonous plantations only reach 10 years. The yield profile after Goh et al. (1994) draws a strong augmentation of the yield with increased plantation age from the date of planting up to a maximum age of 10 years, followed by a period of stagnation or even reduction in yield. These findings were confirmed for three different rainfall scenarios (Corley and Tinker, $2003)$.

The application of chemicals is significant in both production systems, even though the implemented variables differ in detail. The smallest effect is estimated for rubber production with agglomerated chemicals (fertilizer, herbicides, soil fertility treatment). In oil palm production, autochthonous production presents a significant utilization of fertilizer, in contrast to the transmigrant estimation which shows a significant herbicide application. Nevertheless, the effect is negative, which points to a decrease in output when herbicide application is increased. This could indicate an overuse of herbicide in terms of two modes of operation. Firstly, the application of herbicides in such strong concentrations not only affects the targeted ground cover, but the palm itself. This is frequently accompanied by incorrect application techniques which commonly appear in smallholder cultivations. 
Secondly, discussions relating to the advantage of plant covers from certain plants such as legumes, has been commonplace in the literature.

The utilization of herbicides in plantations to extinguish the plant cover which offers a protective surrounding for the oil palm can therefore negatively affect yield. The removal of such ground cover can lead to stronger erosion and runoff and can also be labour demanding.

In addition to the preceding variables there is the capital variable, which is represented by a rather small coefficient in both production systems. These findings do not likely coincide with the hypothesis of a capital-intensive oil palm production. This divergence may be due to the applied metrology of capital (vehicles such as trucks and tractors) in our estimation. Following comparisons with the relevant coefficients, other results confirm the earlier stated assumption of labour-intensive rubber production in comparison to a less labour-intensive oil palm production.

Summing up all plausible point elasticities of the estimation - plot size, labour, capital, and all the kinds of chemicals used in the estimations - provides us with a measure of scale elasticities of 0.829 for rubber, 1.03 for oil palm autochthonous, and 0.884 for transmigrant oil palm farmers. The scale elasticity indicates decreasing returns to scale for the rubber and transmigrant oil palm production, while for the autochthonous oil palm production, slightly increasing returns to scale are indicated. The mean returns to scale for rubber and transmigrant oil palm are significantly different from one another, as indicated by the ttest. Furthermore, the one-sided test shows that the RTSs are most likely to be below one. The t-test for autochthonous oil palm indicated returns to scale significantly different from one and significantly bigger than one. The economic interpretation of decreasing returns to scale hints at a input increase with a less than proportional output increase. These are mostly found in smaller and more labour-intensive farms, where smaller volumes of production are also efficiently feasible. This also fits to rubber production, which is relatively small in production size and volume, especially in smallholder productions.

Table 2.2: Returns to Scale for oil palm transmigran, oil palm autochthonous and rubber production

\begin{tabular}{lccc}
\hline & OP-Transmigrant & OP-Autochthonous & Rubber \\
\hline RTS & 0.884 & 1.03 & 0.829 \\
\hline
\end{tabular}

Increasing returns to scale, where doubling the input more than doubles the output, are seen in economics as an indicator for larger and more capital-intensive productions. Higher investments in productions, tractors, seedlings and chemicals generally correlate with high scale elasticities. This might strengthen the hypothesis of a capital-intensive oil palm cultivation, at least for the autochthonous producers, who operate on a bigger plot size than the transmigrants. 
The different regions included in the estimation of oil palm production systems show differences in production levels. Regions which are close to the provincial cities such as Batanghari and Muara Jambi show notable advantages in production level. The last region, Bungo, also displays an unexpected effect on production. This remains currently unexplained.

The hypothesis of a capital-intensive oil palm production and a labour-intensive rubber production only partly pertains to our results. The abundance of working hours and the marginal product of labour, in combination with the significant coefficient of labour, fit to the assumption of a labour-intensive production for rubber. Furthermore, the decreasing returns to scale also indicate a labour rather than capital-intensive production.

Nevertheless, a low coefficient of capital, especially for rubber production may, not hint at a capital-intensive production. However, the slightly elevated coefficient of the cost of fertilizer for the autochthonous oil palm production and the marginal increasing returns to scale both point in the direction of a capital-intensive production.

\subsubsection{Efficiency scores}

An average degree of technical efficiency differs between the two smallholder productions. Rubber production reaches an average efficiency estimate of 0.74 and a standard deviation of 0.15 , meaning a possible increase in output by $35 \%$ with the given inputs.

In oil palm production, the degree of efficiency is lower for autochthonous farmers with an estimate of 0.66 and $34 \%$ inefficiency at a standard deviation of 0.21 . The estimation for transmigrant producers reveals a relatively high level of efficiency with 0.91 and $9 \%$ inefficiency at the mean, with a corresponding standard deviation of 0.17 .

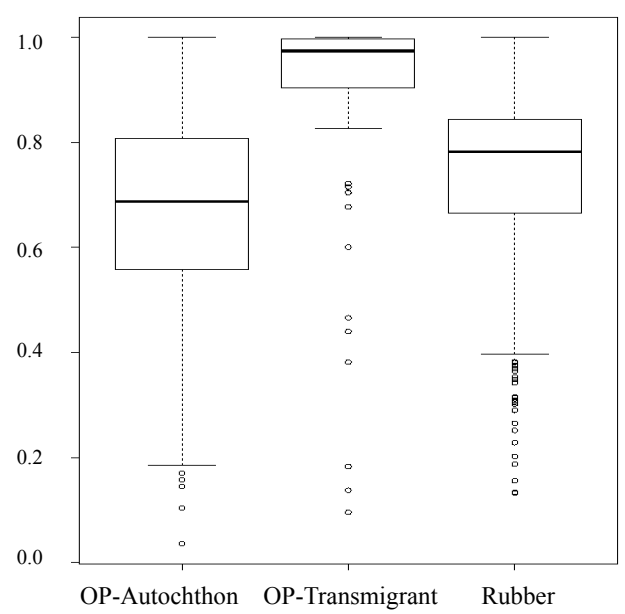

Figure 2.1: Efficiencies over the production systems

The gamma estimate, the ratio of the variance of inefficiency over the total error variance $\gamma=\sigma_{u}^{2} / \sigma_{u}^{2}+\sigma_{v}^{2}$, lies at 0.321 for rubber production indicating that a rather large part of the error variance is due to noise. The ratio for oil palm production lies at 0.629 for 
transmigrant producers and 0.696 for autochthonous farmers, indicating that a bigger share of the error variance arises from inefficiency and may therefore allow more precision in the estimation.

Looking at the distributions of the efficiencies inside the different production systems, a distinct variation is obvious. The segmentation of the efficiencies, listed in Table 2.3, reveals a higher agglomeration of transmigrant oil palm and rubber farmer in the highest segment between 0.75 and 1 . For autochthonous farmers, who coincide with the lower efficiency values, the largest share of farmers is in the middle segment between 0.25 and 0.75. The substantial difference of the efficiency levels between transmigrant farmers and

Table 2.3: Distribution of efficiencies

\begin{tabular}{|c|c|c|c|c|c|c|}
\hline Production system & Quantile & Obs. & Mean & Std. Dev. & $25 \%$ & $75 \%$ \\
\hline \multirow{4}{*}{ Rubber } & $>75$ & 6 & 0.173 & 0.039 & 0.134 & 0.202 \\
\hline & $25-75$ & 289 & 0.607 & 0.118 & 0.537 & 0.704 \\
\hline & $>75$ & 437 & 0.844 & 0.066 & 0.795 & 0.869 \\
\hline & $\varnothing$ & 732 & 0.745 & 0.155 & 0.664 & 0.844 \\
\hline \multirow{4}{*}{ Oil palm ${ }_{\text {Transmigrant }}$} & $>75$ & 3 & 0.139 & 0.044 & 0.096 & 0.183 \\
\hline & $25-75$ & 9 & 0.601 & 0.136 & 0.466 & 0.704 \\
\hline & $>75$ & 105 & 0.958 & 0.048 & 0.927 & .997 \\
\hline & $\varnothing$ & 162 & 0.909 & 0.168 & 0.904 & .997 \\
\hline \multirow{4}{*}{ Oil palm ${ }_{\text {autochthonous }}$} & $>75$ & 8 & 0.158 & 0.066 & 0.124 & 0.202 \\
\hline & $25-75$ & 91 & 0.569 & 0.134 & 0.480 & 0.682 \\
\hline & $>75$ & 63 & 0.843 & 0.065 & 0.791 & 0.872 \\
\hline & $\varnothing$ & 117 & 0.655 & 0.205 & 0.557 & 0.807 \\
\hline
\end{tabular}

the other two production systems, indicate an advantage in the combination of the PIR and NES program for the producers. Comparison between the oil palm groups reveals in particular significant differences in their efficiency of production. The participation of TSP, patronizing producer financially and via training, positively alters the level of efficiency. Operating with less inefficiencies, producers were able to translate the advantages of the support provided to their production process. Non-participants of NES and/or PIR, mostly found in autochthonous villages, previously grew traditional crops, such as extensive rubber or even rubber plantations, before changing to oil palm production with a time lag in adoption (Gatto et al., 2015). Our results indicate that the independent transition accompanied by other factors, such as a lack of infrastructure, resulted in less efficient productions. McCarthy (2010) reports similar findings, calling the second wave of independent adoption a 'laissez faire' scenario, which bears high potential for unbalanced development diffusion McCarthy et al. (2012).

A closer look at the attributes linked to each segment might provide an explanation for a 

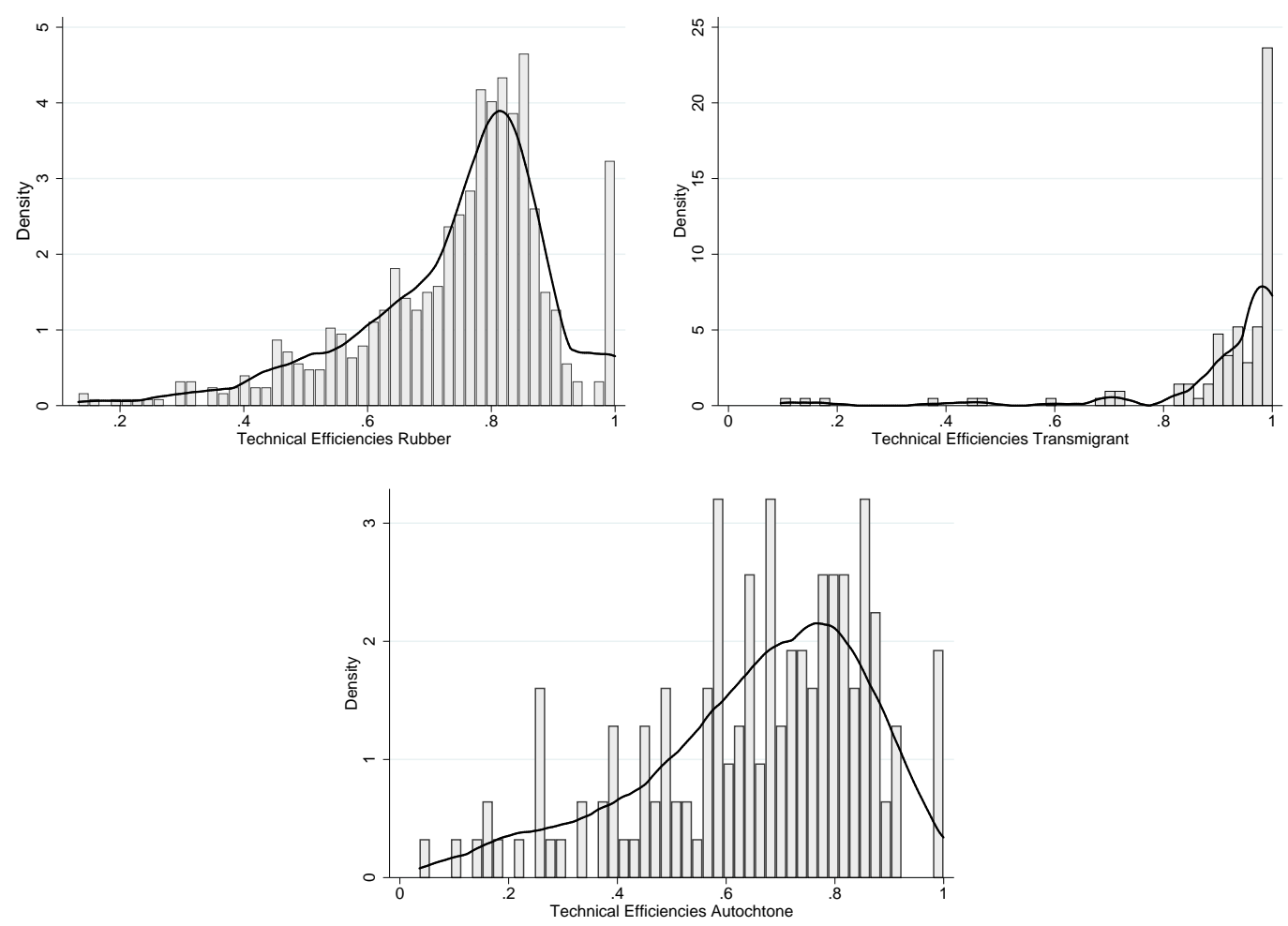

Figure 2.2: Distributions of efficiencies: rubber (top left), oil palm transmigrant (top right), oil palm autochthon (bottom)

better understanding of the diverse structure of efficiencies.

In the case of rubber producers, the segment containing the most efficient farmers, shown between 0.75 and 1, operates on the largest plot in comparison to the other two segments. Even so, the confidence interval of plot size is the widest. Equally telling, more hours of labour are allocated in this segment, in comparison to rubber producers belonging to the lowest segment. In the latter case, farmers tend to have the highest cost of chemicals, especially herbicides. The share of herbicides with respect to the total chemical cost lies at almost $100 \%$. This is in stark contrast to the two more efficient segments in which the share of herbicides lies at $37 \%$ for the $2^{\text {nd }}$ and $32 \%$ for the $3^{\text {rd }}$ segment.

With regard to transmigrant oil palm farmers, the only attribute which can be linked to the lowest efficient segment is a rather scant usage of labour, representing half of the other two segments.

When considering the most efficient transmigrant producers, the descriptive statistics discern the smallest plot sizes but, similar to the rubber producers, the widest confidence interval. Furthermore, the $3^{r d}$ segment farmers cultivate the oldest plantations in contrast to the two lower efficient segments. Likewise, the latter attribute can be linked to the most efficient autochthonous farmers but even so, the plantations are generally younger than those belonging to transmigrant farmers. At the mean, the most efficient farmers own plantations which are around two years older than the least efficient ones. These 
two additional years are relevant for production, especially in the early growth stages. Looking at the least efficient autochthonous farmers, an agglomeration of the biggest plots is observed alongside a doubling of the cost of fertilizer when compared to the most efficient farmers.

The substantial inefficiencies observed for autochthonous farmers may be a consequence of the land and labour scarcity revealed in the productions. The potential increase in returns to scale for autochthonous farmers with the limitation in the production inhibit the possible scale efficiency resolving in inefficient allocation of the inputs. This may partly contribute to the explanation of the inefficiencies in rubber production.

Since this comparison is a rather superficial overview of the efficiencies, the actual effects of producer specific characteristics on efficiency may reveal a better understanding of production. The results of the attributes' estimation are listed in Table 2.4. The results of the scaling property model specified in Equation 2.5 show significant differences in efficiency levels, depending on the farm-specific characteristics, as we expected.

\section{Rubber}

Among all significant estimates, the biggest effect on the distance to the frontier, and hence efficiency, emanates from the cycle dummy which is a categorical dummy for the frequency of harvesting the rubber. The estimation demonstrates an increase in efficiency of production with an increasing rate of harvesting frequency.

The most prominent effect on efficiency is reached by harvesting at least once every 10 days, with a $1 \%$ reduction in the distance to the frontier, in comparison to $0.26 \%$ for once in 15 days, or no improvement at all for 30 days, where the latter is the baseline. This implies a higher efficiency, if the farmer collects the full rubber pots of each tree with a higher frequency. An explanation for this effect might lie in the reduction of the probability of losing rubber due the falling over of the collecting pot, rain and other hazards. Next to changes in cultivation practice to raise the efficiency, several institutional settings influence the level of inefficient production.

First, a positive influence can be derived from the share of land, for which the producer is in possession of the certificate of landownership. With a one percent expansion of the land under the certificate, the producer shortens the distance to the frontier by $0.33 \%$. Most farmers possess a certificate for either the total production area or none at all, dependent on the acquisition of the land. The ownership of land is linked to security for the farmer; secure ownership encourages the farmer to make investments in the plantations.

Secondly, sharecropping arrangements can alter the distance to the frontier for each farmer. A sharecropping arrangement after Janvry (2004) constitutes a production where the output is distributed between multiple farmers who cultivate the land either together or alone; this takes the form of either wage contracts (where the landlord is the entrepreneur) or 
Table 2.4: Estimation results for $z$-variables

\begin{tabular}{|c|c|c|c|}
\hline \multirow[b]{3}{*}{ Variable } & \multicolumn{2}{|c|}{ Oil Palm } & \multirow[t]{2}{*}{ Rubber } \\
\hline & Transmigrant & Autochthon & \\
\hline & \multicolumn{2}{|c|}{ Coeffitients } & Coeffitients \\
\hline $\ln ($ size $)$ & $1.658^{* * *}$ & & \\
\hline Income share & $-12.885^{* * *}$ & & \\
\hline Dual production & $2.347^{* * *}$ & $0.637^{* * *}$ & \\
\hline Contract Supp. & $-2.552^{* * *}$ & $-0.783^{* *}$ & \\
\hline Landshare & & $-0.438^{*}$ & $-0.331^{* *}$ \\
\hline Distance & & $0.066^{* *}$ & $0.023^{*}$ \\
\hline Distance $^{2}$ & & $-0.002^{* *}$ & $0.001^{* *}$ \\
\hline Sharecropping & & & $-0.526^{* * *}$ \\
\hline Harvest Cycle_15 (days) & & & $-0.262^{*}$ \\
\hline Harvest Cycle_10 (days) & & & $-1.015^{* * *}$ \\
\hline Intercept & 0.409 & $-0.744^{* * *}$ & -0.061 \\
\hline
\end{tabular}

rent contracts (where the tenant is the entrepreneur). If the plot is managed together, the share of output in appropriation can differ from the share of cost of inputs, depending on the arrangement. The incorporated dummy in the estimation reveals a positive effect of such arrangements on the efficiency. Producers pegged into a sharecropping arrangement tend to shorten their distance to the frontier by $0.50 \%$. 96.39\% of farmers entering into such an arrangement own the land, leaving them as the landlord.

In the literature the efficiency of sharecropping is discussed controversially. Settings where the landlord is in charge of the management and monitoring of the plantation and the tenant provides the labour are expected to be less efficient. Losses in efficiency are pinned to disincentives for investments for not shared inputs such as labour and capital and additionally lack of monitoring; this is known as the "Marshallian inefficiency". The positive effect of sharecropping, in our case, seems to overcome the Marshallian inefficiency, which may result from a number of different factors.

Firstly, the risk of losing their means of existence pushes a tenant to work at their maximum capacity and consequently equalizes the cost share of input with the output share for the landlord (Sadoulet et al., 1994).

Secondly, the two sharecroppers have a strong social link with each other, preventing inefficient behavior on both sides.

Thirdly, and tied in with the second point, if the tenant seeks personal recognition for their work and a link to their landlord, they are able to utilize the relationship in order to attain a higher social rank based on their level of effort.

Subsequently, with an equal sharing of all costs and outputs, the incentive for opportunistic behavior - and with that, the Marsahllian inefficiency - disappears. Fourthly, sharecropping arrangements are found in productions which experience low monitoring costs but carry a certain amount of risk, mostly found in simple production with low 
numbers of participants. Both arguments fit the characteristics of the rubber production (Hayami and Otsuka, 1993).

Finally, the distance to the buyer shows a bivalent effect on the efficiency level, with a significance level of $10 \%$. The estimation of the two distance coefficients, one as a continuous variable and the second as its squared term, reflects the varying effects with increasing distance. The estimation results reveal a change from a negative effect on efficiency to a positive effect with increasing distance. Therefore, with greater distances to buyers, the farmer may achieve better sales and marketing arrangements than at shorter distances. The point at which this reverses for rubber lies at $63 \mathrm{~km}$. Consequently, if rubber is sold to a trader $100 \mathrm{~km}$ further away than the trader at our mean distance, a farmer can increase his efficiency by $1.38 \%$ ceteris paribus.

\section{Oil palm autochthonous}

Equally relevant for efficiency is the distance to the buyer for the autochthonous oil palm producers; this is even more significant at a $5 \%$ level. Here, the turning point from reducing efficiency to increasing efficiency lies at $47 \mathrm{~km}$.

Due to the historical development of plantations, the establishment of autochthonous oil palm farmers was initially based on the independent decisions of farmers to transition from rubber to oil palm production. Since the surrounding production system was dominated by rubber production, the infrastructure and oligopoly-market for oil palm is relatively underdeveloped in autochthonous areas. These findings may indicate losses for farmers by selling to a close-by middle trader, who exerts a higher market power, not only in prices, which would not affect our estimation directly, but furthermore by having lower incentives to support or invest into a binding buyer-seller-relations with farmers having no competition pressure. These effects are more likely to be observed in remote areas. The latter case coincides with the results of Kopp and Brümmer (2015) concerning the comparison of profits of traders in remote and non-remote areas.

The share of land for which the farmer is in possession of the certificate of landownership is also relevant for the production of the autochthonous farmer. Likewise, the expansion of landshare under certificates lifts the efficiency level of the producer. In this case, the distance to the frontier shortens by $0.43 \%$ with a $1 \%$ increase of the share, at a significance level of $10 \%$. The virtue of a larger share under ownership over the land under cultivation offers the producer a certain certainty, leading to possible advanced management practices and higher investments. Consequently, the overall production is likely to be more efficient.

Furthermore, the producers have the possibility to improve on their efficiency level by choosing contractual arrangements. The estimation reveals a decrease in the distance to the frontier by $0.75 \%$ if the producer is currently under contract or was in years past. The advantages associated with contract arrangements may be found in secure purchase 
channels for output and occasional provision of inputs or even management guidelines. The autochthonous farmer is particularly likely to benefit from the latter convenience of contractual support ,as he did not experience the advantage of a close-support program.

The last $z_{i}$ variable expressing the heterogeneous effects of individual producers over the efficiencies is the dummy for simultaneous rubber and oil palm production. At a $1 \%$ significance level, the coefficient shows an enlargement of the distance to the frontier by $0.63 \%$, when the producer allocates his resources, either materials or labour, to his oil palm plantation and additionally to a rubber plantation.

\section{Oil palm transmigrant}

In general, the efficiency of transmigrant oil palm production experiences rather strong fluctuations depending on two case specific variables enhancing the distance to the frontier and two variables curtailing the distance to the frontier.

Coherent with the findings for the autochthonous farmer, the degree of efficiency for transmigrant farmers is likewise altered through dual production and contractual support. The simultaneous production of rubber and oil palm shows an even stronger effect of $2.34 \%$ for the transmigrant farmer. Producers with dual production use less fertilizer for oil palm production, which may result in lower values of efficiency.

The second producer-specific characteristic, which augments the inefficiency of the production, results from plot size. An increase in plot size by $1 \%$ leads to an enhancement in the distance to the frontier by $1.65 \%$. This may be due to controlling issues and the overstocking of daily work correlated with the additional plot size. An augmentation of plot size without increasing palm numbers enlarges the distance between the palms which augments labour time. Moreover, larger gaps in between palms may result in control issues in terms of weeding and tree health and hence reduce output.

As mentioned above, producing under contractual arrangements benefits the level of efficiency of production in both oil palm producer groups. The difference in the transmigrant group is found in the magnitude of the effect. The contractual arrangement shortens the distance and hence decreases the inefficiency by $2.55 \%$. Shifting reasons for the difference in the transmigrant farmer group may lie in the setting in which they were placed. Through the PIR and NES structure, the producers are placed in areas only connected to the estate mill, restricting selling options. Producers without a contract to the mill need to organize themselves outside this setting, requiring more effort due to scarcer opportunities, thus reducing the efficiency of production.

The index of income distribution reveals a rather strong impact on the degree of efficiency. The index, calculated as the Herfindal-index, is a measure of the evenness of the distribution of the income of the family. A household with a diversified income would be linked to an index of close to one, while a household with only one source of income 
would be linked to a low index number. The results reveal an extremely positive effect on the degree of efficiency. The higher the diversification of a household's income, the higher the efficiency on the plot level. Reasons for this may be twofold: One striking difference between the low diversified and high diversified group lies in the application of fertilizer. The cost of the overall chemicals for the highly diversified producers is significantly lower, at a $5 \%$ significance level, than the overall costs of chemicals in the low diversified group. The utilization of the fertilizer seems to be more efficient for the high diversified farmers. Reasons for this ramification might be due to the spillover effects of the different income sources, which may result in more knowledge relevant to production. In addition to this, as some income sources offer additional outputs for a plot, i.e. birds, timber, the handling of the inputs and overall care of the plot tends to be more cautious. Nevertheless, while these results stand in contrast to the dual production variable, the effect is obliterated in magnitude.

The extremely strong effects on the level of efficiency ensuing from producer-specific attributes may be due to the already high levels of efficiency of transmigrant producers. In this case, even a small change in the production setting can increase or decrease the efficiency to a rather high degree.

\subsection{Conclusion}

The study aims to look at the question of productivity differences and determinants of inefficiency in and between the two main cash crops produced in Sumatra: rubber and oil palm. Through the analysis of the determinants of productivity and inefficiency, we hope to indicate a way to move the producers closer to the best-practice frontier in order to reduce the pressure on land and simultaneously the expansion of agricultural land into lowland rainforest. The degree of technical efficiency is estimated using a stochastic translog production frontier on plot-level, using data from a household survey conducted in 2012 .

The estimation reveals a systematic difference in the production of oil palm between transmigrant producers and autochthonous producers, not only in terms of efficiencies levels, but also in terms of the production process. Empirical results concerning the productivity of both crop production systems confirm returns to scale below one for both transmigrant oil palm production and rubber production. On the other hand, autochthonous oil palm producers work under returns to scale above one. These differences are linked to the size of the production, especially in the case of oil palm.

Looking at the estimation results in more detail, land scarcity is observed in all three production estimations, as the plot size manifests as the biggest coefficient in the production. In addition, labour and chemicals such as fertilizer and herbicides are significantly 
relevant for each production.

As with efficiency, the estimation reveals strong differences between the production systems as well as differences within each production. Autochthonous oil palm producers exhibit the lowest degree of efficiency, followed by rubber producers. Transmigrant oil palm farmers show a relatively high level of efficiency in their production. This divergence implies that the earlier implemented programs positively support the smallholder production of oil palm. We can therefore say that the intended effect of the government to promote a good establishment of plantations through their transmigrant support program has been reached.

In addition to this, institutional settings such as the ownership of land certificates and especially sharecropping arrangements between farmers, enhance the efficiency of rubber production. Furthermore, the distance to the trader influences the efficiency not only in rubber, but also in autochthonous oil palm systems. Farmers selling to traders outside their village or farther away increase their efficiency, while selling to local traders has the opposite effect. Subsequently, in the case of both oil palm groups, contractual arrangements with a trader affects the efficiency level positively.

The combination of these effects may lead to the assumption that producers aim for security in their production, especially in choosing institutional settings. The transmigrant support program ameliorated the producers' primary setting through training and links, which were substituted by risk sharing arrangements, ownership of land, and contractual security now that the program is finished. However, the estimation results show that a strong bond to local traders reduces the efficiency, resulting in local price manipulation and losses to the middleman in the supply chain.

Even so, the latter effect is voided by other impacts on efficiency. The question of how to specifically support these production systems further and the correct the allocation of production factors to enhance the productivity and efficiency are interesting topics for further research. 


\section{CHAPTER 3}

\section{Environmental Efficiency in the Case of Rubber}

This chapter addresses the environmental efficiency of small-scale rubber producers in our study area. Enhancing the previous approach from distance functions to directional distance functions by introducing an environmental dimension to the estimation, the underlying trade-off function between the economic output and the environmental effects can be quantified. This chapter provides a fundamental contribution to the research in the development of sustainable production, in particular with respect to policy implementation. In the next section, an introduction to the subject of environmental efficiency or equally eco-efficiency is presented, followed by an explanation of the additions to the previous methodology. Subsequently, the results of the estimation are displayed and discussed before concluding remarks are provided at the end of the chapter.

\subsection{Introduction}

In the last decades, concerns about sustainable development and environmental problems have risen from society. As a result, organizations, firms and producers face a demand for sustainable production to demonstrate all-encompassing environmental performance. In light of this demand, a widespread definition of sustainable development was consolidated in three components by Welford (1995). Firstly, the environment is included in the economic process and not observed as separate from it. Secondly, the equal distribution of goods between all members of society are important and thirdly, the prospective recognition of resources is also considered a vital component (Welford, 1995).

In order to translate Welford's ideas to the production of agricultural products, which is 
an important source of income, we must consider that the benefits are simultaneously accompanied by impacts on the environment such as pollution, nutrient losses, biodiversity losses and climate change effects.

These factors must of course be taken into close consideration for an environmental efficiency analysis. In recent literature attempts to measure all aspects of production has been summarized in terms of 'ecological efficiency'. The most popular definition of eco-efficiency was established by the World Business Council for Sustainable Development (WBCSD);

"Eco-efficiency is reached by the delivery of competitively-priced goods and services that satisfy human needs and bring quality of life, while progressively reducing environmental impacts and resource intensity throughout the life circle, to a level at least in line with the earth's estimated carrying capacity" (DeSimone and Popoff, 2000).

Today the general term eco-efficiency

"refers to the ability to create more goods and services with less impact on the environment and less consumption of natural resources, thus involving both economic and ecological issues" (Picazo-Tadeo et al., 2012).

Our study area Sumatra (and especially Jambi) in Indonesia, is a typical example of environmental degradation as a result of economic development in terms of agricultural expansion and intensification, highlighting the scarcity of land resources and potential inefficiency in terms of eco-efficiency (Laumonier et al., 2010; Gaveau et al., 2007). The rapid change and intensive production of cash crops has been favourable for economic development, but various environmental and social concerns can be attributed to this development.

The expansion of production into areas of lowland rainforest is seen as a major threat to biodiversity conservation, the functionality of ecological systems, climate change, and the sustainability of production with respect to soil and water pollution (Eye on Aceh, 2007; Belcher et al., 2005). Next to deforestation, monoculture production is often linked to undesired side-effects and by-products. One of the by-products of production is seen in the abundance of alien plant species in the natural ecosystem habitats in the plantation sites. Through agricultural intensification, a change from preceding subsistence strategies, in the form of extensive swidden farming, to monoculture cash-crop cultivation, has been observed (Potter, 2001).

This change gives exotic organisms the chance to settle in the disturbed habitats of Indonesia. Consequently, invasive plants have the potential to cause problems in monoculture rubber and oil palm plantations. The threat originating from invasive plants altering the surrounding environment can be categorized as a direct and indirect effect. Firstly, the 
direct effect occurs through the invasive plants' excretion of secondary compounds via leaf leachates, leaf litter, and root exudates. The excretion of secondary compounds is part of the general physiology of plants, but invasive plants are exotic to their infested environment, and consequently impact the nutrient cycles in a different manner to native plants. This effect is manifested by a reduced abundance of supporting microbial communities and altered litter compositions in the invaded areas (Weidenhamer and Callaway, 2010; Liao et al., 2008; Sanon et al., 2009; Standish et al., 2004).

As a second direct effect, secondary compounds create a disadvantaged environment for native plants, giving the invasive species an advantage. This direct effect is also called the 'novel weapon hypothesis' (Weidenhamer and Callaway, 2010). The oppression of the native flora and fauna may diminish or eradicate important supporters of the ecosystem, as well agents essential for tree pollination.

The indirect effects of invasive plants on the environment are seen in the new or elevated need for herbicides to reduce or extinguish the exotic plants. Literature shows a variety of findings on the impact of herbicide application on the surrounding environment, from small and ephemeral to high. The majority of this paper focuses on glyphosate and paraquat. The most common impact concerns the alteration of the functional structure of soil bacteria and its resultant reduction (Lupwayi et al., 2009; Widenfalk, 2005; Allen et al., 2015).

Alongside the direct and indirect effect, the more general concern lies in the expansion of the distribution of invasive plants, resulting in an identical flora and fauna without local diversification covering all five continents. Due to the high competitiveness of the invasive plants, this threat can already be observed in some parts of the world.

Considering the stated main concerns from the ecological point of view, a reduction - or ideally extinction - of the invasive plant population would be a small accomplishment in terms of the environmental impact on monoculture plantations. Nevertheless, profit maximizing attitudes of producers lead to the presence of the undesired by-product maximizing production decisions, contradicting the environmental goal. Thus, determining the interdependence of economic performance and the disturbance of the ecosystem function - invasive plants - and the overall efficiency of the production is a crucial step in reconciling both goals and sustainable development. At the same time the high participation of smallholder producers and the herterogenity, as a result of diverse establishment and management settings, is possibly linked to potential losses of outputs. Eradicating these potential losses by augmenting the efficiency of production reduces this already, depending on the present inefficiency level.

Based on this goal, this chapter seizes on the works of Färe et al. (2005, 2007), Chung et al. (1997), and Njuki and Bravo-Ureta (2014) and applies a Directional Output Distance 
Function (DODF) to quantify the interdependency of both outputs through the underlying trade-off function, on the grounds of a multidisciplinary data-set incorporating variables on economic performance and plot level data describing the state of the environment.

Even though the productivity and efficiency of oil palm and rubber have been the objective a few researches (Hasnah et al., 2004; Alwarritzi et al., 2015; Lee et al., 2013; Wilcove and Koh, 2010; Allen et al., 2015; Rubiana et al., 2015) the strength and novelty of this research lies in the unique combination of data-sets on plot level. This accurate measure of the heterogeneity inside the production system, as a result of diverse establishment and management settings, enables us to estimate individual environmental efficiency. Thus we can derive the potential output losses and reduction possibilities of the environmental disturbances due to inefficiency, before entering the costly trade-off between the desired and the undesired production outputs.

The structure of this chapter is as follows: the first section briefly presents and explains the methodology of the DODF approach. The third part introduces the specific empirical model adjusted to our research aim and the collected data is presented in the same chapter. In section 3.3, the estimates' outcomes are introduced and analysed under certain economic criteria ${ }^{1}$. Finally, we conclude our research with a summary of our findings and prospects for production.

\subsection{Methods and Material}

\subsubsection{Environmental production function and efficiency}

First attempts to estimate and analyse production's trade-off function and the overall efficiency under consideration of undesired by-products embedded their reciprocal into the production function as an input (see Pittman, 1981; Knox Lovell et al., 1995; Reinhard et al., 1999; Hailu and Veeman, 2001).

Even though the approach was justified by the stronger similarities between the undesirable output and input characteristics, as opposed to general output characteristics (Pittman, 1981; Knox Lovell et al., 1995), this concept was challenged by Färe et al. (2005). He argues that environmental disturbances are more likely consequences of production and by-products and the strong disposability of undesired output. This reviewed concept lead to numerous deterministic approaches using the nonparametric linear programming technique of DEA in combination with transformed distance functions to compose a best practice frontier. Färe et al. (1986) established a hyperbolic distance function, following the concept of input-output oriented distance functions by Debreu (1951), Malmquist (1953), and Shephard (1953), allowing for an expansion in the desirable output and a

\footnotetext{
${ }^{1}$ Ideas for the analysis were inspired by Färe et al. (2005), which form the focus of this paper.
} 
reduction in the undesirable input. They went on to introduce differentiation between the weak and strong disposability of outputs in a parametric setting. From these various approaches, two main paths to measure efficiency in the presence of desired and undesired outputs have come forth: the Directional Distance Function (DDF) approach introduced by Färe et al. (2005) and Chung et al. (1997), and the by-production approach.

The latter displays the production of the desired and undesired output separately over individual production functions. (Murty et al., 2012; Fernández et al., 2002). The DDF, based on the concept of the distance function of Shephard $(1953,1970)$, allows for the simultaneous reduction in the undesired output, while enhancing the production of the desired output in different proportions, reflecting the maximizing strategy of our producers.

The transformation function is estimated in a single equation combining undesired outputs and polluting and non-polluting inputs together. This concept, and the related transformation function concepts, have been applied by various researchers, such as Färe et al. (2005), Atkinson and Dorfman (2005), Fernández et al. (2005), Färe et al. (2007), Macpherson et al. (2010), and Njuki and Bravo-Ureta (2014). The by-production approach separates the production of the undesired outputs and individual production functions.

The DODF, originally developed by Chambers et al. (1998), represents a special case of the Output Distance Function (ODF) introduced by Shephard (1970). The difference lies in the use of a directional vector in comparison to a radial measurement for the technical inefficiency which is advantageous for non-proportional scaling. Considering a production process, where output set $P(x)$ represents the set of desired outputs and undesired outputs $(y, b)$, the set of outputs that can be produced by the inputs $\left(x_{1}, \ldots x_{k}\right)$ is specified by

$$
P(x)=\{(y, b): x \quad \text { can produce } \quad(y, b)\} \quad x \in \Re_{+}^{N}
$$

For the specification of the ODF, we introduce the directional vector $g=\left(g_{y},-g_{b}\right)$ with $g \in \Re^{M}$, as presented by Färe et al. (2005). After incorporating this, the direction of the maximization of distance between the observed output $(y, b)$ and the frontier is defined, leading to the parametrization of the DODF as

$$
\vec{D}_{o}\left(x, y, b, g_{y} ;-g_{b}\right)=\max \quad\left\{\beta:\left(y+\beta g_{y}, b-\beta g_{b}\right) \in P(x)\right\}
$$

From the axioms underlying the ODF, we can derive the properties of the DODF to extract further information in the following way: firstly, the output set needs to be a closed set, implying that when no inputs are used, no outputs are produced. This allows us to assume that an increase in inputs can only increase, or at least not decrease, the output set. This is also known as strong disposability. 
Likewise, we can assume strong disposability for the desired output. By virtue of this assumption, we allow the desired output to be reduced without any losses, if an observed vector combination of both outputs was already attained at a higher level. Therefore,

$$
\text { if }(y, b) \in P(x) \quad \text { and } \quad\left(y^{\prime}, b\right) \leq(y, b) \text { then } \quad\left(y^{\prime}, b\right) \in P(x)
$$

In contrast to the strong disposability of inputs, we assume only a joint weak disposability for the outputs. This assumption reflects the idea of abatement costs for a reduction in the undesired output. Decreasing the undesired output over a given vector of inputs must lead to a proportional decrease in the desired output (Färe et al., 2015).

By default, production of the desired output is always linked to the production of bad output, therefore neither output can be produced without the other. This is stated by the null-jointness assumption (Färe et al., 2015). This assumption has been challenged by Henningsen and Henningsen (2015) for special productions, where a simultaneous reduction in the undesired output and increase in the desired output might not be suitable.

While the radially measuring ODF, introduced by Shephard (1970), includes a multiplicative homogeneity function, we make use of an additive translation property for the estimation of the DODF. Through the translation property, a value $\theta g_{q}$ is added to the desired output, while $\theta g_{b}$ is simultaneously subtracted from the undesired output. The $\theta$ value represents the possible reduction in the distance.

$$
\begin{array}{r}
\vec{D}_{o}\left(x, q+\theta g_{q}, b-\theta g_{b}, g_{q},-g_{b}\right)=\vec{D}_{o}\left(x, q, b, g_{q},-g_{b}\right)-\theta \\
\theta \in \Re
\end{array}
$$

Applying a DODF stochastically takes two components into account when a deviance between the observation and the frontier occurs. On the one hand, the traditional random noise term captures the stochastic effects, while on the other hand, a one-sided error term $u_{i}$ captures the technical inefficiency, defined by $-\vec{D}_{o}\left(x, q, b ; g_{q},-g_{b}\right)$. As a result, we add the error term $v_{i}$ to the previous equation and write the frontier as:

$$
\begin{array}{r}
-\theta \equiv \vec{D}_{o}\left(x, q+\theta g_{q}, b-\theta g_{b}, g_{q},-g_{b}\right)-u_{i}+v_{i} \\
\theta \in \Re
\end{array}
$$

While the random noise term $v_{i}$ is normally distributed $N\left(0 ; \sigma_{v}^{2}\right)$, independently from $x_{i}$, various distributions were attributed to the positive inefficiency term $u_{i}, u_{i} \geq 0$. These ranged from an underlying distribution of $N^{+}\left(0 ; \sigma_{u}^{2}\right)$ applied by Aigner et al. (1977) to distributions dependent on observation characteristic variables (Wang and Schmidt, 2002).

The first inclusion of the latter proposal by Pitt and Lee (1981) and Kalirajan (1981) al- 
lowed for a two-step estimation regressing the characteristics on the predicted inefficiency values via OLS. This was highly criticized because of bias issues. Consequently, Kumbhakar et al. (1991), Battese and Coelli (1995), Reifschneider and Stevenson (1991), Caudill and Ford (1993), Caudill et al. (1995), and Simar et al. (1994) proposed a simultaneous estimation of the production function and the effects arising from firm characteristics on the efficiency under adequate distributional assumptions. Kumbhakar et al. (1991) and Battese and Coelli (1995) included the effect of the characteristics through the mean of the $u$ distribution, while Reifschneider and Stevenson (1991), Caudill and Ford (1993), and Caudill et al. (1995) implemented the scaling property, where the variance parameter of the distribution of $u$ is dependent on the efficiency effects.

Adapting the latter dependence with an underlying half-normal distribution of the $u$, we can say that $\sigma_{u}(z, \delta)$ depends on the characteristics $z$, leading to a distribution of $u$ in the form of $N^{+}\left(0 ; \sigma_{u}(z, \delta)^{2}\right)$, where $\sigma_{u, i}^{2}(z, \delta)=\sigma \exp \left(z_{i}^{\prime} \delta\right)$.

The magnitude of the effect of the $z$-variables is computed by equation 3.5 , due to the non-linear relationship between $E\left(u_{i}\right)$ and $z$. Based on the half-normal distribution of $u$ and the parametrization of the exogenous effects on inefficiency the computation of the marginal effect is given by

$$
\frac{\partial E\left(u_{i}\right)}{\partial z[k]}=\delta[k] \frac{\sigma_{u, i}}{2}\left[\frac{\phi(0)}{\Phi(0)}\right]=\delta[k] \sigma_{u, i} \phi(0)
$$

The technical efficiency and corresponding noise term for each individual can be extracted through the mode of the conditional distribution of $u$ as proposed by Jondrow et al. (1982) or Battese and Coelli (1988). The point obtained estimates the efficiency values and can be derived via

$$
T E_{i}=E\left[e^{-u_{i}} \mid \varepsilon_{i}\right]
$$

as presented by Kumbhakar and Lovell (2000).

\subsubsection{Specifications for the Directional Output Distance Function (DODF)}

Given the axioms of the DODF, an empirical specification is needed which allows for the most flexible functional form, while still abiding with the underlying axiom. Following Chambers (2002) and Färe et al. (2005), we choose a quadratic functional form, as the translation property can be easily applied via restricting the estimation parameters.

A crucial point of the empirical specification of the model concerns the choice of the directional vector. Sensitivities of results towards different implemented directional vectors have been shown in several studies; the latest was presented by Tsionas et al. (2015) in a Bayesian estimation approach. Despite their concerns, the implied data-driven vector produced results analogous to those from the commonly used $g=(1,-1)$ vector. The latter 
vector has the advantage of being able to facilitate the parametrization of the quadratic function according to the translation property. Furthermore, it perfectly mirrors the reduction of the undesired output and the increase in the desired output (Feng and Serletis, 2014).

Criticism can be made regarding the equal weight given to both the reduction and the increase, which might not reflect the political desire for the elimination of undesired byproducts (Hampf and Kruger, 2014). As a result of the susceptibility in this case, we apply a variety of vector directions, as a means of comparison. Nevertheless, after adequate discussion, the $g=(1,-1)$ vector seems to be the best fit for the primary analysis and general empirical specification.

In order to estimate the DODF stochastically, we avail ourselves of the translation property. The choice of the $\theta$ term is completely arbitrary, and affords us the opportunity to use the DODF for further estimation. With that in mind, we set $\theta=-q$. Based on this parameterization which includes one desirable $(M=1)$ and one undesirable $(L=1)$, the DODF can be written as

$$
\begin{aligned}
& \vec{D}_{o}\left(x_{i},\left(q_{i}+\theta\right),\left(b_{i}+\theta\right), 1,-1\right) \stackrel{!}{=} \vec{D}_{o}\left(x_{i}, q_{i}, b_{i}, 1,-1\right)-\theta \\
& =\alpha_{0}+\sum_{k=1}^{K} \alpha_{k} x_{i, k}+\sum_{m=1}^{M} \beta_{m}\left(q_{i, m}+\theta_{i}\right)+\sum_{l=1}^{L} \gamma_{l}\left(b_{i, l}+\theta_{i}\right) \\
& +\frac{1}{2} \sum_{i=1}^{K} \sum_{k=1}^{K} \alpha_{k k^{\prime}} x_{i, k} x_{i, k^{\prime}}+\frac{1}{2} \sum_{m=1}^{M} \sum_{m^{\prime}=1}^{M} \beta_{m m^{\prime}}\left(q_{i, m}+\theta_{i}\right)\left(q_{m, m^{\prime}}+\theta_{i}\right) \\
& +\frac{1}{2} \sum_{l=1}^{L} \sum_{l^{\prime}=1}^{L} \gamma_{l, l^{\prime}}\left(b_{i, l}+\theta_{i}\right)\left(b_{l, l^{\prime}}+\theta_{i}\right) \\
& +\sum_{k=1}^{K} \sum_{m=1}^{M} \nu_{k m} x_{i, k}\left(q_{i, m}+\theta_{i}\right)+\sum_{k=1}^{K} \sum_{l=1}^{L} \rho_{k l} x_{i, k}\left(b_{i, l}+\theta_{i}\right) \\
& +\sum_{m=1}^{M} \sum_{l=1}^{L}\left(q_{i, m}+\theta_{i}\right)\left(b_{i, l}+\theta_{i}\right) \\
& \theta \in \Re
\end{aligned}
$$

\subsubsection{Data}

This research relies on two combined surveys: one is a socio-economic household survey including 600 smallholders of Jambi Province on Sumatra, Indonesia, conducted by another sub-project of the CRC $990^{2}$, while the second survey covers the environmental data and includes a sub-sample from the household survey of 135 smallholder rubber farmers.

\footnotetext{
${ }^{2}$ The household survey covering a variety of socio-economic and consumption data is further described in the publications of Euler et al. (2015); Drescher et al. (2016); Faust et al. (2013)
} 
The household survey, conducted at the end of 2012, covers five regions (Sarolangun, Batanghari, Muara Jambi, Tebo, and Bungo) in the province of Jambi. A stratified sampling approach seemed the best fit to mirror geographical and regional disparities, which are stretched out through the province. Forty villages were selected in a two-step random selection, equally distributed over four sub-regions in each of the five regions. To account for dissimilarities in terms of village population size, an adjusted amount of farmers were randomly selected as opposed to using constant sampling numbers. Thus, the randomly selected villages were categorized by size in four quarters: 6, 12, 18, and 24 households were then randomly selected, depending on their category (Faust et al., 2013).

For the environmental data-set, one third of the previously sampled households from the household survey were re-sampled to extract information on the state of biological diversity and plant abundance. From each sub-sampled farmer, we collected vegetation data relating to the major plantation site. To that end, a sampling site was established in the form of a $5 \times 5$ meter plot on which the understory vegetation of the plantation in question was adequately represented. Within the plot, all plants were counted and identified.

The descriptive statistics of all the relevant variables evolving from the data-set are summarized in Table 3.1, where we include rubber production per plot for the last year $(q)$ and invasive plants ${ }^{3}$ per plot $(b)$ for the production function as the desired and undesired output. We also include the following inputs: size of the plot $(x 1)$, hours of labor per plot (x2), plantation age (x3), and cost of all chemicals (fertilizer, herbicides, soil amends) $\left(x_{4}\right)$. Each input and output was normalized by its mean prior to the estimation.

Table 3.1: Descriptive statistics

\begin{tabular}{llrrrr}
\hline Variable & Unit & Mean & Std.dev. & Min & Max \\
\hline Rubber & kg & 3045 & 2966 & 240 & 24000 \\
Invasive Plants & plant & 217 & 307 & 0 & 1750 \\
Plot size & ha & 2.1 & 1.8 & .02 & 10 \\
Labor & hours & 1649 & 1595 & 71 & 15000 \\
Plantation Age & years & 19.2 & 8.4 & 5 & 55 \\
TC. Chemicals & .000 Ruphia & 676 & 1764 & 0 & 16225.5 \\
\hline
\end{tabular}

\subsection{Results and Discussion}

We applied a variety of directional vectors in order to capture the effect of the different directions. Even though the proportional relationship of the efficiencies and other economic characteristics of the farm will not change, the absolute values will be strongly affected

\footnotetext{
${ }^{3}$ Names and abundance in percentage of invasive plants on the plot are presented in the appendix in Figure B.3
} 
by the choice of the directional vector. A range of angles, between $25^{\circ}$, the smallest possible angle concerning convergence, and $89^{\circ}$, the largest angle including a reduction in the undesired output, were applied in the model. After evaluating the results of the grid of directional vectors using the Akaike Information Criterion (AIC), the smallest feasible vector was shown to be the correct choice. Nevertheless, estimation with a $25^{\circ}$ vector is less meaningful for most of the coefficients. Moreover, a vector of $25^{\circ}$ would imply a stronger focus on the reduction in the undesired output, which may be controversial to the average producers, who are more likely to operate under the logic of profit maximization. Therefore, we follow the example of Färe et al. (2005) and set $g=\left(g_{y},-g_{b}\right)=(1,-1)$, representing an angle of $45^{\circ}$. This choice reflects a compromise between the number of violations and a low AIC and the equal reduction of environmental disturbance and economic output.

Prior to evaluating the estimation of the DODF in its empirical specification, we ran tests for the general inclusion of the non-negative inefficiency component in the model through the LR-test, where the null hypothesis is set as $\sigma_{u}^{2}=0$. Since this null hypothesis lies on the boundary of the parameter feasible space, the LR statistics follows a mixed chisquared distribution $(1 / 2) \chi_{0}^{2}+(1 / 2) \chi_{1}^{2}$ (Coelli, 1995). The test results show a rejection of the null hypothesis at a $1 \%$ significance level (Table 3.2). For further model specifications concerning the production function, LR-tests were used to exclude the non-relevant variables. The coefficients of the estimated DODF are listed in the appendix in Table

Table 3.2: LR-test results for testing the presence of inefficiency

\begin{tabular}{lrr}
\hline $\mathrm{LL}_{\text {OLS }}$ & -57.39 & \\
$\mathrm{LL}_{S F A}$ & -35.06 & \\
& $\mathrm{LR}$ Value & 44.66 \\
& critical value $0.01 \mathrm{df}(8)$ & 19.384 \\
\hline
\end{tabular}

B.1. Two out of the five first order coefficients are significant at a $10 \%$ level, and three out of five are equally significant as second order coefficients. The special interest in this estimation lies in the coefficient of the bad output, bstar $=\left(b_{i}-\left(\theta_{i} g_{b}\right)\right.$, which is significant at the $10 \%$ level in the first order and highly significant as a second order term. The only significant input in our production function is plot size, even though all inputs tested positive for their relevance in the model through the LR-test. Second order coefficients, next to plot size and hours of labor, are also significant in addition to an interaction with the bad output and plantation age.

The curvature of the frontier is likely to be concave, since the second order coefficient of $q$, represented by the coefficient bstarsq due to the translation property, is negative. The monotonicity assumptions were violated in $4 \%$ or 6 out of the 135 cases regarding the elasticity of the bad output with respect to the good output. In 7 out of the 135 
observations, the condition $\vec{D}_{o}(x, y, b, 1,-1) \geq 0$ was not satisfied, leading to a $5.2 \%$ violation of the null-jointness condition.

In order to gain better insight into the underlying relationship between inputs and outputs in smallholder rubber production, interpretation of the input elasticities with respect to the distance is helpful. All of the input elasticities listed in Table 3.3 are positive at the mean, indicating an increase in the distance through enhancing the frontier and therefore the overall production. The highest effect on the frontier emanates from the input plot size, $x_{1}$, with 0.514 , representing a $0.51 \%$ increase in the distance for a one percent increase in the input use. The elasticity of labor, $\mathcal{E}_{\text {Labor }}$ is the second highest coefficient with $0.28 \%$, indicating a moderate increase in output with an increase in labor. After summing up

Table 3.3: Summary of the elasticities

\begin{tabular}{lccccc}
\hline Variable & Mean & Std. Dev. & $25 \%$ & $75 \%$ & Number of obs. \\
\hline $\mathcal{E}_{b}$ & 0.340 & 0.195 & .249 & .449 & 135 \\
$\mathcal{E}_{\text {Size }}$ & 0.514 & 0.293 & 0.410 & 0.633 & 135 \\
$\mathcal{E}_{\text {Labor }}$ & 0.282 & 0.354 & 0.061 & 0.345 & 135 \\
$\mathcal{E}_{\text {Pl.age }}$ & 0.170 & 0.249 & 0.022 & 0.271 & 135 \\
$\mathcal{E}_{\text {TC.Chemical }}$ & 0.022 & 0.065 & -.014 & 0.038 & 135 \\
RTS & 0.818 & 0.454 & 0.535 & 0.952 & 135 \\
\hline
\end{tabular}

all input elasticities, a scale elasticity of 0.818 at the mean is obtained, revealing decreasing returns to scale, ceteris paribus. Regarding the economic interpretation, decreasing returns to scale hint at an input increase with a less than proportional output increase. These are mostly found in smaller and more labor-intensive farms, where smaller volumes of production are also efficiently feasible. This suits the considered rubber production, which is relatively small in size and volume, especially in smallholder productions.

\subsubsection{Technical efficiency of the production}

From the estimation of the DODF, efficiency values for each individual can be derived, the subsequent distribution values of which are reported in Table 3.4. The counter value of the estimated efficiency - inefficiency - can be seen as the maximum possible desired output expansion and the maximum undesired output contradiction to reach the frontier. Values greater than zero indicate an inefficiency in the production, while a value of $\vec{D}_{o}(x, y, b, 1,-1)=0$ signifies total efficiency.

The estimation results report a mean efficiency of 0.75 , corresponding to an inefficiency of 0.25 . This relates to a possible expansion in production by $755 \mathrm{~kg}$ of rubber per year and the equivalent reduction of 54 invasive plants per plot considering the normalized data and the directional vector of $\vec{D}_{o}(x, y, b, 1,-1)$. Even though the biggest share of observations lies above an efficiency of 0.75 , the mean reflects substantial inefficiencies 
Table 3.4: Distribution of the efficiencies

\begin{tabular}{lccccc}
\hline Quantile & Number of obs. & Mean & Std. Dev. & $25 \%$ & $75 \%$ \\
\hline$\vec{D}_{o}(x, y, b, 1,-1)$ & 135 & 0.7521 & 0.2334 & 0.671 & 0.910 \\
$\vec{D}_{o}(x, y, b, 1,-1)<.25$ & 10 & 0.1671 & 0.059 & 0.135 & 0.211 \\
$\vec{D}_{o}(x, y, b, 1,-1) .25-.75$ & 36 & 0.578 & 0.142 & 0.483 & 0.718 \\
$\vec{D}_{o}(x, y, b, 1,-1)>.75$ & 89 & 0.888 & 0.067 & 0.842 & 0.944 \\
\hline
\end{tabular}

in the production. Low values tend to indicate a less competitive and less specialized market with low pressure for producers (Kumbhakar and Lovell, 2000). From our field observations, this coincides with smallholder rubber markets in Sumatra, where the only controllable feature is the quality of the raw product, and both traders and producers do not pay too much attention to this.

Plotting the individual efficiencies against the number of invasive plants on the respective sites, a slight linear increase of invasive plants with decreasing efficiencies can be discerned (Figure 3.1). Hence, plots with higher occurrences of exotic plants tend to be less efficient in overall terms, reinforcing our hypothesis that exotic plants which are a disturbance to the ecosystem also can affect the output level in terms of inefficiency. However, plotting the yearly yield against the efficiency reveals no such pattern.

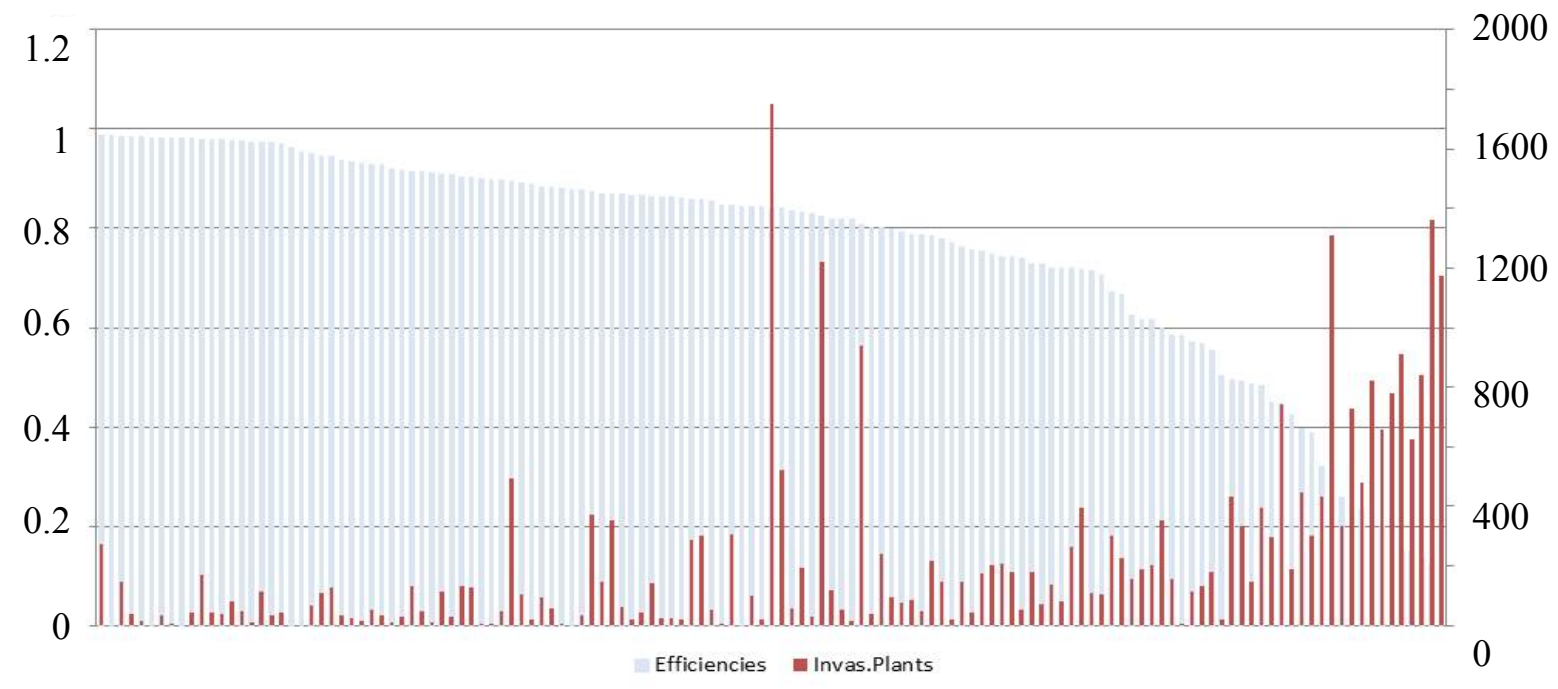

Figure 3.1: Efficiencies over invasive plants

After comparing efficiency groups on the basis of the relevant variables, some notable differences come to light. In correspondence with the preceding findings, producers with low efficiencies have, as the hypothesis suggested, the highest number of invasive plants, followed by the intermediate group and the high efficiency group.

The DODF is simulated with the inputs at the sample mean in Figure 3.2; the resultant shape fits our results when keeping the chosen directional vector of $g=(1,-1)$ in 
mind. It shows an increase in the undesired output of invasive plants, while at the same time exhibiting an increase in the desired output of rubber in $\mathrm{kg}$. As a result, a clear outward-bending trade-off between the desired and undesired output underlies the production. Other criteria such as allocation of labour is lowest in the highest efficiency group,

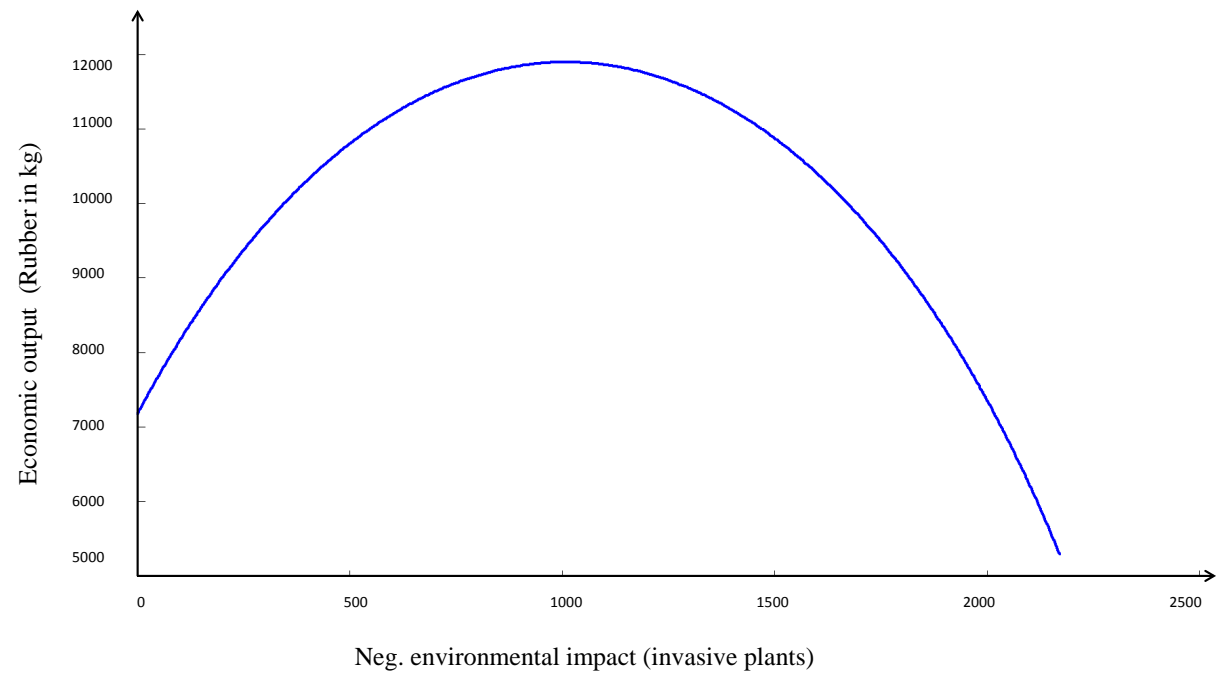

Figure 3.2: Interaction of invasive plants and the economic output

signifying a more efficient use of the available labour force. Furthermore, the efficiency distributions show a higher level of efficiency in producers with smaller plots at the mean.

We allow the systematic inefficiency component $u$ to be heteroscedastic by modeling a multiplicative relationship between the variables accounting for heteroscedasticity, such as farm characteristics, and the distribution parameter of the systematic inefficiency component $\sigma_{u}$.

After including all collected covariates, both the significance and relevance of the variables were checked through LR-testing. Thus, the variables under consideration are plot size, $\left(x_{1}\right)$, chemical weeding, application of gylphosate, participation in a transmigrant support program (TSP), contractual arrangements, years of education, and burning as a clearing method. The estimated coefficients and the corresponding marginal effects are listed in Table 3.5. Out of the seven covariates, five are at least significant at the $5 \%$ level.

The largest effect on the distance, and thus inefficiency, reveals the completion of a marketing contract. A contractual linkage to a trader or a factory will increase the efficiency by $1.06 \%$. This effect might be slightly over-estimated since only five of our farmers entered into such an agreement; this result should therefore be considered with due care.

Even though the size of the rubber plot is also part of the production function, an effect on the efficiency is salient in terms of the p-value. The coefficient shows an elongating effect on the distance to the frontier with a marginal effect of 0.58 . Thus, a $1 \%$ increase 
Table 3.5: Estimation results of the covariates and the corresponding marginal effects

\begin{tabular}{lllcccc}
\hline & \multicolumn{3}{l}{ Estimation Results } & \multicolumn{4}{c}{ Marginal Effects } \\
\hline Variable & Coefficient & t-value & Mean & Std. Dev. & $25 \%$ & $75 \%$ \\
\hline Size & $0.972^{* * *}$ & 3.80 & 0.58 & 1.76 & 0.11 & 0.43 \\
Chem. Weeding & $-0.639^{* * *}$ & -3.22 & -0.38 & 1.15 & -0.28 & -0.08 \\
Glyphosate & $0.651^{* * *}$ & 2.74 & 0.39 & 1.18 & 0.08 & 0.29 \\
TSP & -2.300 & -0.67 & -1.37 & 4.17 & -1.02 & -0.28 \\
Contract & $-1.780^{*}$ & -2.10 & -1.06 & 3.22 & -0.79 & -0.22 \\
Education & $-0.447^{* *}$ & -2.17 & -0.26 & 0.80 & 0.20 & -0.05 \\
Burning & $-0.373^{* *}$ & -2.28 & -0.22 & 0.67 & -0.16 & -0.05 \\
Constant & $-0.852^{* * *}$ & -2.87 & & & & \\
\hline
\end{tabular}

*** Estimate is significant at $1 \%$ level of significance

** Estimate is significant at $5 \%$ level of significance

${ }^{*}$ Estimate is significant at $10 \%$ level of significance

in the plot size would increase the distance to the frontier by $0.58 \%$, amplifying the inefficiency as a result. This effect on the efficiency seems reasonable, since the larger the plot the more difficult it is to control the weeds between the trees, especially in smallholder production and with daily tapping. These effects coincide with the preceding findings concerning the efficiency distributions. The application of glyphosate also increases the inefficiency, and was included as a dummy variable. The utilization of glyphosate prolongs the vector by $0.39 \%$, while other active ingredients of numerous herbicides did not show any effect. Decreasing effects on the distance, and thus the inefficiency, are further indicated through general weeding with chemical herbicides, increasing the level of education, and the practice of burning to eradicate undergrowth, as well as plantation establishment. The range of the reduction varies from $0.22 \%$ if burning is used as an eradication technique, to a $0.26 \%$ decrease, when years of education are extended by $1 \%$, up to a maximum of $0.38 \%$ for the application of chemicals for weeding. The variable TSP represents the participation in the governmental transmigrant support program; this tested positive for inclusion in the model, although it was not found to be significant.

The contradictory effects of herbicide application in general and the specific use of glyphosate are rather exceptional and may be explained in a number of ways. Glyphosate is the only systematic herbicide used by farmers that affects not only the leaves it contacts, but also inhibits growth in roots, intentionally eradicating the complete plant. Upon closer inspection of plots and farmers using glyphosate, an elevated abundance of one specific invasive plant - Asystasia gangetica - was revealed. After linking the results with this information, the following conclusion can be made. The specific type of herbicide and the nature of invasive plants allows them to recover faster than local plants, giving them a competitive advantage in the environment, especially when their strength lies in fast germinating seeds, as in the case of Asystasia gangetica (Othman, 1993). 


\subsubsection{Shadow price calculation}

As part of understanding the trade-off between the desired and undesired outputs a monetary quantification of the trade-off is required. Since markets for the undesired output in our specification are not existent we estimate the shadow price, based on our specified DODF with the vector $g=(1,-1)$ and the corresponding revenue function. In combination with the price of the desired output we can derive the absolute price for the undesired output.

The price information for the desired output states the yearly aggregated rubber price per $\mathrm{kg}$ over the last four years, given by the association of rubber enterprises "Gabungan Perusahaan Karet Indonesia" (Gapkindo). The computation of the undesired output's price is solved by the following equation Färe et al. (2005):

$$
q=-p * \frac{\partial \vec{D}_{o}(x, y, b, 1,-1) / \partial b}{\partial \vec{D}_{o}(x, y, b, 1,-1) / \partial y} * \frac{\mu q}{\mu b}
$$

Due to the normalization of our variables, we need to multiply the derivatives from the equation by the ratio of means of the good output to the bad output to receive real values. The interpretation of the multiplied derivatives, the shadow price of invasive plants, describes the amount of production that must be relinquished in order to reduce the undesired output by one unit moving along the efficient points on the frontier. Thus, from the estimation results, the price for one invasive plant lies between 134,921 IDR in 2012 and 76,706 IDR in 2015 at the mean, as listed in Table 3.6. The drop of global rubber prices is also reflected in the diminishing shadow price. Due to violations of monotonicity, six observations of the shadow price estimation were dropped in order to avoid scaling in the reverse direction on the frontier (Färe et al., 2005). The relation between the shadow price and the abundance of invasive plants bestows further insight on the shape of our trade off function. It seems that plots with a low abundance of invasive plants are linked to higher shadow prices as opposed to plots with a high abundance. This arouses the suspicion of a steeper slope in the area of low abundance, coinciding with the concave curve.

Plotting the individual shadow prices against producers' characteristics such as plot size and labour input does not reveal any strong patterns, which could lead to any further conclusion (Figure B.1 and B.2).

\subsubsection{Efficiencies and shadow price over different groups}

Smallholder rubber production in Sumatra can be separated into extensive and intensive cultivation. Both are differentiated by the intensification of management and the plantation establishment. Due to differences in management, it can be stated that a more extensive cultivation quantifies a more sustainable production, which is therefore more 
Table 3.6: Shadow price calculated for $2012-2015$ by average rubber prices (in .000 IDR)

\begin{tabular}{cccccc}
\hline Year & Obs & Mean & Std. Dev. & $25 \%$ & $75 \%$ \\
\hline 2012 & 129 & 134.92 & 90.13 & 80.93 & 163.58 \\
2013 & 129 & 107.21 & 71.61 & 64.31 & 129.98 \\
2014 & 129 & 83.10 & 55.51 & 49.85 & 100.75 \\
2015 & 129 & 76.71 & 51.24 & 46.01 & 92.10 \\
\hline
\end{tabular}

environmentally efficient. The t-tests on the estimated efficiencies reveal a significant variation in the efficiencies at the mean of $5 \%$. The extensive production results in a mean efficiency of $0.642(n=19)$ and the more intensive production yields $0.769(n=116)$.

The differentiation in shadow price by the grade of intensification - extensive and intensive - results in a lower shadow price of 60,976 IDR for the extensive producers, while intensive producers would have to forgo 79,256 IDR for an invasive plant, taking the prices of 2015 into account. This relates to $8 \mathrm{~kg}$ of rubber in extensive production and $10 \mathrm{~kg}$ of rubber in intensive production for the eradication of one invasive plant.

Considering these results, the stated hypothesis of higher environmental efficiency on account of the invasive plants cannot be supported. The lower output combined with the higher amount of invasive plants on the extensive plots places the producers even further away from the best-practice frontier. This highlights a broader potential to increase the output of extensive production and reduce the invasive plants on the plot with the given production inputs. The lower shadow price displayed in the extensive production indicates a more shallow segment of the trade-off curve, coinciding with the larger amount of invasive plants on extensively cultivated plots and the outward-bending concave tradeoff curve. Therefore, at an efficient point of extensive production the desired reduction in the invasive plants is coupled with a smaller output decrease than in intensive productions.

\subsection{Conclusion}

This study aims to look at the underlying trade-off between smallholder rubber production - one of the main cash crops in Sumatra - and the surrounding ecosystem, and to investigate the determinants of technical and environmental efficiency within the production. With the application of a DODF including a desired output, rubber, and an undesired output, the amount of invasive plants on a plot site, we allow for the reduction of the latter variable and the simultaneous increase in the desired output. The unique data set, resulting from a household and environment survey conducted in 2012, allows for a plot level analysis for 135 producers.

We find a concave trade-off curve between the desired output and the undesired output, indicating an increase in invasive plants and therefore a higher disturbance in the natural 
ecosystem with an increase in the desired output. On account of this trade-off curve, intensification of the plots would result in a higher level of ecosystem service degradation. Furthermore, the prediction shows substantial inefficiencies, leaving room for amelioration of the production processes by moving towards a higher rubber output level and reducing the number of undesired invasive plants. By calculating the shadow price of the undesired output, we give a monetary value to the reduction of the invasive plant output by one unit, which constitutes a substantial part of the yearly yield, after exploiting all potential output ameliorations.

The determining of drivers of inefficiency - the potential economic output losses and environmental disturbance - due to systematic shortfalls, reveals three major results showing the potential for sustainable development which could help to shape future policies. First, smaller plots in the estimation presented overall higher efficiencies, reinforcing the ongoing smallholder participation. Second, the contractual linkages increased the efficiency of production, most likely through creating secure distribution channels. Third, the application of glyphosate increased, in contradiction to the general usage of herbicide, the inefficiency of production. This combined with the indirect effect of invasive plants stated by Lupwayi et al. (2009) and Widenfalk (2005) suggests that the industry should re-think the strongly promoted application of glyphosate, especially without accurate training. Next to these three main findings, the different effects of farm characteristics show that, through management and institutional settings, low efficiency can be positively influenced.

Contrary to our hypothesis, extensive production did not result in lower ecosystem disturbance, as shown by lower overall efficiencies. For future research, an application of the by-production approach might be informative to some extent, since the environmental and technical efficiency can be analysed separately; this was not possible in our case given the definition of the DDF over a combined output vector.

As an overall result, the impact on the environment and the disturbance of the natural ecosystem could be reduced without a big loss to profits, if productions were levelled up to higher efficiencies. 


\section{CHAPTER 4}

\section{Soil Quality Parameters and their Effect on Efficiency}

In the following chapter the discussion on interdependence between oil palm and rubber production and environmental factors is extended. For this purpose, we make use of a deterministic approach implementing soil fertility parameters in a two-stage estimation, which will be explained in the second section. Soil fertility is measured on the basis of C-content, bulkdensity, N-content and C/N-ratio samples. As soil fertility varies across plantations, this chapter aims to identify possible structural differences in the efficiencies describing interdependency. The impact of soil fertility on the efficiency of production might finally provide insight into options to revert these effects through fertilization, enhancing the sustainable use of soils. Moreover, this chapter compares different soil types affected through transformation and their efficiencies. While the first section provides an overview of the changes regarding the land-use in Jambi with respect to soils and its degradation, the second chapter introduces the applied DEA and the bootstrapping algorithm. The third section presents the applied data set resulting from a household survey and soil measures conducted in Sumatra in 2012, followed by a section displaying the results. This chapter closes with a discussion on the results and a following summary.

\subsection{Introduction}

After decades of growth the demand prognoses for biofuels (Agrarzeitung, 2016) and the expected expansion rate for rubber is increasing. Production in the major cultivating countries (Malaysia, Indonesia, Thailand) is further intensifying to meet the strong demand (FAO, 2015). While in some cases oil palm plantations are established on former extensive 
rubber plantations, mostly natural lowland rainforest is converted to intensify the landuse in the form of monoculture rubber and oil palm plantations (Koh and Wilcove, 2008). A second form of the intensification contemplates the increase in the degree of production on existing sites (Lambin and Meyfroidt, 2011). The island Sumatra is, next to Kalimantan, a typical example of land transformation for the benefit of agricultural production accounting for nearly half of the total loss of primary forest in Indonesia (Laumonier et al., 2010; Gaveau et al., 2007; Margono et al., 2014).

Both types of intensification have raised concerns regarding the negative impacts on the environment (Koh and Wilcove, 2008; Fitzherbert et al., 2008; Fargione et al., 2008). One major concern is the degradation of soils linked to the intensification of production (Guillaume et al., 2015). As a result of land scarcity, producers are moving plantations further into peatland areas and areas with heavily degraded soils, enhancing greenhouse gas emissions through land transition. While smallholder producers enhance their income and hence their livelihood through the intensification of existing plantations, this intensification is also linked to extensive ecosystem degradation (Barnes et al., 2014). Recent studies from the same research area reveal a strong decrease in Soil Organic Carbon (SOC) and Soil Organic Nitrogen (SON) following forest conversion to oil palm and rubber plantations due to high soil erosion and a reduction in organic matter input to the soil (Guillaume et al., 2015; de Blécourt et al., 2013). Soil degradation is additionally associated with diminished microbial activity responsible for nutrient cycling, thus indicating soil fertility losses (Guillaume et al., 2016b). The transformation of nitrogen through microorganisms from dead organic matter to a plant-available-form declined in plantations (Allen et al., 2015). The negative impact of agricultural intensification on the physical properties of soil and nutrient recycling indicates a serious threat to soil fertility and its ability to support agricultural production in the tropics. Adjusted management practices, however, could mitigate the impact on ecosystem services provided by the soil or even increase soil fertility. Fertilization could compensate for decreased nutrient supply through the recycling of organic matter.

The degradation of soils and the loss of fertility in the plantations will likely influence the efficiency of crop production by diminishing the production potential. A negative relationship between decreased soil fertility on the efficiency of production, would in the end question the sustainability and persistence of rubber and oil palm production and the effectiveness of fertilization. For an analysis of the impact of soil quality parameters on production efficiency we apply a two-stage estimation, using DEA to construct efficiency estimates. In the second step we implement a truncated regression accompanied by a bootstrapping algorithm to estimate the effects of soil quality parameters on the efficiencies. 


\subsection{Theoretical Foundation}

\subsubsection{Productivity and efficiency}

In this research, we are concerned with the evaluation of producers performance and the possibility of ameliorating their production. In this context we distinguish between two performance measures - productivity and efficiency.

In general terms, productivity is measured as the ratio of the output(s) to the input(s). We can differentiate between the partial productivity which measures a specific output with respect to a specific input in contrast to the total factor productivity. The latter takes the ratio of all involved outputs and all inputs into account (Cooper et al., 2007). While productivity is an average measure of production with respect to inputs and the outputs or specific output of the production, the efficiency measure allows for a comparison with respect to a potential reachable output at the current technology state and input setting. Efficiency enables quantification of real and monetary improvement potentials as well as quantifying the generalization of relative performance indicators. At the base of both the efficiency and the productivity analysis, lies an estimation of the production function which considers all production factors (Coelli et al., 2005; Scheel, 2000).

The discussion of efficiency measures started with Koopmann (1951) and Debreu (1951). The former defined a point as 'Koopman efficient',

"if an increase in any output requires a reduction in at least one other output or an increase in at least one input, and if a reduction in any input requires an increase in at least one other input or a reduction in at least one output" (Fried et al., 2008).

Their work was enhanced by Farrell (1957) by integrating multiple inputs in the efficiency calculation. In his definition the point of technical efficiency "reflects the ability of a firm to obtain maximal output from a given set of inputs" Coelli et al. (2005). The underlying comparison of the current state of production with the technical efficient point, originates either from the inputs reduction prospective - input-oriented - or the output enhancing prospective - output-oriented. Both performance measures can be easily explained in a situation of one input and one output under constant returns to scale (Figure 4.1 on the left). Plotting the input on the horizontal axis and the output on the vertical axis, the slope of the line reflects the frontier starting from the origin. The line represents the maximum feasible output at the given input, hence the efficient frontier. All producers therefore, lie either below the frontier or on the frontier, corresponding to efficient production (Cooper et al., 2007). Points considered as inefficient, ergo lying below the frontier, can reach the efficient frontier, either by enhancing their output or reducing their input. The former movement is represented in a raise of output by the length of $\mathrm{BB}_{\mathrm{O}}$ and the 

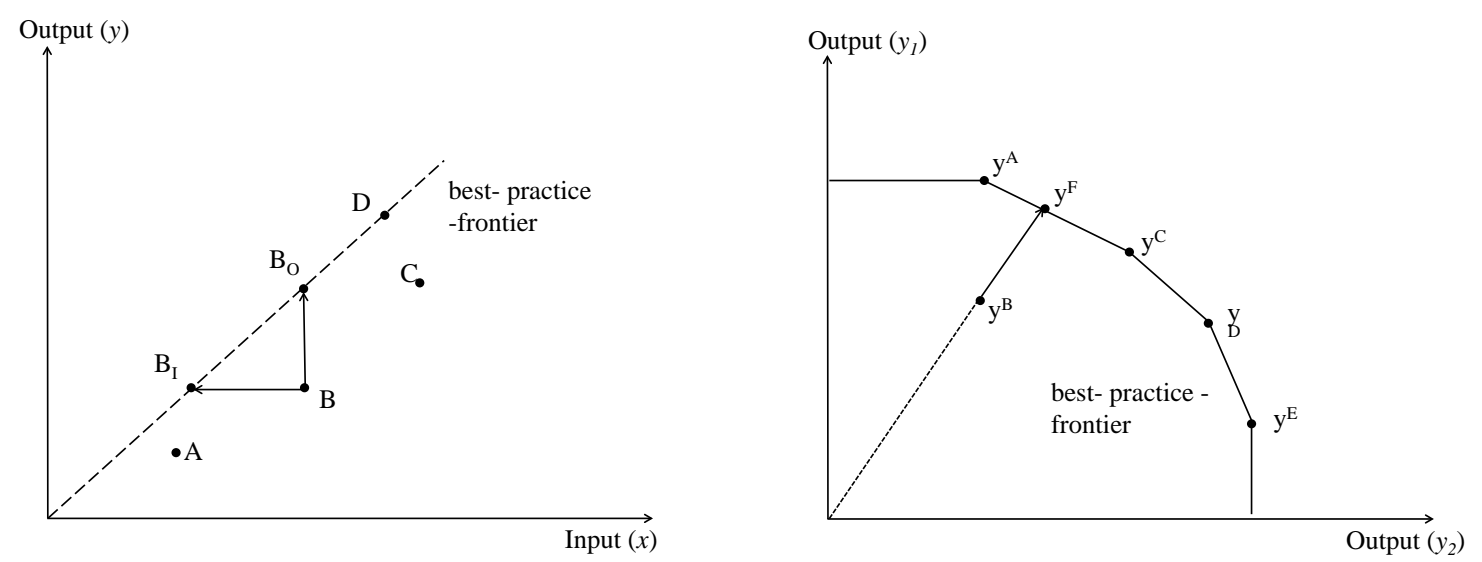

Figure 4.1: DEA input and output-oriented efficiency measure with 1 input and 1 output (on the left); DEA output-oriented efficiency measure with 2 outputs and 1 input (on the right) (after Farrell, 1957)

latter in the reduction of inputs by the length of $\mathrm{BB}_{\mathrm{I}}$.

Extending the single input-single output to a one input and two output setting, we can plot the efficient frontier in the form of a concave curve, which envelopes all producers (Figure 4.1 on the right). The producers on the efficient frontier $\left(y_{A}, y_{C}, y_{D}, y_{E}\right)$ show the highest output with the smallest amount of inputs, therefore displaying the most efficient producers with no distance to the frontier. The grade of the inefficiency of the producers below the frontier, can be measured by the ratio of the length of the line $0 y_{F} / 0 y_{B}$.

Both depictions were given under the consideration of CRS. The assumption of CRS would imply an adequate scale of production for the farm. Another possibility assumes increasing or decreasing returns to scale. Here, the proportionate change between the input and output can be either larger or smaller than 1. VRS are more likely in the sector of agricultural production and especially in smallholder production, since the producers seldom operate on optimal scale size. Estimating efficiency values at CRS will lead to different values than an estimation under VRS. The ratio of the CRS efficiency to the VRS efficiency is known as the scale efficiency (Figure 4.2). Under the assumption of CRS, the measure of efficiency is equal for input-orientation and output-orientation (Banker et al., 1984; Banker, 1984; Coelli et al., 2005). Over the past 50 years, various approaches to estimate the frontier and the definition of the efficient unit, have been presented. An extensive overview on this subject is given by Fried et al. (2008) and it appears that two approaches have been repeatedly implemented to estimate the best-practice frontier for diverse production; DEA and SFA. The difference between both approaches lies in the way of computation of the frontier. The non-parametric approach, DEA, envelops the given data, composed of input and output data, most closely, using linear programming techniques. Here, the highest production points define the course of the frontier. The SFA, however, uses parametric estimation to estimate a production frontier, most likely 


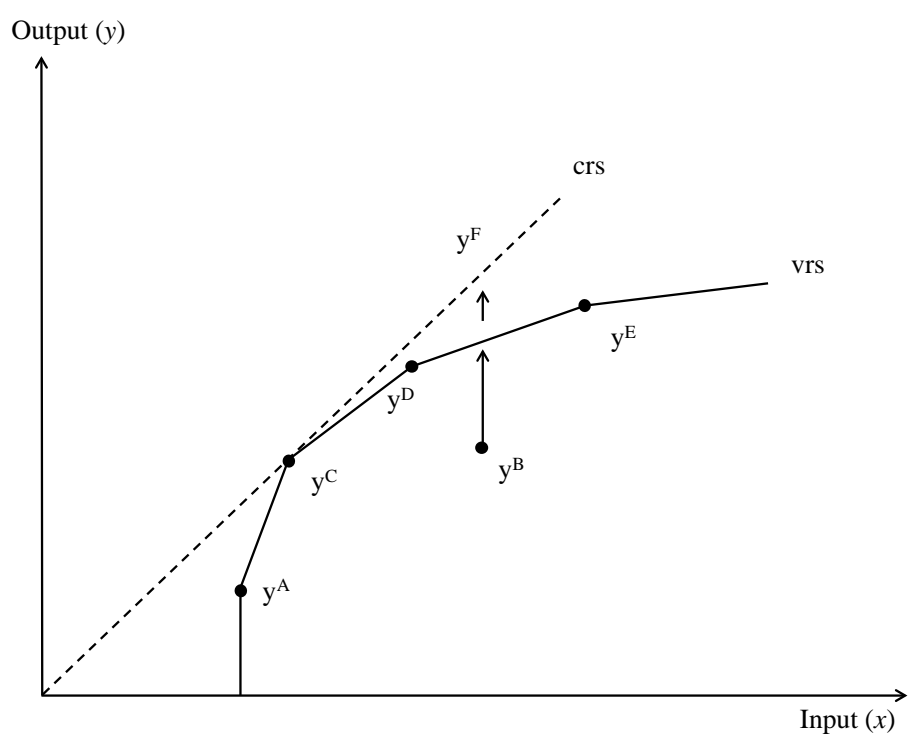

Figure 4.2: Efficiency under VRS and CRS (after Farrell, 1957)

to the underlying data set. Here, a specific form of the production function is assumed and defined, of which the parameters are estimated, prior to the estimation. The SFA factors in derivation of the data due to measurement errors or unobserved occurrences via the estimation parameters, therefore reducing the sensitivity to outliers. Advantages and disadvantages are seen in both estimation techniques (Fried et al., 2008; Cooper et al., 2007; Coelli et al., 2005; Gubi, 2006).

\subsubsection{Data Envelopment Analysis (DEA) construction}

The construction of the mathematical program precedes the definition of our production possibility set $T$, which describes our production. The production possibility set is defined by

$$
T=\left\{(x, y): \in x \quad \Re_{+} \mid \quad x \quad \text { can produce } y\right\}
$$

All inputs and outputs included in the calculation, are inserted as weighted versions of the producers' inputs and outputs, derived from the underlying data. By applying these variable weights and a priori assumption, measurement and scaling issues are avoided (Cooper et al., 2007). The measurement of efficiency in DEA is defined by the ratio of a producers performance point to the best observed performance, therefore the most obvious way to set the problem is the construction of the ratio over all producers $i=1, \ldots, I$. The mathematical problem is stated as follows,

$$
\begin{array}{cl}
\operatorname{Min}_{v, \mu} \quad v^{T} x_{0} / \mu^{T} y_{0} \\
\text { Subject to } \quad v^{T} x_{i} / \mu^{T} y_{i} \geq 1, i=1, \ldots, I \\
v, \quad \mu \geq 0
\end{array}
$$


with $x_{0}$ and $y_{-} 0$ as the vectors of the inputs and the outputs which are evaluated. The $x_{i}$ and $y_{i}$ stand for vectors of the inputs and outputs of the $i$ th producer taken from the sample. In this way, values for the multipliers $v$ and $\mu$ are calculated, which reassemble the maximum efficiency for each ith-producer, at the given constraints. Rewriting this linear problem in an envelopment version, to avoid infinite solutions, lead to the CharnesCooper-Rhodes (CCR) model proposed by Charnes et al. (1978).

$$
\begin{aligned}
& \operatorname{Max}_{\phi, \lambda} \phi \\
& \text { Subject to } X \lambda \leq x_{0} \\
& \phi y_{i} \leq Y \lambda \\
& \lambda \geq 0
\end{aligned}
$$

where $\phi$ represents a scalar and $\lambda$ stands the weights of the inputs as an Ix1 intensity vector. Rewriting the production possibility set, including the restrictions leads to

$$
T^{C C R}=(x, y): y \leq Y \lambda, X \lambda \leq x, \lambda \geq 0
$$

Similar to the linear programming solution over the ratio, the efficiency of each producer is evaluated over the distance to frontier at the given constraints. Hence, the $\phi$ values are equivalent to the efficiency level of the producer. A value of $\phi=1$ would indicate a fully efficient producer, with no possibility to expand further to the best-practice frontier. A value below $\phi<1$ on the other hand represents an inefficient producer and the potential to expand output further to the frontier. This linear problem needs to be solved for each observation in the sample, generating a set of $\phi, \lambda, v$, and $\mu$.

As the preceding discussion on the returns to scale displayed, the assumption of VRS might be more accurate in the case of imperfect operational scales of producers. Relaxing the third assumption, constant returns to scale, by adding the convexity constraint to the envelopment program, accommodates this problem.

$$
\begin{aligned}
& \operatorname{Max}_{\phi, \lambda} \quad \phi \phi \\
& \text { Subject to } \quad X \lambda \leq x_{0} \\
& \phi y_{i} \leq Y \lambda \\
& \lambda \geq 0, \quad \sum_{i} \lambda_{i}=1
\end{aligned}
$$

The idea to relax the assumption of CRS was first introduced by Afriat (1972) and further developed and popularised by the Banker-Charnes-Cooper (BCC) envelopment program; named after Banker et al. (1984). The relaxed assumption, or added restriction, is also 
included in the adjusted production possibility set,

$$
T^{B C C}=(x, y): y \leq Y \lambda, X \lambda \leq x, \lambda \geq 0, \sum_{i} \lambda_{i}=1
$$

- With a slightly more flexible form of the linear problem, the best-practice frontier envelops the points of observation more tightly, extending into the 'over floating' area. As a result the efficiencies of the BCC are higher than when compared to the CCR. The variation between the $\mathrm{CCR}$ and $\mathrm{BCC}$ efficiency values are seen as the scale efficiency (Figure 4.2). The divergence, stated by $v \leq \mid \geq 0$, can either be positive or negative, indicating increasing, constant or decreasing returns to scale (Fried et al., 2008). The scale efficiency therefore depicts "the impact of scale size on the productivity" of the producers under consideration (Thanassoulis, 2001).

The piecewise linear programing technique of the DEA approach is linked to a disadvantage concerning the measurement of efficiency values. The inefficiency level of producers operating below the best-practice frontier, will be measured, after Farrell (1957), by the radial possible expansion to the frontier. In specific cases, the frontier runs parallel to either the $\mathrm{x}$ or the $\mathrm{y}$ axis, indicating an equal level of output at different input levels (Figure 4.1 on the right). Even so, with the expansion of the production to an efficient point, such as $y_{A^{\prime}}$ with $\phi=1$, the producer could further move to the production point $y_{A}$ with an even higher input-output ratio. This setting is known as output-(input) slacks (Coelli et al., 2005).

\section{The Two-stage approach}

Following the DEA efficiency estimation this analysis applies an additional step to account for the effects of several explanatory variables on the DEA efficiency estimates. This twostage regression - first step DEA efficiency calculation, second step regression of DEA efficiency estimates on covariates - has been applied in various forms and fields. The limitation of the efficiency estimates being bounded by one (no producers lies above the best practice frontier in DEA) fostered the discussion of an adequate regression model.

While some researchers neglect the limitation and apply an OLS model (e.g. Chirikos and Sear, 1994; Stanton, 2002) or transform the DEA efficiency estimates to normal distributed values e.g. log, boxcox, etc., Lovell et al. (1994) choose to follow Andersen and Petersen (1993) in their method to alter the comparison set for the unit under evaluation by excluding the unit itself. As a result the efficiency estimates are no longer bounded by 1 . The most common approach to account for this lopsidedness is the application of a censored model (tobit) for the second stage estimation. Nevertheless, the latter approach still implies the possibility of observing values below the limit, although no such data exists. In the case of DEA efficiency estimates no such values are possible, therefore we follow Simar and Wilson (2007) and apply a truncated regression model, where no values 
are observable below (above) the truncation point. However, a general discussion was started by Grosskopf (1996) and Simar and Wilson (2007) about correlation in all two stage approaches. Grosskopf (1996) addresses the correlation between the second step explanatory variables and the variables included in the DEA efficiency estimation which causes problems in the distribution of the error terms. Additionally, Simar and Wilson (2007) raises the concern of the serial correlation of the DEA efficiency estimates in finite samples in all two-stage approaches, leading to an invalid estimation of inference. As a result Simar and Wilson (2007) propose a truncated regression model over a bootstrapping method for a feasible and consistent inference with two algorithms. While the algorithm \#1 generates through single bootstrapping more consistent confidence intervals, the algorithm \#2 accounts next to the confidence intervals for the appearing bias through double bootstrapping. Since the Monte Carlo results of both algorithm revealed an increase in the Root-Mean-Square Error (RMSE) through the implementation of the bias correction in smaller sample sizes, we follow the algorithm \#1 in our application.

To increase the validity of results, we regress the DEA efficiency estimates on each soil quality parameter.

\subsection{Data and Study Area}

This research was again carried out in the lowlands of Jambi province on the island Sumatra, Indonesia. Jambi province can be seen as an example of environmental degradation as a result of economic development in terms of agricultural expansion and intensification, highlighting the scarcity of land resources. The expansion of rubber and oil palm cultivation production has placed Jambi province fifth in oil palm production and third in rubber production in Indonesia. While oil palm adoption, fostered by governmental PIR in the early 1980s, came to a peak in 2007, the production area itself is still increasing, in terms of production (McCarthy and Cramb, 2009). The Indonesian government aims to remain one of the leading producers of oil palm and therefore the cultivated area is estimated to expand to 20 million ha in the next four years (EIA and Telapak, 2012). Even so oil palm plantations are growing steadily, rubber plantations cover over 3.5 million ha and are expected expand further to meet the world demand.

The data was collected during a household survey, combining socio-economic data and soil quality measurements ${ }^{1}$. The conducted survey includes 38 oil palm producers and 134 rubber producers ${ }^{2}$. stretched over five region of the province of Jambi (Sarolangun, Batanghari, Muara Jambi, Tebo, and Bungo) which fit the classification of production

\footnotetext{
${ }^{1}$ The socio-economic data was collected in a household survey, covering a variety of socio-economic and consumption data for 600 households, and is further described in the publications of Euler et al. (2015); Drescher et al. (2016); Faust et al. (2013)

${ }^{2}$ Some observations had to be dropped from the total data set of 208 producers, because the plantations were not harvested, yet
} 
criteria.q In each region eight villages were selected by a two-step random selection, where the number of farmers were adjusted to the varying size of the villages to compensate overor under-sampling (Faust et al., 2013). One third of the originally selected farmers was randomly re-selected for soil quality measures and a second smaller household survey. For this purpose, on the main plot of each sub-sampled producer, a 25 square meter area was established inside the plantation at a site which adequately represented the classification of the plantation. Additionally, in each sample site four soil samples were taken according to the plantations type, oil palm plantation, rubber plantation and extensive rubber (Figure C.1 $)^{3}$.

\subsubsection{Descriptive statistics}

The descriptive statistics of all variables relevant for the analysis, extracted from the data-set, are summarized in the appendix in Table C.1 and Table C.2. As the output we include yield per plot over the last year $(q)$. As inputs we include size of the plot $\left(x_{1}\right)$, hours of labour per plot $\left(x_{2}\right)$, cost of fertilizer $\left(x_{3}\right)$, and in the case of rubber cultivation we add the cost of fuel $\left(x_{4}\right)$. Additionally, the table displays the soil quality measures.

Our data shows a gap in distribution concerning some of the soil quality parameters. The measured C-content range from $1.63 \%$ to $55.73 \%$ in rubber plantations and $0.59 \%$ to $58.84 \%$ in oil palm plantation, indicating the establishment of plantations on organic and mineral soil. Although soils with a C-content up to $13 \%$ (9\% in rubber) have values that are more or less equally abundant, there appears to be a distribution gap for values from $13 \%$ to $58 \%$. Following the definition of soil classification of the IUSS Working Group WRB (2015), soils exploring a C-content above $20 \%$ are classified as organic soils which fits with five of our 38 oil palm plantations and three of our 134 rubber plantation. Because degraded organic soils can have a C-content lower than $18 \%$, generating problematic soil classifications, in combination with the exhibited gap in the distribution, we set the limits of mineral soil at $13 \%$, building the base data-set underlying the efficiency analysis. Those observations above $13 \%$ (mineral soils) were excluded from further analysis concerning the effects on efficiencies.

For the DEA all observations - rubber $(n=134)$, oil palm $(n=38)$ - are included, since we could not warrant different underlying technologies. Even though the included variables differ at their mean, the marginal number of observations with organic or unspecified soils do not give any indication on the potentially differences underlying production. Furthermore, we separated the data-set into two subgroups of high (optimal) fertility measured at a C-content between $3 \%$ and $6.5 \%$ and low (reduced) fertility ${ }^{4}$ with a C-content below

\footnotetext{
${ }^{3}$ Extensive rubber is not planted in rows, therefore we had to adjust the sampling frame

${ }^{4}$ Although a more accurate differentiation of the soil groups would be to use three groups; below $3 \%$ between 3 and $6.5 \%$ and above $6.5 \%$, due to the low numbers of observation and the uncertainty about the fertility level of the highest group, we decided, at least for the first round of analysis to use only two
} 
$3 \%$ and above $6.5 \%$. The descriptive statistics for these groups are displayed in Table C.4 in the appendix.

\subsection{Results and Discussion}

We estimate the best practice frontier for both production types using the DEA. For the definition of the frontier we include the inputs plot size, cost of fertilizer, and hours of labour to the respective output yield in kg per plot over the year (Table C.1 and Table C.2). The specification of the model was tested via LR-test to avoid over- and underestimation of the model.

Prior to the DEA calculation, we check for any possible inter-linkages between the soil quality and the production process of oil palm and rubber. The constructed correlation matrix between the outputs, the different inputs and the soil quality parameters (see appendix Table C.5) do not show any significant differences. Comparing further the two subgroups of soil fertility at the mean of the output and the considered inputs, we can see marginal differences, but these differences are insignificant (Kruskal-Wallis and t-test $\mathrm{p}=<0.05$ (Table C.6).

The density plots highlight graphically differences in the distributions between the two soil fertility groups. In oil palm, the cost of fertilizer is generally lower but denser on more fertile soils while on less fertile soils a wider range of cost is spent on fertilizer. It should be kept in mind, however, that $19 \%$ of oil palm producers do not apply any fertilizer. A wider range of cost per kilogram is spent on less fertile soils as opposed to the high fertile soils (Figure 4.3). For rubber, where $28 \%$ apply fertilizer, farmers spend on average less money for fertilizer on more fertile soils as opposed to on low fertile soils. Looking closely, we can observe an distribution gap in the cost of fertilizer with a range from 13 $125000 \mathrm{Rp}$ to $4000000 \mathrm{Rp}$. Concerning the cost of fertilizer per produced kilogram, the distribution shows, a slightly wider and clinched range in comparison to the more fertile grounds. There is a significant difference in the cost of fertilizer and the cost of fertilizer per produced kilogram between low and high fertility soils (Kruskal-Wallis test p-value = 0.013 and $\mathrm{p}$-value $=0.005)$.

\subsubsection{Results of the efficiency estimation}

\section{Oil palm}

Following the initial indications of small differences in soil quality parameters, we extend the analysis to the efficiency of production. According to the size of our data-set, especially concerning oil palm production, we employ the DEA. The definition of the highest production points and the consequential output-oriented comparison of each observation with those points results in a mean inefficiency value of 1.457 (VRS) and 1.494 (CRS)

groups 


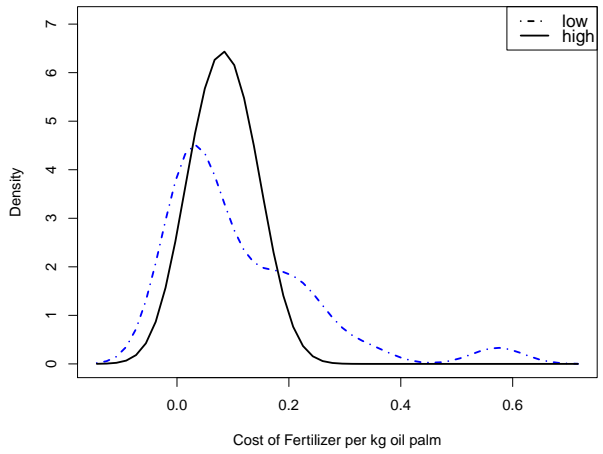

(A)

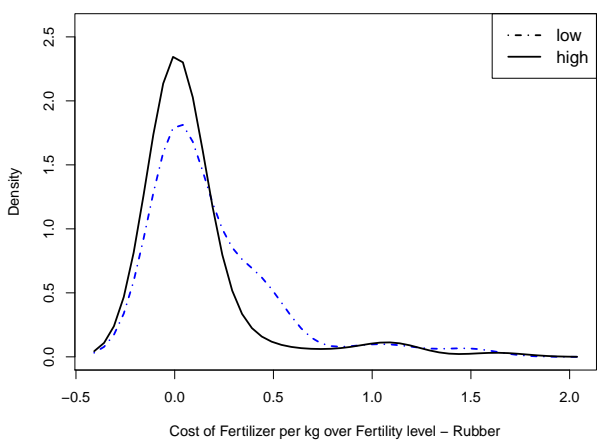

(C)

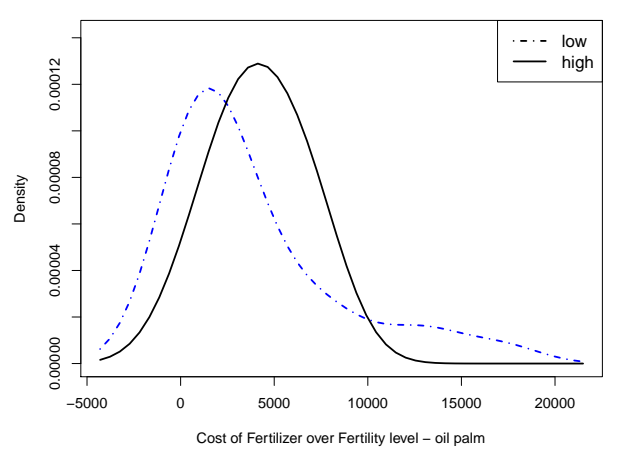

(B)

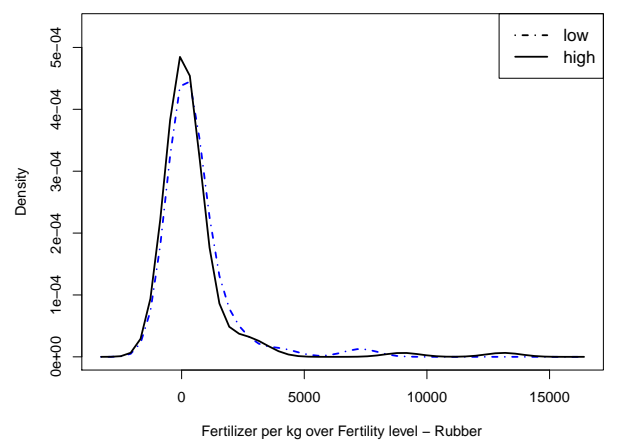

(D)

Figure 4.3: Distribution of fertilizer cost per kg yield over the C-value level - oil palm (A); Distribution of fertilizer cost over the C-value level - oil palm (B); Distribution of fertilizer cost per $\mathrm{kg}$ yield over the C-value level - rubber plantation (C); Distribution of fertilizer cost over the C-value level - rubber plantation (D) 
when calculated following Farrell (1957); corresponding 0.79 (VRS) and 0.77 (CRS) efficiency when calculated following Shephard (inverse of the Farrell inefficiency) (Bogetoft and Otto, 2011). The efficiency indicates a possibility to increase output by $21 \%$ and $23 \%$ without allocating additional resources to production. The efficiency values range

Table 4.1: Efficiencies of oil palm and rubber, with separation in intensive and extensive production (VRS)

\begin{tabular}{lcccccc}
\hline & Min. & 1st Qu. & Median & Mean & 3rd Qu. & Max. \\
\hline Oil Palm & 0.30 & 0.61 & 0.92 & 0.79 & 1 & 1 \\
& & $\phi=1$ & 11 (Obs.) & & $29.95 \%$ & \\
Rubber & 0.09 & 0.33 & 0.48 & 0.53 & 0.68 & 1 \\
& & $\phi=1$ & 15 (Obs.) & & $11.19 \%$ & \\
& & & & & & \\
Int. Rubber & 0.09 & 0.34 & 0.51 & 0.55 & 0.72 & 1 \\
& & $\phi=1$ & 14 (Obs.) & & $11.86 \%$ & \\
Ext. Rubber & 0.12 & 0.30 & 0.37 & 0.41 & 0.42 & 1 \\
& & $\phi=1$ & 1 (Obs.) & & $6.25 \%$ & \\
\hline
\end{tabular}

from 0.30 (VRS and CRS) to the outer frontier values of 1 (Table 4.1 and C.3)). Eleven (VRS) and seven (CRS) farmers define the frontier as fully efficient producers, representing $28.95 \%$ and $18.42 \%$ of all observations. The distribution values ( $1^{\text {st }}$ quantile, median, and $3^{\text {rd }}$ quantile) indicate a left skewed distribution. In the situation of VRS eleven out of the twelve peers are actively compared to another observation, whereby two observations work as reference points in more than $50 \%$ of the observations.

\section{Rubber}

The efficiencies for the rubber production are comparatively low compared with the oil palm (Table 4.1 and C.3)). The mean is calculated as 0.53 (VRS) and 0.42 (CRS) with fifteen producers on the outer border (11.19\%) considering VRS and 5 (3.7\%) for CRS. A separation over the production intensities - extensive and intensive cultivation - shows significantly lower efficiency levels for the extensive rubber than the intensive production which coincides with the general assumptions (t-test p-value $=0.018$ and Kruskal-Wallis $\mathrm{p}$-value $=0.038$. The efficiency level of extensive rubber reflects $14 \%$ more inefficiency opposed to intensive production.

The comparison of efficiencies from mineral plantations to organic (peat) rubber plantations reveals higher efficiencies for plantations on mineral soils (t-test p-value $=0.007$ ) The difference at the mean reflects $16 \%$ more inefficiency for peat plantations. Oil palm plantations do not reveal differences in efficiencies based on mineral and organic soils. 


\section{Scale efficiency}

The performance of a farm is contingent upon the scale size. An optimal scale size, which is assumed to give CRS concerning this specific calculation, relates to the highest productivity, possible under the given technology. A production below or above the optimal scale size indicates scale inefficiency and as a result opportunities to ameliorate performance. The results of the DEA calculation for oil palm production reveal that $76 \%$ of the farmers work below the efficient scale size, while the rest are on or above the optimal scale size. In rubber $44 \%$ are below and $56 \%$ are on or above the optimal scale size. Despite these numbers, an adequate guideline to adjust to the optimal scale size is not possible, since the optimal scale size is not dependent on one of the included inputs, but on the weighted inputs and output. The optimal adjustment to this subject is therefore unique for each observation.

Prior to the subsequent estimation we test whether the general production underlies constant or variable returns to scale (Simar and Wilson, 2002). Using the 'Silverman' bandwidth as a smoothing parameter in sampling after Silverman (1986) the null hypothesis of constant returns to scale in rubber production can be rejected at a p-value of 0.03 in favour of the alternative hypothesis of variable returns to scale. Thus we assume that the production of rubber is labour-intensive rather than capital intensive. Oil palm production seems to underlie CRS since we fail to reject the null hypothesis (p-value = $0.576)$.

\subsubsection{Soil and efficiency}

Since the DEA itself does not give any insight into the effect of soil quality on performance, the next step is to combine the soil data with the economic data. The scatterplots in Figure C.2 and Figure C.3 present an overview of the underlying relationship between each soil quality and the output oriented Farrell efficiency.

The promiscuous and scattered disposal of the observation points does not reveal an obvious relationship between soil quality parameters and efficiencies. In the case of rubber and the C-Value a slight relationship was observed similarly for oil palm production and $\mathrm{C} / \mathrm{N}$ Ratio. Moreover, the scatter plot reveals the left-sided skew due to the one-sided limited values of the Farrell efficiencies of one to infinity. This skew-truncation will be discussed in more detail in the following sections.

A further possibility to reveal structural differences in the effect of soil quality parameters on efficiencies lies in the group wise comparison. For this purpose, the calculated efficiencies are segregated by reference to the soil quality groups (e.g. low fertility, high fertility, low bulkdensity, high bulkdensity). The application of the Kruskal-Wallis test allows us to check for structural differences of the efficiencies in each sub-group. Due to the restric- 
tion of the efficiency values between one and zero leading to a non-normal distribution and multiple samples, neither the t-test nor the Mann and Whitney are appropriate. The results are mostly negligible except for the efficiencies of rubber plantation in the segregation of bulkdensity ( $\mathrm{p}$-value $=0.021$ ) and the $\mathrm{C} / \mathrm{N}$-ratio in case of oil palm plantations $(\mathrm{p}$-value $=0.063)$. In these cases, the Kruskal-Wallis test rejects the null hypothesis of equal efficiency values at the mean of the sub-groups in favour of the alternative hypothesis of structural differences in the efficiencies. The boxplot in Figure 4.4 reflects the

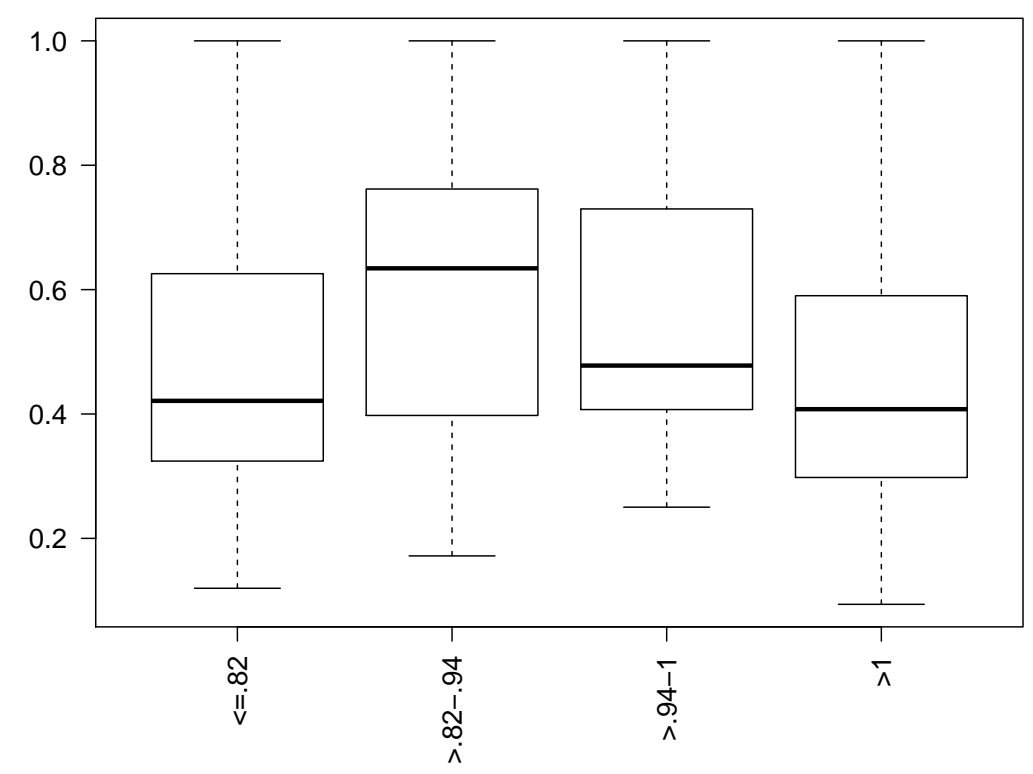

Figure 4.4: Differences in efficiency over the bulkdensity, divided in four subgroups a) below $8.2, b$ ) $8.2-9.4$, c) 9.4 to 1

results of the Kurskal-Wallis test. For rubber the bulkdensity is divided into sub-groups of a) below 8.2 , b) $8.2-9.4$, c) 9.4 to 1 , and d) above 1 . The two middle groups show higher efficiencies as opposed to the low and high bulkdensity groups.

The $\mathrm{C} / \mathrm{N}$-ratio is segregated into two groups representing ratios below and above $14 \%$. Soils above this threshold are categorized by partially higher decomposed plant material similar to forest conditions (Ahl et al., 2006). The difference in the efficiency, at mean, of the two groups with 0.74 and 0.84 shows higher efficiencies for larger $\mathrm{C} / \mathrm{N}$-ratio in oil palm plantations (Kruskal-Wallis p-value $=0.063$ ). This reflects a difference of $4361 \mathrm{~kg}$ of FFB in the harvest.

\section{The Two-stage approach}

The structural differences highlighted by the Kruskal-Wallis test can only confirm differences at the mean. Consequently, a regression of the DEA efficiency estimated on the covariates is more appropriate for uncovering structural differences. A basic OLS regression previous to further model specifications, comprising all DEA estimates with a 
C-content below 13\%, reveals a marginally significant, positive effect on efficiency only for the C-content in rubber plantations (printed in the appendix). Nevertheless, the OLS estimation is of poor quality regarding the given p-value $(0.151)$ and a $R^{2}$ of $1 \%$ explanation, indicating the models lack of validity. Structural differences due to bulkdensity levels were found to be insignificant, despite the Kruskal-Wallis test. The OLS's efficiency estimation of the soil qualities in oil palm plantations do not show any effects. Similar to the OLS model of the rubber plantations the explanatory power of the estimation is poor.

However, the OLS estimation does not account for the skewness of the efficiency estimates (no producers lie above the best practice frontier in DEA), hence occasionally larger values than one are predicted during estimation. The ongoing discussion has led to a truncated regression model which we apply in the next step. Nevertheless, the OLS estimation results concerning rubber plantations dissolve themselves when accounting for the limited dependent variable in the truncated regression, giving no indication of structural effects. The results for oil palm plantations are similar, which is why the originally found structural differences in efficiencies due to either $\mathrm{C} / \mathrm{N}$-ratio and bulkdensity or C-content differences are not confirmed. Although not highly, significant the coefficients are larger in their magnitude as opposed to the OLS estimation the coefficients suggested.

In virtue of serial correlation issues raised by Simar and Wilson (2007) and the likelihood of inadequate approximation of the estimators true sampling variation, we apply the proposed algorithm \#1 to generate a consistent and valid confidence interval, but include the complete set of $\hat{\delta}_{i} \geq 1$ (Table 4.3 and Table 4.2). By applying the algorithm a consistent confidence interval for the estimated coefficients of $\beta$ are calculated additionally to the bootstrapped $\hat{\beta}^{*}$. The margin of the effect on efficiency cannot be clearly understood, but the coefficient's sign already gives insight into the effect's direction. The C-content of rubber plantations, regarding the bootstrapped estimation, appears to influence the efficiency bivalent. The combined coefficients display a convex curvature implying at first a diminishing in the Farrell efficiency estimate with C-content augmentation and later an increase in the Farrell efficiency value with a stronger augmentation of the C-content in the soil. Hence, up to a certain threshold, efficiency increases with C-content augmentation. The bootstrapped confidence intervals clearly exclude zero for the $\hat{\beta}^{*}$ of C-content, C-content squared, and also $\hat{\sigma}^{*}$ attributing at the covariate a significant influence on the inefficiency of production.

Applying the bootstrap algorithm \#1 in combination with the truncated model on the efficiency estimates and the oil palm plantation $\mathrm{C} / \mathrm{N}$-ratio yield confidence intervals which imply a significance for $\mathrm{C} / \mathrm{N}$-ration in plantations. Similarly, the negative coefficient of the $\mathrm{C} / \mathrm{N}$-ratio reduces the inefficiency in a linear way and hence augments the efficiency. 
Table 4.2: Estimation of truncated model and bootstrapped model for rubber

\begin{tabular}{lcccc}
\hline Variable & $\hat{\beta}$ & $\hat{\beta}^{*}$ & $\mathrm{CI}_{\text {lower }}$ & $\mathrm{C}_{\text {upper }}$ \\
\hline Intercept & 4.28 & 1.66 & -32.84 & 31.025 \\
C-content & -21.38 & -11.98 & -54.09 & -8.05 \\
C-content sq. & 1.91 & 1.017 & 0.63 & 4.84 \\
\hline & $\hat{\sigma}$ & $\hat{\sigma}^{*}$ & $\mathrm{CI}_{\text {lower }}$ & $\mathrm{C}_{\text {upper }}$ \\
& 8.31 & 5.91 & 4.67 & 14.8 \\
\hline
\end{tabular}

Table 4.3: Estimation of truncated model and bootstrapped model for oil palm

\begin{tabular}{lcccc}
\hline Variable & $\hat{\beta}$ & $\hat{\beta}^{*}$ & $\mathrm{CI}_{\text {lower }}$ & $\mathrm{C}_{\text {upper }}$ \\
\hline Intercept & 21.05 & 4.82 & 1.37 & 45.25 \\
C/N-ration & -10.01 & -1.64 & -19.03 & -8.15 \\
\hline & $\hat{\sigma}$ & $\hat{\sigma}^{*}$ & $\mathrm{CI}_{\text {lower }}$ & $\mathrm{C}_{\text {upper }}$ \\
& 7.72 & 2.34 & 5.88 & 13.96 \\
\hline
\end{tabular}

\subsubsection{Discussion}

The control for correlations between the inputs of production and the soil quality parameters did not suggest any linear relationship. However, marginal distributional differences indicated adjusted fertilizer application in rubber plantations. On soils demarcating lower fertility, based on C-content levels, larger sums are spent on fertilizer application. The lower C-content indicates less organic matter, hence less nutrients, calling for a higher fertilization of the plantations which is observed in our setting. This would indicate an adjusted application of fertilizer to the soil quality in rubber plantations. It is not clear whether the adjusted management is carried out in full awareness by the producer or whether it occurs as a result of lower yields and the subsequent single known modulation. However, the effect of fertilization is not reflected by an elevated or at least equal level of soil fertility. As a result, one could question the effectiveness of the fertilizer application or look to other soil-related issues, such as water stress or nutrient leaching. Even though similar trends were found in oil palm plantations no significant differences were revealed to strengthen this hypothesis.

Regarding the efficiency levels, our results present lower levels in rubber production as opposed to oil palm plantations which coincides with results from previous studies and are therefore not further explained. The variation in efficiency levels between intensive rubber production and extensive rubber production can be explained by less intensive utilization of inputs and the establishment mode. The most striking difference reflects the investment in fertilizer; extensive producers allocate no money to fertilizer (Table C.1). These findings are also reflected in previous studies. 
The results present divergent efficiency levels for mineral and peat (organic) plantations, coinciding with findings from Alwarritzi et al. (2015). The less efficient peat plantations may be subject to water logging problems in the plantations reducing the decomposition and nutrient uptake due to a lack of oxygen. Moreover, these soils are likely to be less affected by fertilization due to a lack of absorbing sites for the nutrients. Various hypotheses may be applicable here and all are interlinked with each other, making one correct explanation difficult. The conversion of peatlands, and the observed augmenting conversion of highly degraded soils, for the establishment of new plantations in virtue of the lack of free land, is ill-fated in two ways. Firstly, because of the high amounts of $\mathrm{C}$ stored in peatlands the conversion results in higher greenhouse gas emissions as opposed to the conversion of mineral soils. Secondly, the results show a lower efficiency in peatland soils.

\section{Rubber}

Structural differences in the efficiencies on the ground of variations in soil quality parameters are reflected in two ways by our results; bulkdensity and C-Value.

Even though bulkdensity could only explain small variation in the efficiencies, the results are important. The level of bulkdensity represents the weight of a soil at a given volume, and hence the level of a soil's compaction. A low value indicates a low level of compaction while a high value represents heavily degraded and compacted soils (Cresswell and Hamilton, 2002). Low efficiencies at low levels of bulkdensity is coherent with the earlier discussion on the low efficiency of the organic soils. Similarly, low values of efficiency at high levels of bulkdensity is understandable due to highly compacted and degraded soil. The latter restricts the growth of roots which in turn negatively affects the productivity of the tree.

The bootstrapped results of the two-stage regression for the rubber plantations imply a convex curvature for the effect of the C-content in the plantation on efficiency; an increase in the C-content reduces the inefficiency up to a certain threshold and reverses with further augmentation of the C-content. Dependent on the slope of the curvature, the effect of an augmentation in the C-content defines the extent to which the efficiency decreases and increases before and after the threshold. The variation between the bootstrapped and the non-bootstrapped coefficients lies exactly in this point. By applying the bootstrapping algorithm, the slope of the curve is flattened and the incline is reduced. This convex structure can be explained by soil fertility due to the C-content. Soil organic content, reflected by the C-content, is a benchmark for soil fertility, indicating levels of microorganisms responsible for soil decomposition, plant residues and humus. The importance of balanced organic content lies likewise in physical, chemical, and biological characteristics. Each has its best performance (water holding capacity, good decomposition rate minerals, activeness of soil microbes) at an intermediate level between 3 and $6 \%$. Below and above 
this threshold, the mode of action in each segment is obstructed and hence reduces the fertility through a reduced water holding capacity, microbial imbalances and infiltration of the soil. Therefore, the convex curvature, presented by our estimation, fits to the course of soil fertility in virtue of the organic content. The efficiency is thus affected by the fertility of the soil, leaving our producers a margin for output augmentation by adapting to the soil fertility in rubber plantations.

\section{Oil Palm}

$\mathrm{C} / \mathrm{N}$-ratio in the oil palm plantations, as the quotient of the weight portion of the organicbounded carbon and nitrogen, can partly explain structural differences in efficiency. The first results from the Kruskal-Wallis test reveal a higher level of efficiency in plantations with a higher $\mathrm{C} / \mathrm{N}$-ratio than 14 . The subsequent bootstrap estimation also reveals an augmentation of efficiency with an increase in the $\mathrm{C} / \mathrm{N}$-ratio. These results are partially antithetical to the general assumptions about $\mathrm{C} / \mathrm{N}$-ratio. Regarding low values of $\mathrm{C} / \mathrm{N}$ ratio our results are still consistent in the point that a low $\mathrm{C} / \mathrm{N}$-ratio yields low fertility in the soil; low soil fertility can easily be coherent with inefficiency by reducing the production level. Up to a certain point the linear augmentation of $\mathrm{C} / \mathrm{N}$-ratio and the efficiencies, displayed by our results, are further consistent with the literature. Above a certain threshold - mostly a ratio above 14 - a high amount of poorly decomposed organic matter is assumed due to acid and anaerobic conditions. These conditions lower the efficiency which would further suggest a reduction in efficiency. Nevertheless, the estimation results predict a monotone linear relationship.

\section{Consistency of Estimation}

Even though the bootstrapping results are partly consistent with literature, the results should be read with careful consideration. The explanatory power of the precedent OLS estimation results with a p-value above 0.1 and 0.2 were not convincing. One reason for this inconsistent estimation may be found in the wide spread efficiencies contrary to the rather less varying soil quality parameters. Subsequently, the high variation in the dependent variable is unlikely solely due to the implicated covariates. Moreover, the low numbers of observations, especially for oil palm plantations, increase the sensitivity towards outliers on both sides of the equation, enhanced by the DEA approach. The effect of soil parameters are present, after careful consideration of our results, but may play a marginal role next to other covariates. Stronger structural difference due to soil quality parameters are thus preferably found in ranges of higher efficient producers. An extension of the analysis by segmenting the producers by efficiency levels, therefore amplify our results. 


\subsection{Conclusion}

The aim of this study was to analyse, if the observed degradation of the soils through the intensification of land-use further influences the production itself, by affecting the efficiency. The soil quality as measured by parameters such as C-content, N-content, $\mathrm{C} / \mathrm{N}$-ratio, and bulkdensity was included in a two-stage regression, after calculating the efficiencies of the production with the use of the DEA.

The analysis of the inputs reveals an adjusted fertilizer application towards the C-content level, reflected by high investments in fertilizer on soils with low C-Values at least in rubber plantations. Furthermore, peat soils and highly degraded mineral soils experience lower efficiencies as opposed to mineral soil, bringing into question the persistent conversion of forest in these areas due to land scarcity. Focusing on the mineral soils, the soil quality parameters do affect the efficiency of production at a certain rate. For rubber we find a convex curve, describing the impact of C-Value on efficiency while in oil palm plantations the impact is reflected via a linear relation between the $\mathrm{C} / \mathrm{N}$-Ratio and the efficiencies. However, given estimation results, we assume a marginal effect compared to other covariates. 


\section{CHAPTER 5}

\section{Conclusion}

\subsection{Summary}

This dissertation has addressed the question of differences and determinants of technical and environmental efficiency in and between the two main agricultural crops produced in Sumatra, Indonesia: rubber and oil palm. By analysing the determinants of efficiency, we hoped to indicate a way for producers to move closer to the best-practice frontier in order to minimize pressure on land and the expansion of cultivation areas into lowland rainforest. Based on a combined data set, including a household survey and an environmental assessment of the corresponding plot sites conducted in 2012, we find potential in increasing yields by enhancing the efficiency levels of production through farm-specific characteristics, such as farmer support and institutional arrangements.

With an expected population growth of nearly 10 billion in 2050, growth in wealth and with that shifts in dietary compositions the demand on global agriculture and land use are likely to increase. Persistent challenges on agriculture, growing losses of natural resources in light of degradation, declining gains of the new hybrids and climate change along with land scarcity will increase the compulsion for furthering land transformation mainly to the expense of natural ecosystems. Additionally, agriculture intensification will persist to meet the global demand for goods and services provided by land which most likely will result in decreases the functionality of the ecosystems it relies on. As a result, reconciling agricultural production with environmental and social integrity is a hurdle that needs to be overcome with future development via thorough assessments in research, assisting 
political efforts for amelioration.

Despite the highly discussed sustainability of oil palm and rubber production, and the urgency to reconcile the demand for agricultural products such as palm oil and rubber with the environmental and social integrity in a sustainable production, scarce resources have been devoted to empirically quantifying the determinants of production and especially efficiency, much less so, the direct trade-off between production and ecosystem disturbance linked to environmental efficiency in Sumatra, Indonesia.

By addressing this gap, the work at hand identifies and analyses, based on four guiding questions, determinants of technical and environmental efficiency using plot-level data of smallholder producers in Jambi, Sumatra, Indonesia. Moving smallholders closer to the best-practice production frontier via efficiency improvements contributes to the sustainable development of oil palm and rubber production by providing possibilities for minimizing ecosystem disturbance while maximizing economic outputs. This can be seen as an approach to reduce the pressure on land and reducing the necessity to expand into new areas. Therefore, identifying the relevant determinants of efficient production as well as the inter-linkages with environmental services form the focus of this research. This may shed light on methods for the sustainable and economically profitable production of oil palm and rubber.

\section{Key findings of this research:}

Chapter 2 of the presented study, addresses the first two research questions

"What determines, if present, differences in technical efficiency between smallholders within the same transformation system?"

"To what extent are these differences presented in distributional differences of technical efficiency between different transformation systems?"

In regards to the first question, our analysis showed that the historical development of the oil palm and rubber sector separated producers in autochtone and transmigrant groups, leading to significant differences in their production techniques in the case of oil palm. As a result, the TSP, patronizing producers financially and via training, affects the level of efficiency. Operating with less inefficiencies, producers were able to transpose the advantages of given support to their production process. The comparison between the different transformation systems raised by the second question, revealed that rubber producers are exposed to substantial higher inefficiencies, as well as autochthone oil palm producers. Furthermore, extensive rubber producers exhibited an even higher degree of inefficiency in the production as opposed to the intensified cultivation systems. In addition to strong regulation through land and labour scarcity in both production systems, a producer's efficiency is additionally affected by the distance to processing facilities. 
The combination of all these effects leads to the assumption that producers aim for security in their production, especially in choosing vertically closer institutional settings. The early advantages of transmigrant support programs are substituted by risk sharing arrangements, ownership of land, and contractual security at the present time. However, the estimation results show a decline in efficiencies in virtue of a strong bondage to local traders resulting in local price manipulation and losses to the middleman in the supply chain.

Expansion of the two most prominent productions, oil palm and rubber, entails considerable environmental threats which are defined by an underlying trade-off dependency. Linked to the third and fourth research question

"How is the trade-off between environmental disturbances and economic benefits defined?"

"What are the main drivers affecting differences in environmental efficiency?"

Chapter 3 addresses the environmental efficiency in the context of rubber production. The analysis of rubber production reveals an outward-bending trade-off curve between the desired output and the undesired output. As the latter is depicted by the abundance of invasive plants, their higher diffusion aligning with a higher disturbance of the natural ecosystem is associated with an increase in the desired output. Substantial inefficiencies imply room for amelioration of the production processes by expanding towards a higher rubber output and reducing the number of undesired invasive plants. A crucial potential to affecting this modification originates from farm-specific characteristics such as contractual arrangement, education, slash-and-burn techniques, and chemical herbicides, with a special focus on glyphosate.

Soil fertility losses as critical environmental threats posed by oil palm and rubber establishments are assessed in chapter 4, presenting an addition to the previous chapter ${ }^{1}$. The analysis of soil quality parameters and their interdependency with productions efficiency revealed that the expansion of cultivation area aggrandizes towards peat soil and watersaturated mineral soils. Theses soils, postulating even stronger effects in conjunction with climate change, experience lower efficiencies as opposed to mineral soil, questioning even the persistent conversion in these areas due to land scarcity. Focusing on the mineral soils, quality parameters such as C-Value, C/N-ratio and bulkdensity do affect efficiencies of production at a certain rate. Enhancing the C-content in rubber plantations up to a certain threshold results in efficiency gains, which reverses after a threshold, following a convex curve. In oil palm plantations, a linear relation reflects the inter-linkage between the $\mathrm{C} / \mathrm{N}$-ratio and the efficiencies. Adjusted management was found in rubber plan-

\footnotetext{
${ }^{1}$ This chapter is linked to the paper Guillaume et al. (2016a)
} 
tations considering fertilizer application toward the C-content level, reflected by higher investments in fertilizer on soils with low C-content.

\subsection{Policy Implications}

As the results show, the expansion and intensification of rubber and oil palm cultivation accounted for unbalanced production development and lacked in various aspects. Changing this development into a sustainable one is dependent on the involvement of the government, non-governmental organizations (NGOs), the private sector, producers, and their ambition to reduce environmental issues without deducting the possible positive economic benefits. On the basis of the above presented results, we provide several recommendations to these stakeholders to contrive a sustainable and more efficient rubber and oil palm cultivation.

At the time being, the general strategy to evade the additional transition of land is to enhance the yield capacity of existing plantations. In general, policy makers should be aware that the potential to amplify the yields does not lie per se in production intensification on existing plots, involving a change of the input set, as suggested by Borlaug. Another strategy, is to enhance the overall output by increasing efficiency via adjustments of relevant individual production settings. Following our results, an essential precondition for efficient production is the advisory services and structural support for producers. The development of governmental or private agencies supporting producers independently, not only with genre-specific knowledge but further engaging in the establishment of secure institutional settings, might affect the overall efficiency of production. In the context of independent land transformation: autochthone producers mostly located in areas distant to estate schemes are endangered by insecurity, and with that unbalanced development. The gradual independent transition from more traditional land use practices, such as rubber agroforests to oil palm, is mostly accompanied by inefficient plantation establishments due to limited resources and management knowledge. Independent supportive agencies could prevent this and also reduce environmental efficiency.

Ensuring the environmental efficiency of the producers requires substantial policy efforts from this point onwards. The strong focus of policies embarking on strategies enhancing smallholder participation is, in terms of environmental-friendly and sustainable cultivation, a positive development. As our results show, there is considerable potential in the augmentation of environmental efficiency, which implies diminishing ecosystem disturbance whilst simultaneously enhancing economic output. One necessary step would be to adjust the production in terms of the individual settings of the farmers. Small-scale farmers, as our results imply, exhibit a higher level of environmental efficiency, which well go along with the already existing governmental policies' aims to support small-scale farm- 
ers. Even though small-scale farmers exhibit a higher level of environmental efficiency, the profit maximization orientation of producers will not lead to a voluntary reduction in the economic output for the reduction of the incidental ecosystem disturbance ${ }^{2}$. Consequently, governmental policies and the private sector should emphasize the implementation and development of market-based policy instruments, such as certification schemes (exceeding RSPO) or promote management systems such as Good Agricultural Practice. Moreover, bonus regulations (e.g. subsidies) that compensate producers, which purposely lower their economic output in virtue of an enhanced ecosystem function, might further promote the willingness to switch towards production systems considering higher ecosystem functions. Considering the falling rubber prices since the beginning of our survey, the total expenses for the government for coupled compensation payment are dropping. Simultaneously, farmers could demonstrate a higher level of willingness to extensifying their production and accept the payment, in virtue of lower production benefits.

In general, underdeveloped support and knowledge distribution have led to a marginal awareness of and care for ameliorating environmental disturbance, up until now. Considering the environmental efficiency of production, policy makers would gain from further developing producers' knowledge and production genre-specific scope.

The aforementioned general expansion of land as a solution to increase the overall output and the independent transformation of land in the face of general land scarcity on Sumatra has pushed the transition frontier towards peatland. This new development, has due to elevated greenhouse gas emissions through peatland transformation, raised substantial concerns in light of climate change. Our results reveal an indication towards lower efficiencies on these highly risky soils. In this context, policy makers are advised to be more attentive concerning the distribution of land in these areas. In combination with the independent transition of land, producers would benefit from structured concessions policies, allowing benefits from agglomeration effect and existing infrastructure.

\subsection{Limitations and Scope for Further Research}

Despite the strengths of the accurate representation of the environmental factors in the estimations due to the unique data set, this study also has a number of limitations concerning the partly abstract consideration of a complex interconnectedness of ecosystem and agricultural production, which should be addressed by further research.

The results of determinants of the technical efficiency concerning the oil palm farmers, presented in Chapter 3, revealed a substantial decrease in the efficiency levels for farmers involved in both production branches. However, the analysis only accounts for the output of one production, oil palm, without further incorporating economic benefits from the

\footnotetext{
${ }^{2}$ at this point we imply a similar trade-off curve for rubber and oil palm cultivation
} 
second, rubber production. Further research accounting for institutional settings, and other farm-specific characteristics and their effect on the overall efficiency of the aggregate household, for instance by spatial analysis, could provide further insight into the spillover effect between the production fields. The necessity of this is further brought to light by contrary results of the household's income diversification.

The degree of vertical integration along the supply chain of oil palm production was found to have a positive effect on efficiency, considering contractual arrangements. However, the extent of the effect is likely to depend further on the parties involved, especially on the demanding site and the type of contract. Often the contractual arrangements are initiated and executed with the support of farmer organizations. Due to data limitations, a detailed differentiation between the farmer groups and organization, and thus the variety of contractual details, could not be further analysed. Future research on the determinants of efficiency in oil palm should aim to gather more detailed information about the sellerbuyer agreements including the subcontracts with farmer groups and organizations.

Our estimation of the environmental efficiency of rubber producers is based on a data set collected on plot sites. Even though this is a unique data-set and seldom found in economic analysis, it constitutes a limitation to our research. In the estimation of the third chapter, the abundance of invasive plants constitutes a proxy for the ecosystem disturbance. Invasive plants may, however, be only one factor lowering ecosystem functions. As ecosystem function relies on a suite of various factors such as soil, climate, biodiversity, etc., picking one factor might capture only a small fraction of the effect on the ecosystem. A combination, in the form of an index consisting of various factors with potential effects on the ecosystem (Environmental Performance Index (EPI), biodiversity index, soil measures, etc.) could extend our findings to more profound cultivation recommendations concerning eco-efficiency. In the scope of this extension a wider collaboration with other sub-projects of the CRC 990 would be beneficial.

One focus of this research was to quantify the trade-off underlying the production of desired output and the environmental influences it has. In the course of the environmental data collection, and analysing the abundance of plants on the plot-site with respect to the economic benefit and efficiency, revealed a large scatter of plant diversity over relatively similar revenues. While some of the occurring plants are classified as invasive species, a large amount is seen as production-supportive, such as leguminous plants. It is of interest to what extent the share of supportive plants in ground covered cultivations influence the variation in economic benefit with an equal abundance of plants.

In light of the establishment history of plantation, the plantation grounds are diffused through a wide variety of landscapes. The area surrounding the plot site can thus vary from intensive to extensive plantations, with degrees in between, up to forest or eradicated 
landscapes. These neighbouring land-use systems can emphasise a strong impact on the diversity and especially the uniqueness of the plant composition. Including these factors may diminish the possibility to a biased estimation by omitting important information.

Concerning the applied methodologies, the limitations of this research lie in the merging of the environmental and the economic data sets. The uniqueness of the environmental data set led to restrictions in a number of observations due to time and monetary boundaries. Applying stochastic estimation methods was often encountered with difficulties in convergence due to a limited number of observations, especially concerning the oil palm set. Thus, for further analysis, particularly approaches to analyse the environmental efficiency, i.e. through the by-product estimation, a more elaborated data set would allow for more precise estimations. Moreover, to assess the effects of soil quality parameters or the impacts of diverse plant communities on the efficiency, projects with controlled experimental designs could be helpful, even if they are realistically difficult to conduct on a large scale.

Despite the limitations of this research, the conducted survey and accomplished research provides an advance towards the sustainable development of the highly demanded commodities sustaining a large share of the economic benefits of the Indonesian population. Their potential should, in conjunction with the study at hand, further encourage researchers to investigate the possibilities of efficient productions in terms of sustainability. 



\section{CHAPTER 6}

\section{Bibliography}

Afriat, S. N. (1972). Efficiency Estimation of Production Functions. International Economic Review, 13(3):568-598.

Agrarzeitung (2016). Weltweiter Konsum von Pflanzenöl. Agrarzeitung, (49):2. Grafik der Woche.

Ahl, C., Becker, K., Jörgnsn, R., and Wildhagen, H. (2006). Aspekte und Grundlagen der Bodenkunde (32. Edition). Eigenverlag, Göttingen.

Aigner, D., Lovell, C. A. K., and Schmidt, P. (1977). Fromulation and Estimation of Stochastig Frontier Production Function Models. Journal of Econometrics 6, 6:21-37.

Alexandratos, N. and Bruinsma, J. (2012). World agriculture towards 2015/2030. ESA Working Paper, No. 12-03. Food and Agriculture Organization of the United Nations (FAO).

Allen, K., Corre, M. D., Tjoa, A., and Veldkamp, E. (2015). Nutrient leaching losses in lowland forests converted to oil palm and rubber plantations in Sumatra, Indonesia. PLoS One, 10(7):5168.

Alwarritzi, W., Nanseki, T., and Chomei, Y. (2015). Analysis of the Factors Influencing the Technical Efficiency among Oil Palm Smallholder Farmers in Indonesia. Procedia Environmental Sciences (SustaiN 2014), 28:630-638.

Andersen, P. and Petersen, N. C. (1993). A Procedure for Ranking Efficient Units in Data Envelopment Analysis. Management Science, 39(10):1261-1264.

Anderson, J. (1996). Functional values of biodiversity in oilpalm plantation: concepts and approaches for sustainable production. In Ariffin et al., D., editor, Proc.1996 PORIM int. Palm Oil Congr. 'Competitiveness for the 12th century', pages 113-128, Kuala Lumpur. Palm Oil Res. Inst. 
Atkinson, S. E. and Dorfman, J. H. (2005). Bayesian measurement of productivity and efficiency in the presence of undesirable outputs: Crediting electric utilities for reducing air pollution. Journal of Econometrics, 126(2):445-468.

Badan Pusat Statistik Republik Indonesia (2014). Statistical Indonesia 2014. Badan Pusat Statistik Republik Indonesia.

Banker, A. R. D., Charnes, A., and Cooper, W. W. (1984). Some Models for Estimating Technical and Scale Inefficiencies in Data Envelopment Analysis. Management Science, 30(9):10781092.

Banker, R. (1984). Estimating most productive scale size using data envelopment analysis. European Journal of Operational Research, 17(1):35-44.

Barlow, C. (1997). Growth, structural change and plantation tree crops: The case of rubber. World Development, 25(10):1589-1607.

Barnes, A. D., Jochum, M., Mumme, S., Haneda, N. F., Farajallah, A., Widarto, T. H., and Brose, U. (2014). Consequences of tropical land use for multitrophic biodiversity and ecosystem functioning. Nature Communications, 5:5351.

Battese, G. E. and Coelli, T. (1995). A Model for Technical Inefficiency Effects in a Stochastic Frontier Production Function for Panel Data. Empirical Economics, 20:325-332.

Battese, G. E. and Coelli, T. J. (1988). Prediction of Firm-Level Technical Efficiencies with a Generalized Frontier Production Function and Panel Data. Journal of Econometrics, 38(October 1986):387-399.

Belcher, B., Imang, N., and Achdiawan, R. (2005). Rattan, Rubber, or Oil Palm: Cultural and Financial Considerations for Farmers in Kalimantan. Economic Botany, 58:77-87.

Belcher, B. and Schreckenberg, K. (2007). Commercialisation of Non-timber Forest Products: A Reality Check. Development Policy Review, 25(3):355-377.

Bogetoft, P. and Otto, L. (2011). Benchmarking with DEA, SFA and R, volume 157. Springer Science + Business Media, LLC.

Carrasco, L., Larrosa, C., Milner-Gulland, E., and Edwards, D. (2014). A double-edged sword for tropical forests. Science, 346(6205):38-41.

Caudill, B. and Ford, J. M. (1993). Biases in frontier heteroscedasticity. Economics Letters, $41: 17-20$.

Caudill, S. B., Ford, J. M., and Gropper, D. M. (1995). Frontier Estimation and Firm-Specific Inefficiency Measures in the Presence of Heteroscedasticity. Journal of Business \& Economic Statistics, 13(1):105-111.

Chambers, R. G. (2002). Exact nonradial input, output, and productivity measurement. Economic Theory, 20(4):751-765.

Chambers, R. G., Chung, Y., and Färe, R. (1998). Profit, Directional Distance Functions, and Nerlovian Efficiency. Journal of Optimization Theory and Applications, 98(2):351-364.

Charnes, A., Cooper, W. W., and Rhodes, E. (1978). Measuring the efficiency of decision making units. European Journal of Operational Research, 2(6):429-444.

Chirikos, T. N. and Sear, A. M. (1994). Technical efficiency and the competitive behavior of hospitals. Socio-Economic Planning Sciences, 28(4):219-227. 
Chung, Y. H., Färe, R., and Grosskopf, S. (1997). Productivity and undesirable outputs: A directional distance function approach. Journal of Environmental Management, 51(3):229240.

Coelli, T. (1995). Estimators and hypothesis tests for a stochastic frontier function: A Monte Carlo analysis. Journal of Productivity Analysis, 6(3):247-268.

Coelli, T. J., Rao, D. S. P., O'Donnell, C. J., and Battese, G. E. (2005). An Introduction to Efficiency and Productivity Analysis (Second Edition). Springer US.

Cooper, W. W., Seiford, L. M., and Tone, K. (2007). Data Envelopment Analysis. Springer Science + Business Media, LLC, New York.

Corley, R. and Tinker, P. (2003). The Oil Palm (Fourth Edition). Blackwell Science Ltd.

Cresswell, H. and Hamilton, G. J. (2002). Bulk Density and Pore Space Relations. In Keppel, C., Cresswell, H., and McKenzie, N., editors, Soil Physical Measurement and Interpretation for Land Evaluation, pages 35-58. Csiro Publishing.

de Blécourt, M., Brumme, R., Xu, J., Corre, M. D., and Veldkamp, E. (2013). Soil Carbon Stocks Decrease following Conversion of Secondary Forests to Rubber (Hevea brasiliensis) Plantations. PLoS ONE, 8(7):e69357.

Debreu, G. (1951). The Coefficient of Resource Utilization. Econometrica, 19(3):273-292.

DeSimone, L. and Popoff, F. (2000). Eco-Efficiency: The Business Link to Sustainable Development. London: MIT Press, London.

Drescher, J., Rembold, K., Allen, K., Beckscha, P., Buchori, D., Clough, Y., Faust, H., Fauzi, A. M., Gunawan, D., Hertel, D., Irawan, B., Jaya, I. N. S., Klarner, B., Kleinn, C., Knohl, A., Kotowska, M. M., Krashevska, V., Krishna, V., Leuschner, C., Lorenz, W., Meijide, A., Melati, D., Steinebach, S., Tjoa, A., Tscharntke, T., Wick, B., Wiegand, K., Kreft, H., and Scheu, S. (2016). Ecological and socio-economic functions across tropical land use systems after rainforest conversion. Philosophical transactions of the Royal Society of London. Series B, Biological sciences, 371(2015.0275):1-7.

EIA and Telapak (2012). Clear-cut Exploitation: How International Investors \& REDD ${ }^{+}$in West Papua. Envrionmental Investigation Agency, Telapak.

Euler, M., Schwarze, S., Siregar, H., and Qaim, M. (2015). Oil palm expansion among smallholder farmers in Sumatra, Indonesia. EFForTS discussion paper series, 8.

Evenson, R. E. and Gollin, D. (2003). Assessing the impact of the green revolution, 1960 to 2000. Science (New York, N.Y.), 300(5620):758-762.

Eye on Aceh (2007). The "Golden"Crop? Palm Oil in Post-Tsunami Aceh. Eye on Aceh.

FAO (2010). Global Forest Resources Assessment 2010: Main Report. FAO Forestry Paper 163. Food and Agricultural Organization of the United Nations (FAO).

FAO (2014). The State of Food and Agriculture. Food and Agriculture Organization of the United Nations (FAO).

FAO (2015). FAOSTAT. http://faostat3.fao.org/. 2016-05-11. Food and Agricultural Organization of the United Nations (FAO).

Färe, R., Grosskopf, S., and Margaritis, D. (2015). Directional Distance Functions and Applied Economics A Tribute to RG Chambers. 
Färe, R., Grosskopf, S., Noh, D. W., and Weber, W. (2005). Characteristics of a polluting technology: Theory and practice. Journal of Econometrics, 126:469-492.

Färe, R., Grosskopf, S., and Pasurka, C. (1986). Effects on relative efficiency in electric power generation due to environmental controls. Resources and Energy, 8(2):167-184.

Färe, R., Grosskopf, S., and Pasurka, C. A. (2007). Environmental production functions and environmental directional distance functions. Energy, 32(7):1055-1066.

Fargione, J., Hill, J., Tilman, D., Polasky, S., and Hawthorne, P. (2008). References and Notes 1. Science, 319:1235-1238.

Farrell, M. J. (1957). The measurement of productive efficiency. Journal of Royal Statistical Society, 120(3):253-290.

Faust, H., Schwarze, S., Beckert, B., Brümmer, B., Dittrich, C., Euler, M., Gatto, M., HauserSchäublin, B., Hein, J., Ibanez, M., Klasen, S., Kopp, T., Holtkamp, A. M., Krishna, V., Kunz, Y., Lay, J., Mußhoff, O., Qaim, M., Steinebach, S., Vorlaufer, M., and Wollni, M. (2013). Assessment of Socio-Economic Functions of Tropical Lowland Transformation Systems in Indonesia - Sampling Framework and Methodological Approach. EFForTS Discussion Paper Series, 1.

Feintrenie, L., Chong, W., and Levang, P. (2010). Why do Farmers Prefer Oil Palm? Lessons Learnt from Bungo District, Indonesia. Source: Small-scale Forestry, 9(3):379-396.

Feintrenie, L. and Levang, P. (2009). Sumatra's rubber agroforests: Advent, rise and fall of a sustainable cropping system. Small-scale Forestry, 8(3):323-335.

Feng, G. and Serletis, A. (2014). A primal Divisia technical change index based on the output distance function. Journal of Econometrics, 183(1):135-146.

Fernández, C., Koop, G., and Steel, M. (2002). Multiple output production with undesirable outputs: an application to nitrogen surplus in agriculture. Journal of the American Statistical Association, 97(458):432.

Fernández, C., Koop, G., and Steel, M. F. J. (2005). Alternative efficiency measures for multipleoutput production. Journal of Econometrics, 126(2):411-444.

Fitzherbert, E. B., Struebig, M. J., Morel, A., Danielsen, F., Brühl, C. A., Donald, P. F., and Phalan, B. (2008). How will oil palm expansion affect biodiversity? Trends in Ecology and Evolution, 23(10):538-545.

Foley, J. A. (2005). Global Consequences of Land Use. Science, 309(5734):570-574.

Fried, H. O., Lovell, K. C., and Schmidt, S. S. (2008). The Measurement of Prodcutive Efficiency and Productivity Growth. Oxford University Press., New York.

Gatto, M., Wollni, M., and Qaim, M. (2015). Oil palm boom and land-use dynamics in Indonesia: The role of policies and socioeconomic factors. Land Use Policy, 46:292-303.

Gaveau, D., Wandono, H., and Setiabudi, F. (2007). Three decades of deforestation in southwest Sumatra: Have protected areas halted forest loss and logging, and promoted re-growth? Biological Conservation, 134(4):495-504.

Gibbs, H. K., Ruesch, A. S., Achard, F., Clayton, M. K., Holmgren, P., Ramankutty, N., and Foley, J. A. (2010). Tropical forests were the primary sources of new agricultural land in the 1980s and 1990s. Proceedings of the National Academy of Sciences of the United States of 
America, 107(38):16732-16737.

Gilbert, N. (2012). Palm-oil boom raises conservation concerns. Nature, 487:14-15.

Godfray, H. C. J., Beddington, J. R., Crute, I. R., Haddad, L., Lawrence, D., Muir, J. F., Pretty, J., Robinson, S., Thomas, M. S., and Toulmin, C. (2010). Food Security: The Challenge of Feedin 9 Billion People (Review). Science, 327(5967):812-818.

Goh, K. J., Chew, P. S., and Teo, C. B. (1994). Maximising and maintaining oil palm yields on commercial scale in Malaysia. In Chee, K. H., editor, Management for Enhanced Profitability in Plantations, pages 121-141. Kuala Lumpur: ISP.

Gouyon, A. (1993). Does 'jungle rubber' deserve its name? An analysis of rubber agroforestry systems in southeast Sumatra. pages 181-206.

Greenpeace (2013). Certifying Destruction. Greenpeace International.

Grosskopf, S. (1996). Statistical Inference and Nonparametric Efficiency: A Selective Survey. Journal of Productivity Analysis, 7:161-176.

Gubi, G. (2006). Analyse der erfolgs- und effizienzbestimmenden Faktoren im ökologischen Landbau. PhD thesis, Christian-Albrechts-Universität zu Kiel.

Guillaume, T., Damris, M., and Kuzyakov, Y. (2015). Losses of soil carbon by converting tropical forest to plantations: Erosion and decomposition estimated by delta 13C. Global Change Biology, 21(9):3548-3560.

Guillaume, T., Holtkamp, A. M., Damris, M., Brümmer, B., and Kuzyakov, Y. (2016a). Soil degradation in oil palm and rubber plantations under land resource scarcity. Agriculture, Ecosystems E Environment, 323:110-118.

Guillaume, T., Maranguit, D., Murtilaksono, K., and Kuzyakov, Y. (2016b). Sensitivity and resistance of soil fertility indicators to land-use changes: New concept and examples from conversion of Indonesian rainforest to plantations. Ecological Indicators, 67:49-57.

Hailu, A. and Veeman, T. S. (2001). Non-parametric productivity analysis with undesirable outputs: An application to the canadian pulp and paper industry. American Journal of Agricultural Economics, 83(3):605.

Hampf, B. and Kruger, J. J. (2014). Optimal Directions for Directional Distance Functions: An Exploration of Potential Reductions of Greenhouse Gases. American Journal of Agricultural Economics, 97(3):920-938.

Hasnah, Fleming, E., and Coelli, T. (2004). Assessing the performance of a nucleus estate and smallholder scheme for oil palm production in West Sumatra: A stochastic frontier analysis. Agricultural Systems, 79(1):17-30.

Hayami, Y. and Otsuka, K. (1993). The Economics of Contract Choice: An Agrarian Perspective. Oxford University Press., Oxford.

Henningsen, A. and Henningsen, G. (2015). Relaxation of the Null-Jointness Assumption in Productivity Measurements with Undesirable Outputs. Unpublished Manuscript, 32274.

IUSS Working Group WRB (2015). World reference base for soil resources 2014, update 2015 International soil classification system for naming soils and creating legends for soil maps. Food and Agricultural Organization of the United Nations (FAO), Rome.

Janvry, A. D. (2004). Land Rental Contracts. Technical report, Department of Agricultural and 
Resource Economics at the University of California at Berkeley, Berkeley.

Jondrow, J., Knox, C, A., Materov, I. S., and Schmidt, P. (1982). On the Estimation of Technical Inefficiency in The Stochastic Frontier Production Function Model. Journal of Econometrics, 19:233-238.

Kalirajan, K. (1981). An Econometric Analysis of Yield Variability in Paddy Production K. Kalirajan. Canadian Journal of Agricultural Economics, 29(3):283-294.

Kastner, T., Jose, M., Rivas, I., Koch, W., and Nonhebel, S. (2012). Global changes in diets and the consequences for land requirements for food. 109(18):6868-6872.

Knox Lovell, C., Pastor, J. T., and Turner, J. a. (1995). Measuring macroeconomic performance in the OECD: A comparison of European and non-European countries. European Journal of Operational Research, 87(3):507-518.

Koh, L. P. and Wilcove, D. S. (2008). Is oil palm agriculture really destroying tropical biodiversity? Conservation Letters, 1(2):60-64.

Koh, P. L., Miettinen, J., Liew, C. S., and Ghazoul, J. (2011). Remotely sensed evidence of tropical peatland conversion to oil palm. Proceedings of the National Academy of Sciences of the United States of America, 108(12):5127-5132.

Koopmann, T. C. (1951). An analysis of production as an efficient combination of activities, Proceedings of a Conference. In Activity Analysis of Production and Allocation, chapter III, pages 33-97. John Wiley and Sons Inc., London.

Kopp, T. and Brümmer, B. (2015). Moving Rubber to a Better Place - and Extracting Rents from Credit Constrained Farmers along the Way. EFForTS Discussion Paper Series, 9.

Kumbhakar, S. C., Ghosh, S., and McGuckin, J. T. (1991). A Generalized Production Frontier Approach for Estimating Determinnatns of Inefficiency in US Dairy Farms. Journal of Business 83 Economic Statistics, 9(3):279-286.

Kumbhakar, S. C. and Lovell, C. A. K. (2000). Stochastic Frontier Analysis. Cambridge University Press.

Lal, R. (2004). Soil carbon sequestration to mitigate climate change. Geoderma, 123(1-2):1-22.

Lambin, E. F. E. and Meyfroidt, P. (2011). Global land use change, economic globalization, and the looming land scarcity. Proceedings of the National Academy of Sciences of the United States of America, 108(9):3465-3472.

Laumonier, Y., Uryu, Y., Stüwe, M., Budiman, A., Setiabudi, B., and Hadian, O. (2010). Eco-floristic sectors and deforestation threats in Sumatra: identifying new conservation area network priorities for ecosystem-based land use planning. Biodiversity and Conservation, 19(4):1153-1174.

Lee, J. S. H., Abood, S., Ghazoul, J., Barus, B., Obidzinski, K., and Koh, L. P. (2013). Environmental impacts of large-scale oil palm enterprises exceed that of smallholdings in Indonesia. Conservation Letters, 7(1):25-33.

Liao, C., Peng, R., Luo, Y., Zhou, X., Wu, X., Fang, C., Chen, J., and Li, B. (2008). Altered ecosystem carbon and nitrogen cycles by plant invasion: A meta-analysis. New Phytologist, 177(3):706-714.

Lovell, K. C., Walters, L., and Wood, L. (1994). Stratified Models of Education Production Using 
Modified DEA and Regression Analysis. In Charnes, A., Cooper, W. W., Lewin, A. Y., and Seiford, L. M., editors, Data Envelopment Analysis: Theory, Methodology, and Applications, number 1, pages 329-351. Springer Science + Business Media, LLC.

Lupwayi, N. Z., Harker, K. N., Clayton, G. W., O’Donovan, J. T., and Blackshaw, R. E. (2009). Soil microbial response to herbicides applied to glyphosate-resistant canola. Agriculture, Ecosystems and Environment, 129(1-3):171-176.

Macpherson, A. J., Principe, P. P., and Smith, E. R. (2010). A directional distance function approach to regional environmental-economic assessments. Ecological Economics, 69(10):19181925.

Malmquist, S. (1953). Index numbers and indifference surfaces. Trabajos de Estadistica, 4(2):209242.

Margono, B. A., Potapov, P. V., Turubanova, S., Stolle, F., and Hansen, M. C. (2014). Primary forest cover loss in Indonesia over 2000-2012. Nature Climate Change, 4(June):1-6.

McCarthy, J. F. (2010). Processes of inclusion and adverse incorporation: oil palm and agrarian change in Sumatra, Indonesia. The Journal of peasant studies, 37(4):821-850.

McCarthy, J. F. and Cramb, R. a. (2009). Policy narratives, landholder engagement, and oil palm expansion on the Malaysian and Indonesian frontiers. Geographical Journal, 175(2):112-123.

McCarthy, J. F., Gillespie, P., and Zen, Z. (2012). Swimming Upstream: Local Indonesian Production Networks in "Globalized" Palm Oil Production. World Development, 40(3):555569.

MEA (2005). Ecosystems and Human Well-being: Synthesis, volume 5. Island Press, Waashington, DC. Millennium Ecosystem Assessment (MEA).

Meeusen, W. and Broeck, J. V. D. (1977). Economics Department of the University of Pennsylvania Institute of Social and Economic Research - Osaka University. International Economic Review, 18(2):435-444.

Morton, J. F. (2007). The impact of climate change on smallholder and subsistence agriculture. Proceedings of the National Academy of Sciences of the United States of America, 104(50):19680-19685.

Murphy, D. J. (2007). Future prospects for oil palm in the 21st century: Biological and related challenges. European Journal of Lipid Science and Technology, 109:296-306.

Murty, S., Robert Russell, R., and Levkoff, S. B. (2012). On modeling pollution-generating technologies. Journal of Environmental Economics and Management, 64(1):117-135.

Njuki, E. and Bravo-Ureta, B. B. (2014). A Bayesian Approach to Analyzing the Economic Costs of Environmental Regulation in Dairy Farming. Zwick Center for Food and Resource Policy Working Paper Series, (33). University of Connecticut.

Othman, S. (1993). Asystasia intrusa (Bl.). The Southeat Asian Weed Information Centre (SEAWIC).

Picazo-Tadeo, A. J., Beltrán-Esteve, M., and Gómez-Limón, J. a. (2012). Assessing eco-efficiency with directional distance functions. European Journal of Operational Research, 220(3):798809.

Pitt, M. M. and Lee, L.-f. (1981). The Measurement and Sources of Technical Inefficiency in 
the Indonesian Weaving Industry. Journal of Development Economics, 9(1):43-64.

Pittman, R. W. (1981). Issue in Pollution Control: Interplant Cost Differences and Economies of Scale. Land Economics, 57(1):1-17.

Potter, L. (2001). Agricultural Intensification in Indonesia: Outside Pressures and Indigenous Strategies. Asia Pacific Viewpoint, 42(2/3):305-324.

Potter, L. and Lee, J. (1998). Tree planting in Indonesia: trends, impacts and directions. Center for International Forestry Research (CIFOR).

Ramankutty, N. and Foley, J. A. (1999). Estimating historical changes in global land cover : Croplands historical have converted areas. Global Biogeochemical Cycles, 13(4):997-1027.

Rehm, S. and Espig, G. (1991). The Cultivated Plants of the Tropics and Subtropics. verlag josef magraf.

Reifschneider, D. and Stevenson, R. (1991). Systematic Departures from the Frontier: A Framework for the Analysis of Firm Inefficiency. International Economic Review, 32(3):715-723.

Reinhard, S., Lovell, C. a. K., and Thijssen, G. (1999). Econometric estimation of technical and environmental efficiency: an application to Dutch dairy farms. American Journal of Agricultural Economics, 81(1):44-60.

Rist, L., Feintrenie, L., and Levang, P. (2010). The livelihood impacts of oil palm: Smallholders in Indonesia. Biodiversity and Conservation, 19(4):1009-1024.

RSPO (2014). Rountable on Sustainable Palm Oil Impact Report 2014. Roundtable on Sustainable Palm Oil (RSPO).

Rubiana, R., Rizali, A., Denmead, L. H., Alamsari, W., Hidayat, P., Hindayana, D., Clough, Y., Tscharntke, T., and Buchori, D. (2015). Agricultural land use alters species composition but not species richness of ant communities. Asian Myrmecology, 7:73-85.

Sadoulet, E., Fukui, S., and de Janvry, A. (1994). Efficient share tenancy contracts under risk: The case of two rice-growing villages in Thailand. Journal of Development Economics, $45(2): 225-243$.

Sanon, A., Béguiristain, T., Cébron, A., Berthelin, J., Ndoye, I., Leyval, C., Sylla, S., and Duponnois, R. (2009). Changes in soil diversity and global activities following invasions of the exotic invasive plant, Amaranthus viridis L., decrease the growth of native sahelian Acacia species. FEMS Microbiology Ecology, 70(1):118-131.

Sayer, J., Ghazoul, J., Nelson, P., and Boedhihartono, K. A. (2012). Author' s personal copy Oil palm expansion transforms tropical landscapes and livelihoods. Global Food Security journal, 1:114-119.

Scheel, H. (2000). Effizienzmaße der Data Envelopment Analysis. Deutscher Universitätsverlag, Wiesbaden.

Shephard, R. W. (1953). Cost and production functions. Princeton University Press, Princeton, N.J.

Shephard, R. W. (1970). Theory of cost and production functions. Princeton University Press, Princeton.

Silverman, B. (1986). Density Estimation for Statistics and Data Analysis. Chapman \& Hall. 
Simar, L., Lovell, C., and Vanden Eeckaut, P. (1994). Stochastic Frontiers Incorporating Exogenous Influences on Efficiency. Working Paper.

Simar, L. and Wilson, P. W. (2002). Non-parametric tests of returns to scale. European Journal of Operational Research, 139(1):115-132.

Simar, L. and Wilson, P. W. (2007). Estimation and inference in two-stage, semi-parametric models of production processes. Journal of Econometrics, 136(1):31-64.

Standish, R. J., Williams, P. a., Robertson, A. W., Scott, N. a., and Hedderley, D. I. (2004). Invasion by a perennial herb increases decomposition rate and alters nutrient availability in warm temperate lowland forest remnants. Biological Invasions, 6(1):71-81.

Stanton, K. R. (2002). Trends in relationship lending and factors affecting relationship lending efficiency. Journal of Banking and Finance, 26(1):127-152.

Thanassoulis, E. (2001). Introduction to the Theory and Applicatino of Data Envelopment Analysis. Springer Science + Business Media, LLC.

Tilman, D., Fargione, J., Wolff, B., D'Antonio, C., Dobson, A., Howarth, R., Schindler, D., Schlesinger, W. H., Simberloff, D., and Swackhamer, D. (2001). Forecasting agriculturally driven global environmental change. Science (New York, N.Y.), 292:281-284.

Tsionas, E. G., Malikov, E., and Kumbhakar, S. C. (2015). Do Direction, Normalization and the Jacobian Matter in the Productivity Measurements based on the Directional Output Distance Function? Unpublished Paper.

United Nations (2013). World Population Prospects: The 2012 Revision. United Nations (Department of Economic and Social Affairs Population Division), New York.

Vermeulen, S. and Goad, N. (2006). Towards Better Practice in Smallholder Palm Oil Production. Natural Resource Issues Series No. 5. International Institute for Environment and Development, London, UK.

Wang, H. and Schmidt, P. (2002). One-step and two-step estimation of the effects of exogenous variables on technical efficiency levels. Juornal of Productivity Analysis, 18:129-144.

Weidenhamer, J. D. and Callaway, R. M. (2010). Direct and Indirect Effects of Invasive Plants on Soil Chemistry and Ecosystem Function. Journal of Chemical Ecology, 36(1):59-69.

Welford, R. (1995). Environmental Strategy and Sustainable Development: The Corporate Challenge for the Twenty-First Century. Routledge, New York.

Widenfalk, A. (2005). Interactions between pesticides and microorganisms in freshwater sediments- Toxic effects and implications for bioavailability. PhD thesis, Swedish University of Agricultural Sciences, Uppsala.

Wilcove, D. S., Giam, X., Edwards, D. P., Fisher, B., and Koh, L. P. (2013). Navjot's nightmare revisited: Logging, agriculture, and biodiversity in Southeast Asia. Trends in Ecology and Evolution, 28(9):531-540.

Wilcove, D. S. and Koh, L. P. (2010). Addressing the threats to biodiversity from oil-palm agriculture. Biodiversity and Conservation, 19(4):999-1007.

World Bank (2008). Wolrd development report: Agriculture for development. The World Bank, Washington, DC.

Zen, Z., Barlow, C., and Gondowarsito, R. (2005). Oil palm in Indonesian socio-economic 
improvement: a review of options. Working Paper.

6 
A

Appendix Chapter 2

A 


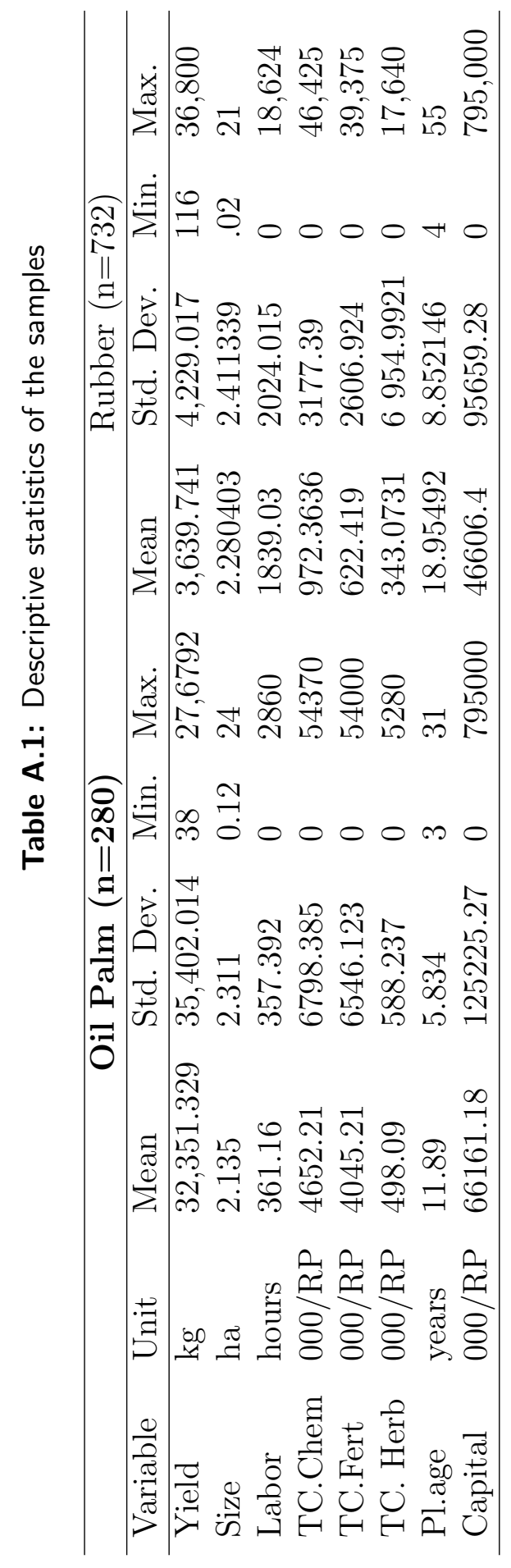


Table A.2: Estimation results: STATA output of the oil palm transmigrant frontier including the $z$-variabels; plot size $(x 1)$, hours of labour $(x 2)$, plantation age $(x 3)$, cost of herbicides $(x 5)$, capital $(x 7)$.

\begin{tabular}{|c|c|c|}
\hline Variable & Coefficient & (Std. Err.) \\
\hline \multicolumn{3}{|c|}{ Equation 1 :ln_y } \\
\hline $\ln \_x 1$ & $0.581^{* *}$ & $(0.170)$ \\
\hline $\ln \_x 2$ & $0.304^{*}$ & $(0.129)$ \\
\hline $\ln \_x 3$ & $-0.277^{\dagger}$ & $(0.144)$ \\
\hline $\ln \_x 5$ & $-0.148^{* *}$ & $(0.056)$ \\
\hline ln_x7 & $0.079^{*}$ & $(0.035)$ \\
\hline D_TC_Herb_TOP & 0.110 & $(0.077)$ \\
\hline sqln_x1 & 0.476 & $(0.330)$ \\
\hline $\operatorname{sqln} \_x 2$ & 0.313 & $(0.199)$ \\
\hline sqln_x3 & $-1.074^{* *}$ & $(0.358)$ \\
\hline $\operatorname{sqln} \_x 5$ & 0.104 & $(0.101)$ \\
\hline sqln_x7 & -0.075 & $(0.047)$ \\
\hline ln_x1_ln_x2 & $-0.542^{* *}$ & $(0.187)$ \\
\hline ln_x1_ln_x3 & -0.035 & $(0.193)$ \\
\hline $\ln \_x 1 \_\ln \_x 5$ & -0.247 & $(0.168)$ \\
\hline $\ln \_x 2 \_\ln \_x 3$ & $-0.271^{\dagger}$ & $(0.153)$ \\
\hline $\ln \_x 2 \_\ln \_x 5$ & 0.085 & $(0.125)$ \\
\hline $\ln \_x 3 \_\ln \_x 5$ & $0.311^{* *}$ & $(0.110)$ \\
\hline ln_x1_ln_x7 & -0.105 & $(0.129)$ \\
\hline $\ln \_x 2 \_l n \_x 7$ & 0.146 & $(0.105)$ \\
\hline $\ln \_x 3 \_\ln \_x 7$ & -0.051 & $(0.097)$ \\
\hline $\ln \_x 5 \_\ln \_x 7$ & 0.024 & $(0.037)$ \\
\hline 1b.Region1_TOP & 0.000 & $(0.000)$ \\
\hline 2.Region1_TOP & $0.490^{* *}$ & $(0.084)$ \\
\hline 3.Region1_TOP & $0.594^{* *}$ & $(0.107)$ \\
\hline 4.Region1_TOP & -0.290 & $(0.266)$ \\
\hline 5.Region1_TOP & $0.207^{\dagger}$ & $(0.121)$ \\
\hline Intercept & -0.192 & $(0.140)$ \\
\hline \multicolumn{3}{|c|}{ Equation 2 : $\ln \operatorname{sig} 2 \mathrm{v}$} \\
\hline Intercept & $-2.612^{* *}$ & $(0.146)$ \\
\hline \multicolumn{3}{|c|}{ Equation 3: lnsig2u } \\
\hline logSizep_TOP & $3.316^{* *}$ & $(1.274)$ \\
\hline Index_Herf_TOP & $-25.769^{* *}$ & $(8.814)$ \\
\hline DDual_TOP1 & $4.693^{* *}$ & $(1.311)$ \\
\hline ContSupport1_TOP1 & $-5.104^{* *}$ & $(1.468)$ \\
\hline Intercept & 0.817 & $(0.852)$ \\
\hline
\end{tabular}


Table A.3: Estimation results: STATA output of the oil palm autochtone frontier including the $z$-variables; plot size $(x 1)$, hours of labour per plot $(x 2)$, plantation age $(x 3)$, cost of fertilizer $(x 4)$.

\begin{tabular}{|c|c|c|}
\hline Variable & Coefficient & (Std. Err.) \\
\hline \multicolumn{3}{|c|}{ Equation 1: y } \\
\hline $\ln \_x 1$ & $0.511^{* *}$ & $(0.116)$ \\
\hline $\ln \_x 2$ & $0.372^{* *}$ & $(0.100)$ \\
\hline $\ln \_x 3$ & $0.293^{* *}$ & $(0.108)$ \\
\hline $\ln \_x 4$ & $0.174^{* *}$ & $(0.061)$ \\
\hline D_Fert_NOP & -0.117 & $(0.115)$ \\
\hline $\operatorname{sqln} \_x 1$ & 0.102 & $(0.257)$ \\
\hline $\operatorname{sqln} \_x 2$ & $-0.545^{* *}$ & $(0.130)$ \\
\hline $\operatorname{sqln} \_x 3$ & $-0.756^{*}$ & $(0.324)$ \\
\hline sqln_x4 & -0.018 & $(0.064)$ \\
\hline $\ln \_x 1 \_\ln \_x 2$ & 0.256 & $(0.156)$ \\
\hline $\ln \_x 1 \_\ln \_x 3$ & -0.043 & $(0.201)$ \\
\hline $\ln \_x 1 \_\ln \_x 4$ & -0.161 & $(0.105)$ \\
\hline $\ln \_x 2 \_\ln \_x 3$ & -0.093 & $(0.159)$ \\
\hline $\ln \_x 2 \_\ln \_x 4$ & 0.142 & $(0.087)$ \\
\hline $\operatorname{ln\_ x3\_ ln\_ x4}$ & 0.117 & $(0.108)$ \\
\hline 1b.Region1_NOP & 0.000 & $(0.000)$ \\
\hline 2.Region1_NOP & 0.120 & $(0.109)$ \\
\hline 3.Region1_NOP & $0.259^{*}$ & $(0.108)$ \\
\hline 4.Region1_NOP & 0.275 & $(0.231)$ \\
\hline 5.Region1_NOP & 0.141 & $(0.220)$ \\
\hline Intercept & $0.522^{* *}$ & $(0.189)$ \\
\hline \multicolumn{3}{|c|}{ Equation 2 : $\ln \operatorname{sig} 2 \mathrm{v}$} \\
\hline Intercept & $-2.323^{* *}$ & $(0.388)$ \\
\hline \multicolumn{3}{|c|}{ Equation 3 : lnsig2u } \\
\hline ContSupport1_NOP1 & $-1.566^{*}$ & $(0.747)$ \\
\hline Landshare_NOP & $-0.876^{\dagger}$ & $(0.493)$ \\
\hline Distance_NOP & $0.132^{*}$ & $(0.054)$ \\
\hline Distance_NOP2 & $-0.003^{*}$ & $(0.001)$ \\
\hline DDual_NOP1 & $1.274^{* *}$ & $(0.416)$ \\
\hline Intercept & $-1.487^{* *}$ & $(0.546)$ \\
\hline
\end{tabular}


Table A.4: Estimation results: STATA output of the rubber frontier including the $z$-variables; plot size $(x 1)$, hours of labour per plot $(x 2)$, plantation age $(x 3)$, cost of fertilizer $(x 4)$.

\begin{tabular}{|c|c|c|}
\hline Variable & Coefficie & (Std. Err.) \\
\hline \multicolumn{3}{|c|}{ Equation 1: y } \\
\hline $\ln \_x 1$ & $0.368^{* *}$ & $(0.050)$ \\
\hline $\ln \_x 2$ & $0.348^{* *}$ & $(0.042)$ \\
\hline $\ln \_x 3$ & -0.011 & $(0.049)$ \\
\hline $\ln \_x 6$ & $0.070^{* *}$ & $(0.025)$ \\
\hline $\ln \_x 8$ & $0.081^{* *}$ & $(0.021)$ \\
\hline D_TC_Chem_RP & $-0.161^{* *}$ & $(0.043)$ \\
\hline sqln_x1 & 0.094 & $(0.075)$ \\
\hline sqln_x2 & $0.074^{*}$ & $(0.032)$ \\
\hline sqln_x3 & $-0.458^{* *}$ & $(0.123)$ \\
\hline $\operatorname{sqln\_ x6}$ & 0.052 & $(0.036)$ \\
\hline sqln_x8 & 0.003 & $(0.023)$ \\
\hline $\ln \_x 1 \_\ln \_x 2$ & 0.002 & $(0.051)$ \\
\hline ln_x1_ln_x3 & 0.058 & $(0.073)$ \\
\hline $\operatorname{ln\_ x1\_ ln\_ x6}$ & -0.004 & $(0.044)$ \\
\hline ln_x1_ln_x8 & $-0.092^{*}$ & $(0.041)$ \\
\hline $\ln \_x 2 \_\ln \_x 3$ & -0.080 & $(0.055)$ \\
\hline $\ln \_x 2 \_\ln \_x 6$ & $-0.103^{* *}$ & $(0.037)$ \\
\hline $\ln \_x 2 \_\ln \_x 8$ & $0.083^{* *}$ & $(0.031)$ \\
\hline $\ln \_x 3 \_\ln \_x 6$ & -0.015 & $(0.043)$ \\
\hline $\ln \_x 3 \_\ln \_x 8$ & 0.021 & $(0.037)$ \\
\hline ln_x6_ln_x8 & $0.041^{\dagger}$ & $(0.024)$ \\
\hline Intercept & $0.517^{* *}$ & $(0.083)$ \\
\hline \multicolumn{3}{|c|}{ Equation 2 : lnsig2v } \\
\hline Intercept & $-1.788^{* *}$ & $(0.104)$ \\
\hline \multicolumn{3}{|c|}{ Equation 3 : lnsig2u } \\
\hline Landshare_RP & $-0.663^{*}$ & $(0.273)$ \\
\hline Distance_RP & $0.046^{*}$ & $(0.023)$ \\
\hline Distance_RP2 & $-0.001^{*}$ & $(0.000)$ \\
\hline 1b.Cycle2_RP & 0.000 & $(0.000)$ \\
\hline 2.Cycle2_RP & $-0.523^{\dagger}$ & $(0.284)$ \\
\hline 3.Cycle2_RP & $-2.030^{* *}$ & $(0.399)$ \\
\hline Share_RP1 & $-1.051^{* *}$ & $(0.318)$ \\
\hline Intercept & -0.122 & $(0.264)$ \\
\hline
\end{tabular}




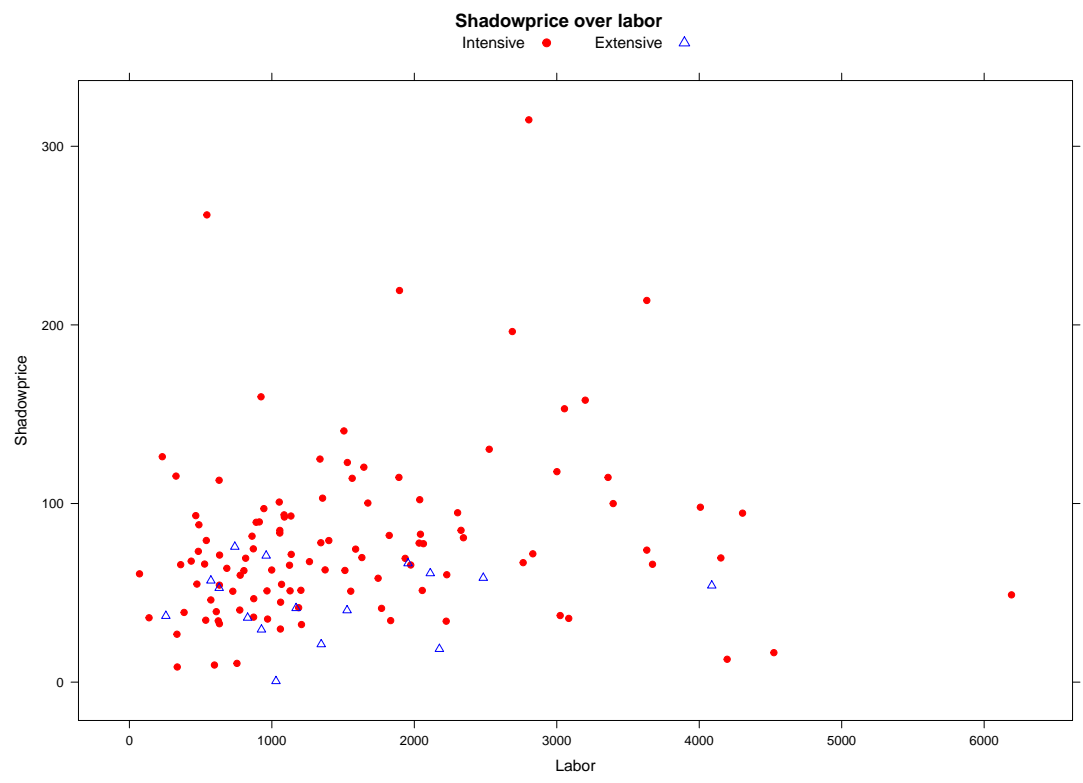

Figure B.1: Scatterplot of the individual shadowprice against the labor input over both management intensity (red dots $=$ intensive , blue triangle $=$ extensive) 


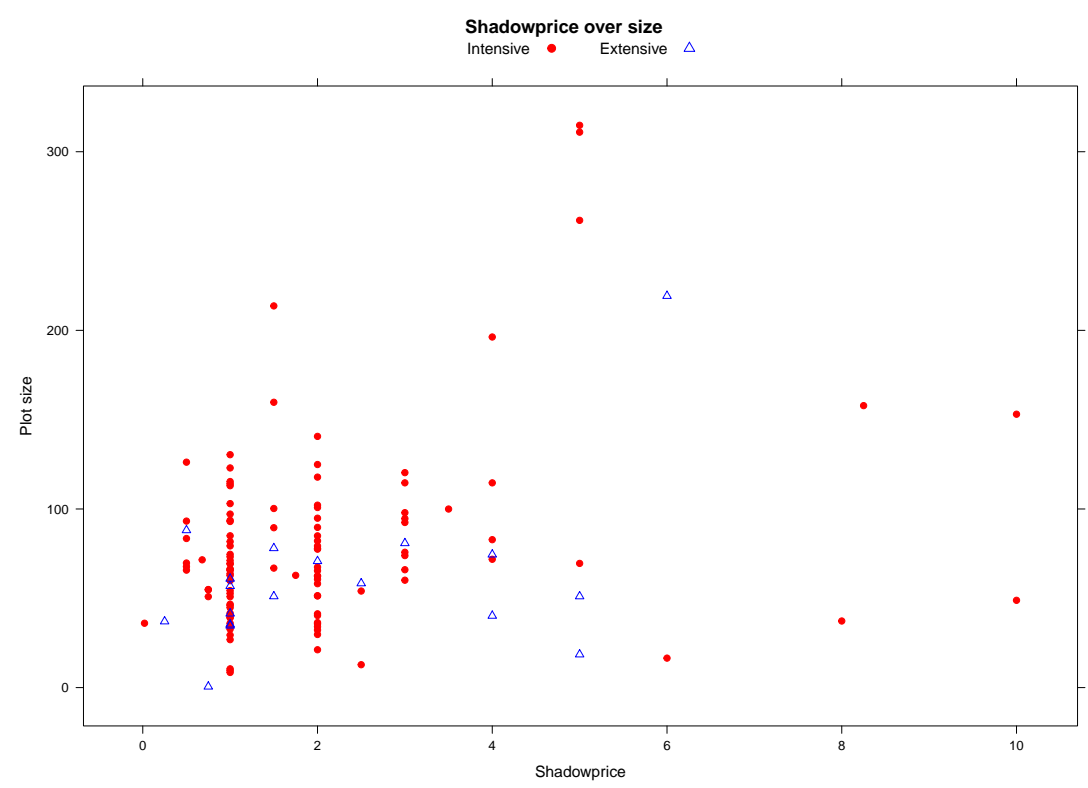

Figure B.2: Scatterplot of the individual shadowprice against the size input over both management intensity (red dots $=$ intensive , blue triangle $=$ extensive)

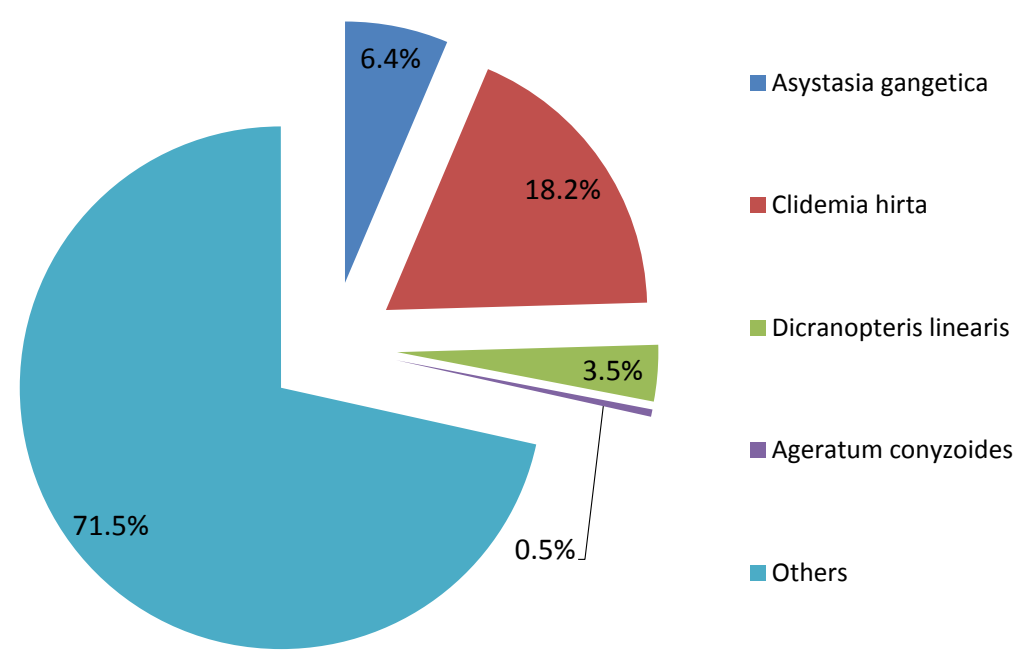

Figure B.3: Distribution of invasive plant and non-invasive plants on average on the sampled plots 
Table B.1: STATA output of the directional output distance function including the $z$-variables; size of the plot (Size), hours of labor per plot (Labor), plantation age (Pl. Age), cost of all chemicals (TC. Chemicals), and the bad output times the directional vector and the translation value $\theta$, $\left(\right.$ bstar $\left.=\left(b_{i}-\theta_{i} g_{b}\right)\right)$.

\begin{tabular}{|c|c|c|}
\hline Variable & Coefficient & (Std. Err.) \\
\hline \multicolumn{3}{|c|}{ Equation $1: \mathrm{n}_{\text {_theta }}$} \\
\hline b_star & $0.166^{*}$ & $(0.098)$ \\
\hline Size & $0.565^{* * *}$ & $(0.212)$ \\
\hline Labor & 0.055 & $(0.169)$ \\
\hline Pl. Age & 0.363 & $(0.281)$ \\
\hline TC. Chemicals & -0.066 & $(0.085)$ \\
\hline Dummy Chemicals & -0.017 & $(0.056)$ \\
\hline b_star ${ }^{2}$ & $-0.129^{* * *}$ & $(0.019)$ \\
\hline $\operatorname{Size}^{2}$ & $-0.443^{* *}$ & $(0.204)$ \\
\hline Labor $^{2}$ & $-0.138^{* *}$ & $(0.058)$ \\
\hline Pl. Age $^{2}$ & -0.319 & $(0.205)$ \\
\hline TC. Chemicals ${ }^{2}$ & -0.004 & $(0.007)$ \\
\hline b_star*Size & $0.133^{* *}$ & $(0.056)$ \\
\hline b_star*Labor & $0.138^{* * *}$ & $(0.041)$ \\
\hline b_star*Pl. Age & $0.150^{*}$ & $(0.084)$ \\
\hline b_star*TC. Chemicals & 0.009 & $(0.018)$ \\
\hline Size*Labor & 0.178 & $(0.145)$ \\
\hline Size*Pl. Age & -0.048 & $(0.206)$ \\
\hline Size*TC. Chemicals & -0.004 & $(0.039)$ \\
\hline Labor*Pl. Age & -0.147 & $(0.171)$ \\
\hline Labor*TC. Chemicals & 0.057 & $(0.035)$ \\
\hline Pl. Age*TC. Chemicals & 0.020 & $(0.081)$ \\
\hline Intercept & 0.055 & $(0.185)$ \\
\hline
\end{tabular}

\begin{tabular}{lcc}
\hline \multicolumn{3}{c}{ Equation $2: \operatorname{lnsig} 2 \mathrm{v}$} \\
\hline Intercept & $-3.462^{* * *}$ & $(0.212)$ \\
\hline Size & $1.945^{* * *}$ & $(0.389)$ \\
Chem. Weeding & $-1.277^{* * *}$ & $(0.451)$ \\
Glyphosat & $1.302^{* * *}$ & $(0.498)$ \\
TSP & -4.602 & $(5.300)$ \\
Contract Supp. & $-3.561^{*}$ & $(1.901)$ \\
Education & $-0.119^{* *}$ & $(0.059)$ \\
Burning & $-0.745^{* *}$ & $(0.372)$ \\
Intercept & $-1.703^{* * *}$ & $(0.640)$ \\
\hline${ }^{* * *}$ Estimate is significant at $1 \%$ level of significance \\
${ }^{* *}$ Estimate is significant at $5 \%$ level of significance \\
${ }^{*}$ Estimate is significant at $10 \%$ level of significance
\end{tabular}


C

Appendix Chapter 4 

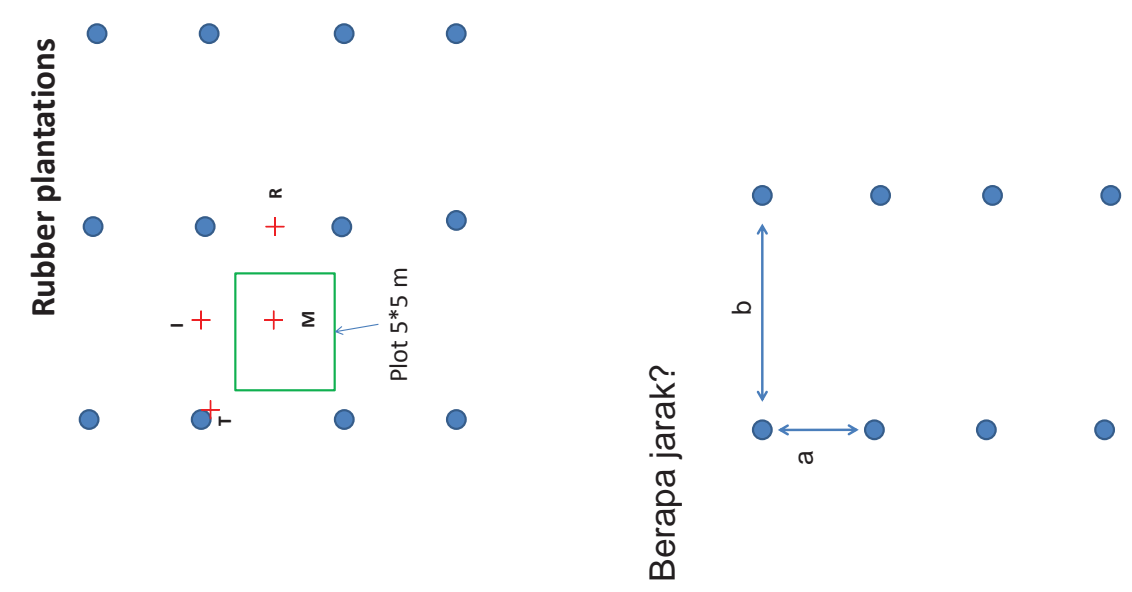

C
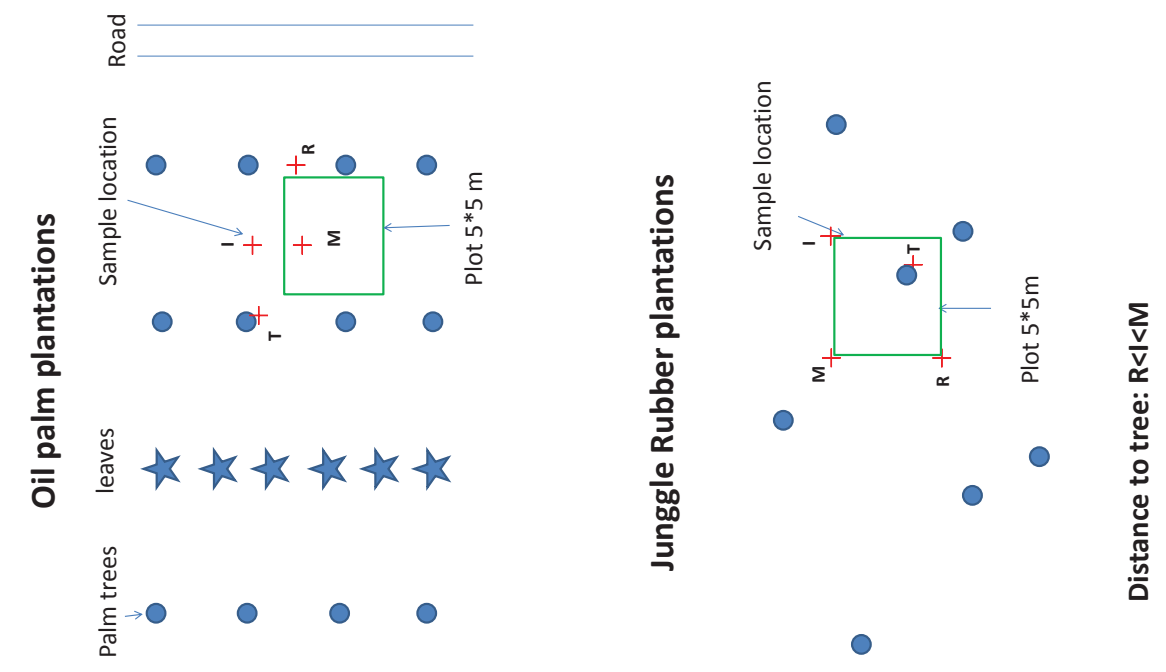

Figure C.1: Soil sampling frame 


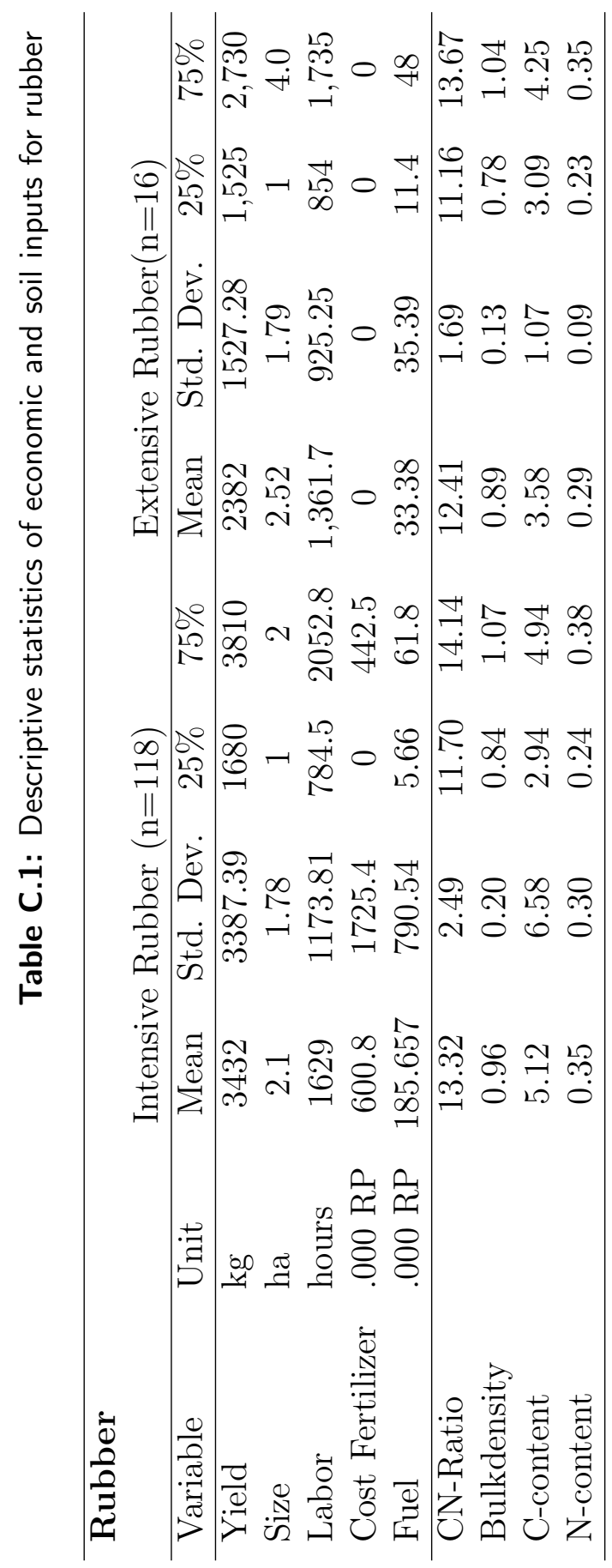


Table C.2: Descriptive statistics of economic and soil inputs for oil palm

\begin{tabular}{llcccc}
\hline \multicolumn{2}{l}{ Oil Palm(n=38) } & & & & \\
Variable & Unit & Mean & std. dev. & $25 \%$ & $75 \%$ \\
\hline Yield & $\mathrm{kg}$ & 43,692 & 34,620 & 21,864 & 46,600 \\
Size & ha & 2.413 & 1.89 & 2 & 2 \\
Labor & hours & 413.4 & 296.53 & 216.8 & 442.0 \\
Cost Fertilizer & $.000 \mathrm{RP}$ & 3563 & 4041.89 & 570 & 4627 \\
Fuel & $.000 \mathrm{RP}$ & & & & \\
\hline CN-Ratio & & 14.71 & 4.38 & 12.03 & 14.93 \\
Bulkdensity & & 1.01 & 0.28 & 0.88 & 1.1941 \\
C-content & & 6.92 & 11.64 & 1.66 & 5.7624 \\
N-content & & 0.37 & 0.43 & 0.13 & 0.4401 \\
\hline
\end{tabular}

Table C.3: Efficiencies of oil palm and rubber, with separation in intensive and extensive production (CRS)

\begin{tabular}{|c|c|c|c|c|c|c|}
\hline & Min. & 1st Qu. & Median & Mean & 3rd Qu. & Max. \\
\hline Oil Palm & 0.30 & $\begin{array}{c}0.55 \\
\phi=1\end{array}$ & $\begin{array}{ll} & 0.87 \\
7 \text { (Obs.) }\end{array}$ & 0.77 & $\begin{array}{c}0.99 \\
18.42 \%\end{array}$ & 1 \\
\hline Rubber & 0.09 & $\begin{array}{c}0.24 \\
\phi=1\end{array}$ & $\begin{array}{c}0.35 \\
5 \text { (Obs.) }\end{array}$ & 0.42 & $\begin{array}{l}0.55 \\
3.7 \%\end{array}$ & 1 \\
\hline Int. Rubber & 0.091 & 0.25 & 0.37 & 0.43 & 0.56 & 1 \\
\hline Ext. Rubber & 0.11 & 0.21 & 0.29 & 0.33 & 0.32 & 1 \\
\hline
\end{tabular}

Table C.4: C-Values distributed over the production types and fertility group (IR = Intensive Rubber, $\mathrm{ER}=$ Extensive Rubber, OP $=$ Oil Palm)

\begin{tabular}{llccccc}
\hline Crop & Soil fertility & Mean & std. dev. & $25 \%$ & $75 \%$ & Observations \\
\hline IR & Low & 3.80 & 2.42 & 2.40 & 2.93 & 40 \\
IR & high & 4.33 & 0.85 & 3.59 & 2.32 & 76 \\
& & & & & & \\
ER & Low & 2.23 & 0.49 & 2.02 & 2.32 & 4 \\
ER & High & 4.03 & 0.78 & 3.48 & 4.52 & 12 \\
& & & & & & \\
OP & low & 2.84 & 3.02 & 1.34 & 2.26 & 26 \\
OP & High & 3.98 & 1.10 & 3.40 & 4.24 & 7 \\
\hline
\end{tabular}



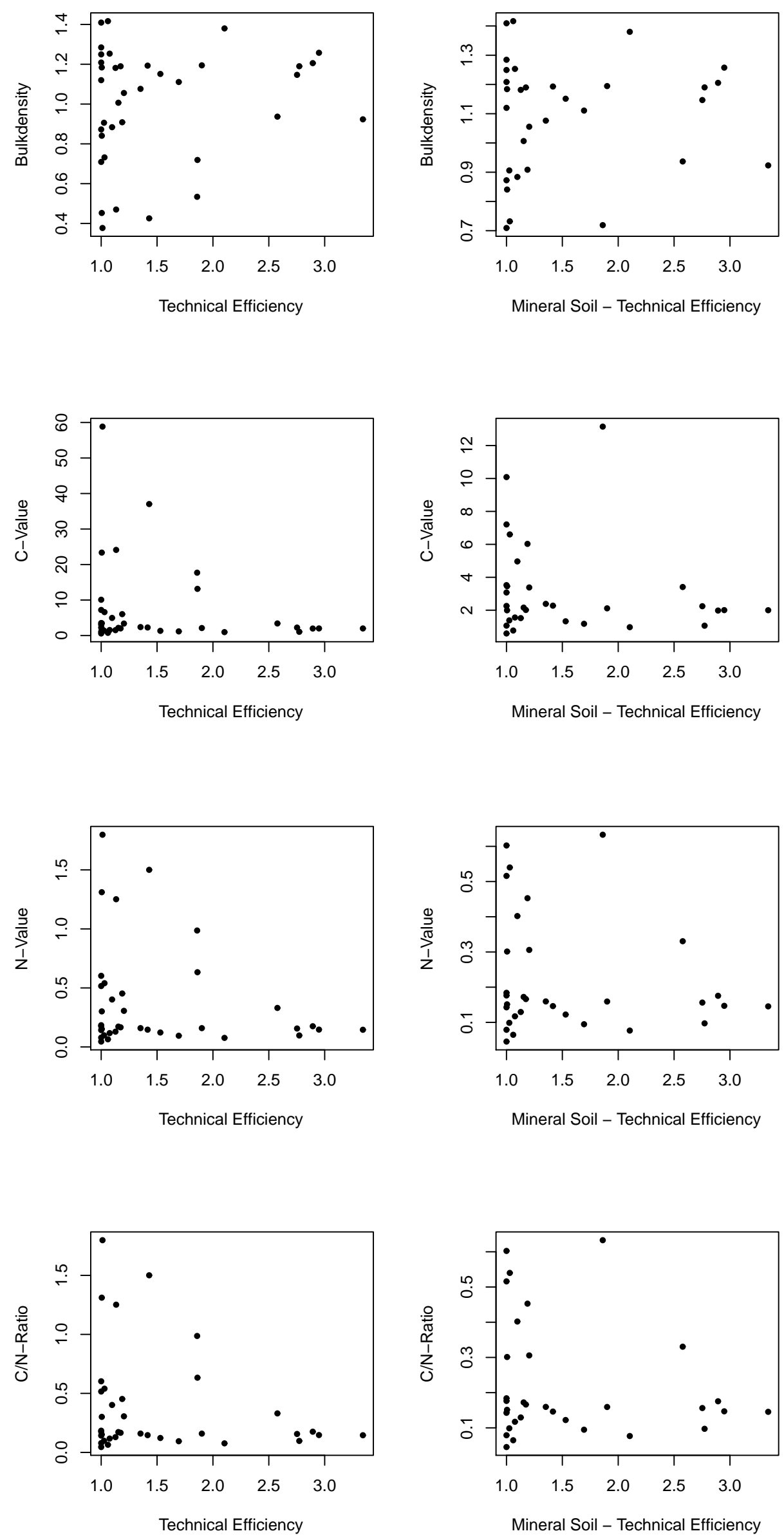

Figure C.2: Oil palm efficiencies over soil quality parameters 


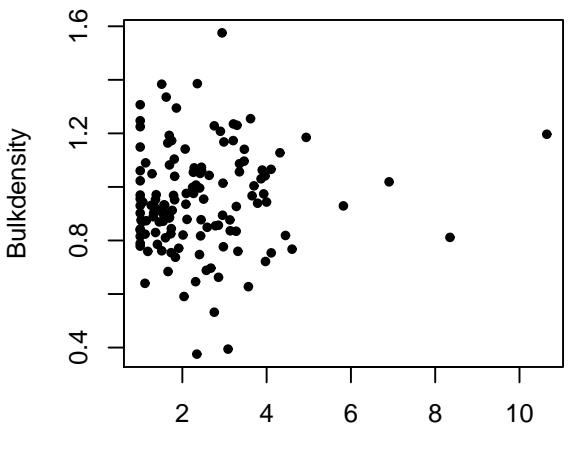

Technical Efficiency
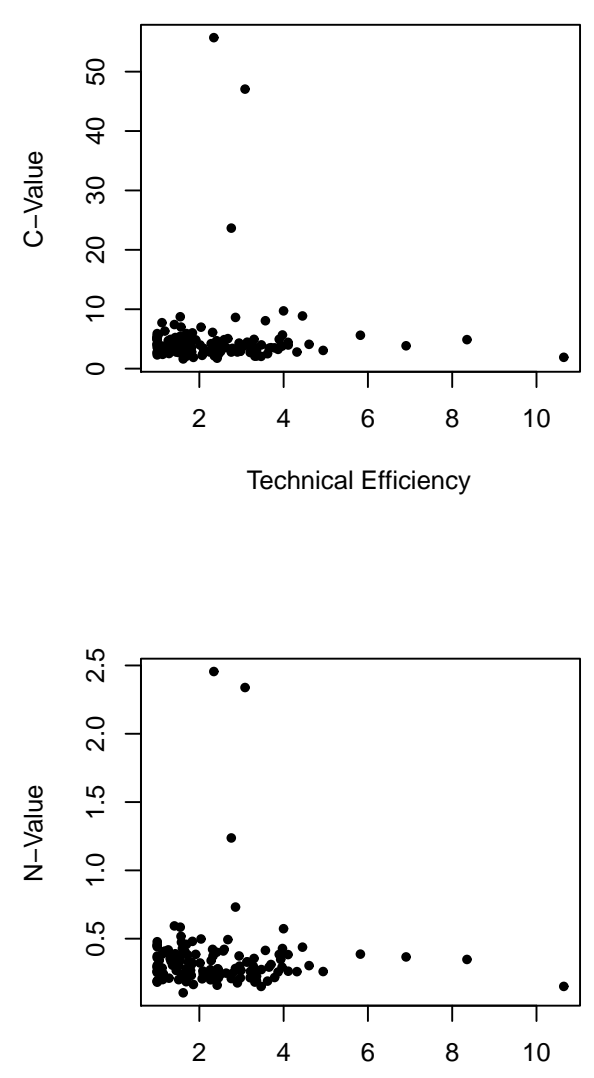

Technical Efficiency

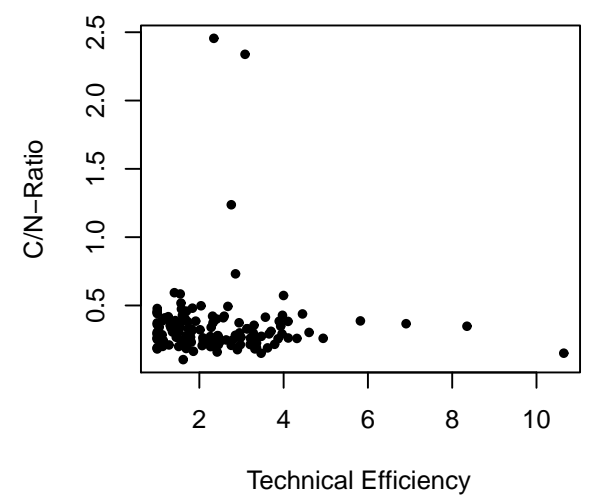

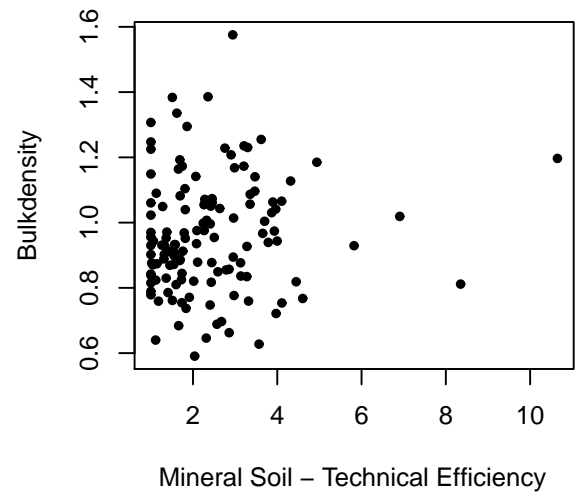

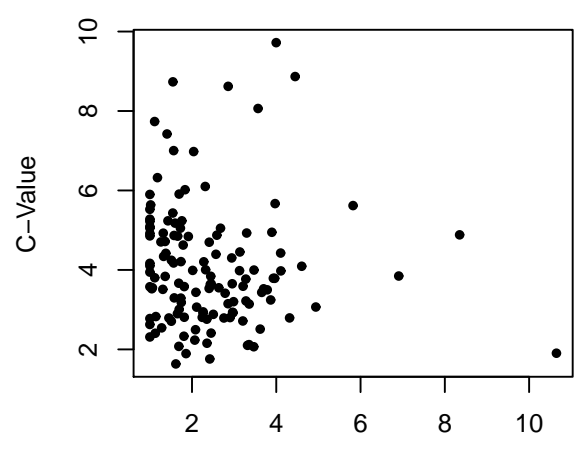

Mineral Soil - Technical Efficiency

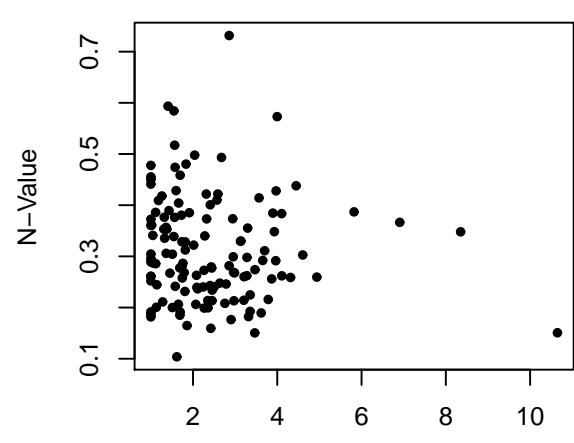

Mineral Soil - Technical Efficiency

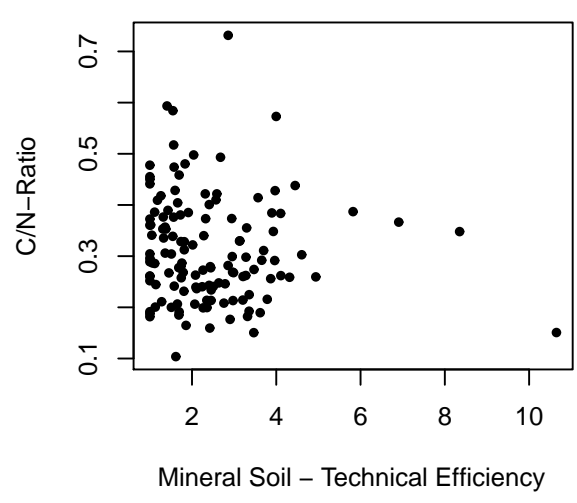

Figure C.3: Rubber efficiencies over soil quality parameters 
Table C.5: This table displays the correlation matrix of soil quality parameters and all inputs and output

\begin{tabular}{|c|c|c|c|c|c|c|}
\hline & & Yield & Size & Labour & TC.Fert & Fuel.SRP \\
\hline \multirow{4}{*}{$\begin{array}{l}\bar{\xi} \\
\bar{\sigma} \\
\tilde{\sigma}^{\prime} \\
\overline{0}\end{array}$} & CN-ratio & 0.058 & 0.015 & 0.062 & -0.224 & - \\
\hline & $\mathrm{N}$-value & -0.109 & -0.070 & -0.131 & -0.305 & - \\
\hline & $\mathrm{C}$-value & -0.112 & -0.091 & -0.123 & -0.249 & - \\
\hline & Bulkdensity & 0.176 & 0.092 & 0.230 & 0.348 & - \\
\hline \multirow{4}{*}{ 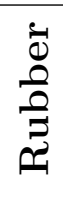 } & CN-ratio & 0.048 & -0.034 & 0.046 & -0.098 & -0.074 \\
\hline & N-value & -0.067 & -0.104 & -0.115 & 0.032 & -0.023 \\
\hline & C-value & -0.059 & -0.094 & -0.104 & 0.024 & -0.022 \\
\hline & Bulkdensity & -0.076 & -0.077 & -0.077 & 0.041 & 0.059 \\
\hline
\end{tabular}

Table C.6: The separation of cost of fertilizer and labor over the fertility groups

\begin{tabular}{|c|c|c|c|c|c|c|c|c|}
\hline Crop & Variable & & Unit & Mean & std. dev. & Min & Max & Obs. \\
\hline \multirow{4}{*}{$\begin{array}{l}\xi \\
\tilde{\sigma} \\
\tilde{\sigma} \\
\overline{0} \\
\overline{0}\end{array}$} & Cost Fertilizer & Low & $.000 \mathrm{RP}$ & 3,873 & 4,596 & 0585 & 4,626 & 25 \\
\hline & & High & & 4,173 & 2,283 & 2,875 & 5,796 & 7 \\
\hline & Labor & Low & hours & 399.4 & 310.8 & 201.8 & 435 & 26 \\
\hline & & High & & 500 & 343.1 & 354 & 593 & 7 \\
\hline \multirow{4}{*}{$\begin{array}{l}\dot{0} \\
\frac{0}{0} \\
\vdots \\
\vdots \\
0\end{array}$} & Cost Fertilizer & Low & $.000 \mathrm{RP}$ & 581.8 & 1,311 & 0 & 532.5 & 44 \\
\hline & & High & & 496 & 1,795 & 0 & 0 & 87 \\
\hline & Labor & Low & hours & 1,577 & 1,095 & 724.3 & 2,092 & 44 \\
\hline & & High & & 1,639 & 1,184 & 865.5 & 2,049 & 87 \\
\hline
\end{tabular}


Appendix Chapter 4

C 